\title{
Artificial neural network in classification of severity levels in crashes with guardrail
}

\author{
Fouad N. Shoukry \\ West Virginia University
}

Follow this and additional works at: https://researchrepository.wvu.edu/etd

\section{Recommended Citation}

Shoukry, Fouad N., "Artificial neural network in classification of severity levels in crashes with guardrail" (2005). Graduate Theses, Dissertations, and Problem Reports. 1647.

https://researchrepository.wvu.edu/etd/1647

This Thesis is protected by copyright and/or related rights. It has been brought to you by the The Research Repository @ WVU with permission from the rights-holder(s). You are free to use this Thesis in any way that is permitted by the copyright and related rights legislation that applies to your use. For other uses you must obtain permission from the rights-holder(s) directly, unless additional rights are indicated by a Creative Commons license in the record and/ or on the work itself. This Thesis has been accepted for inclusion in WVU Graduate Theses, Dissertations, and Problem Reports collection by an authorized administrator of The Research Repository @ WVU. For more information, please contact researchrepository@mail.wvu.edu. 


\title{
Artificial Neural Network in Classification of Severity Levels
} in Crashes with Guardrail

\author{
Fouad N. Shoukry
}

Thesis

Submitted to the College of Engineering and Mineral Resources at West Virginia University in partial fulfillment of the Requirements for Degree of Masters of Science in

Civil Engineering

\author{
David R. Martinelli, Ph.D., Chair \\ Ronald Eck, Ph. D., \\ Darrell Dean, Ph.D.
}

Department of Civil and Environmental Engineering Morgantown, West Virginia

2005

Keywords: Guardrail, Neural Network, Crash Severity 


\title{
ABSTRACT \\ Artificial Neural Network in Classification of Severity Levels in Crashes with Guardrail
}

\author{
Fouad N. Shoukry
}

This research focuses on using artificial neural networks to classify the severity levels of crashes involving guardrails, and to subsequently identify the most significant variables explaining severity in such crashes. Most of the existing research in analyzing guardrail crashes employs statistical analysis to measure severity of crashes and, unfortunately, does not incorporate much information about the factors that affect the severity concerning guardrail crashes. In the mean time, artificial neural networks have been utilized in different areas of transportation to solve engineering problems because of their ability to model non- linearity, and flexibility with large complex data sets. Data for this research were obtained from the Highway Safety Information System and were divided into two groups, the first group included roadway characteristics including guardrail/environment as input, and severity was output. The results showed that light condition, road surface condition, end and type of the guardrail significantly affect severity levels. The second group included vehicle factors and human factors as input and crash severity was output. The resulting classification was significantly affected by the driver age and vehicle impact. Merging all factors in one model resulted in the best classification of different levels of severity (above $93 \%$ in testing classification for different class of severity) and MSE $=0.027089$ in cross validation. The results have demonstrated that the Neural Networks are an effective tool to classify severity levels in crashes with guardrail if appropriate input data is available. 


\section{ACKNNOWLEDGMENTS}

I would like to express my gratitude to my research and academic advisor Dr. David R. Martinelli for providing the focus and direction for completion of this work His help, advice, guidance encouragement and support have been indispensable in completion of this work.

Sincere appreciation must also be expressed to Dr. Ronald Eck for his help and encouragement to complete this work. I would like to thank Dr. Darrell Dean for his time to be a member of the committee.

I would like to thank my wife for her unlimited support during the preparation of this work. I would also like to thank my brother Dr. Samir Shoukry for his encouragement. The author gratefully acknowledges the financial support for his research from Mid Atlantic Universities Transportation Center. 


\section{Table of Contents}

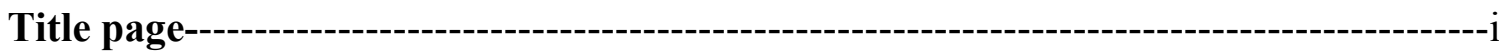

Abstract-------------------------------------------------------------------------------------ii

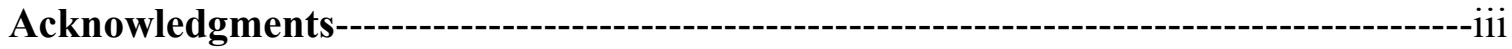

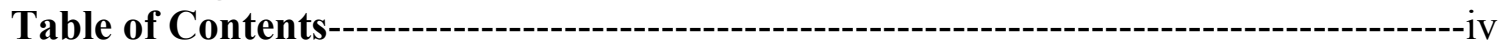

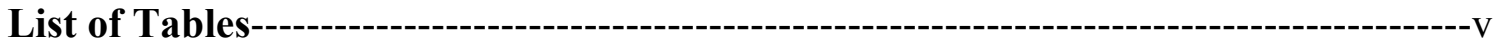

List of Figures------

Chapter 1 Introduction......................................................................................................... 1

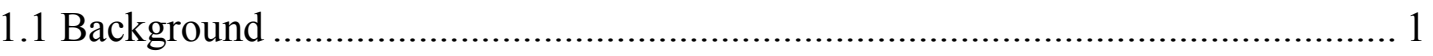

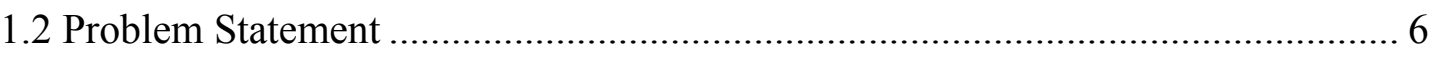

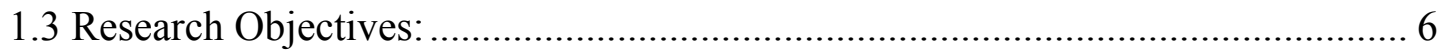

1.4 Thesis Organization................................................................................... 7

Chapter 2 Literature Review ............................................................................................ 9

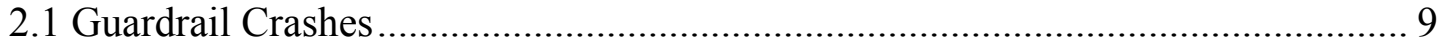

2.2 Factors that are related to Severity ………………….................................... 13

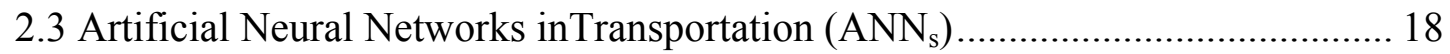

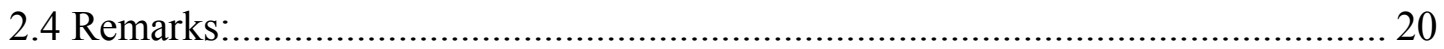

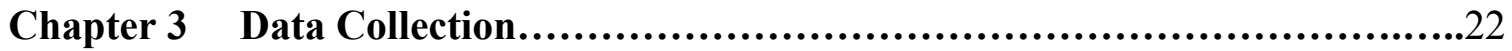

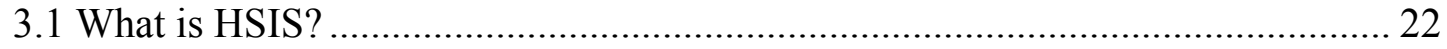

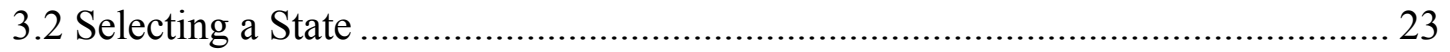

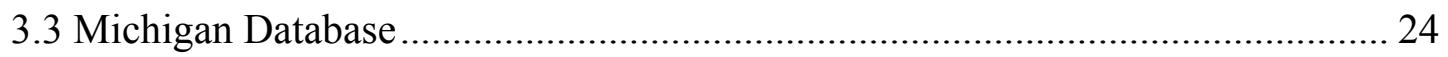

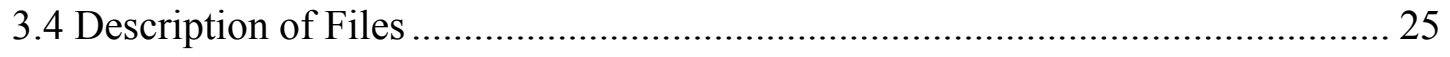

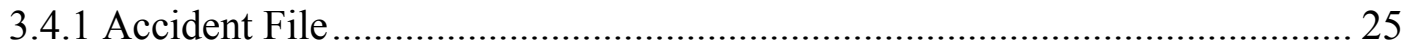

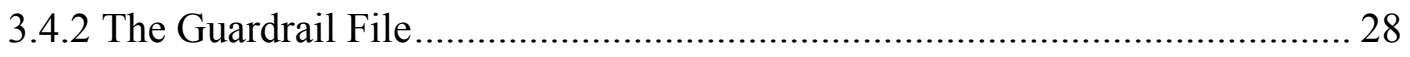

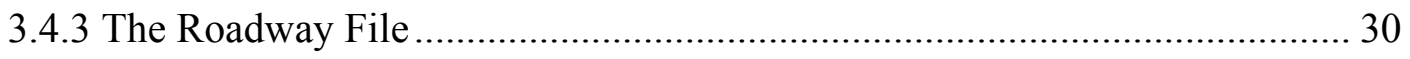

3.5 Codes of Crash Severity in Michigan Data:........................................................ 31

Chapter 4 Methodology .................................................................................................... 33

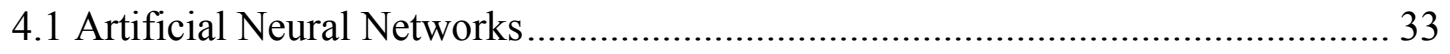

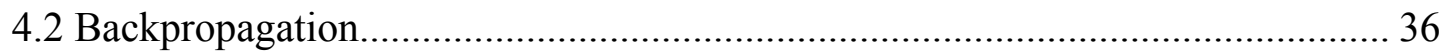

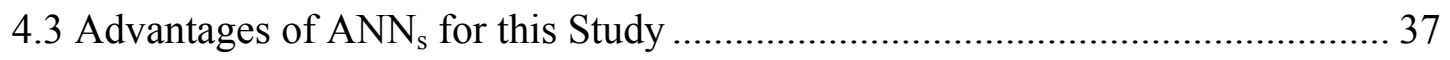




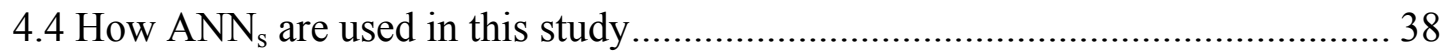

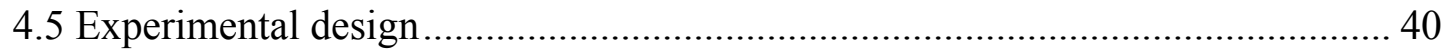

4.5.1Criteria for logic-based reduction of variables ....................................... 40

4.5.2 Measuring Performance of Classification:................................................ 44

Chapter 5 Results............................................................................................... 47

5.1 Input for Roadway/Environment Factors ................................................... 47

5.1.1 Output for Roadway/Environment....................................................... 47

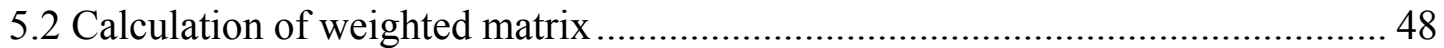

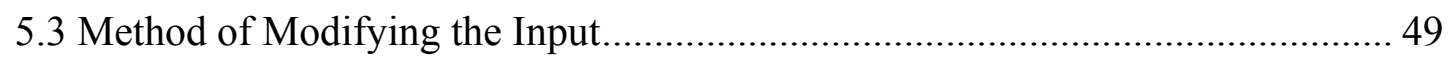

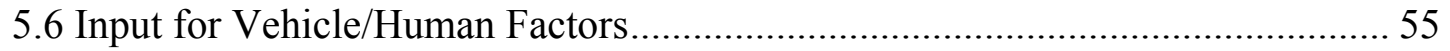

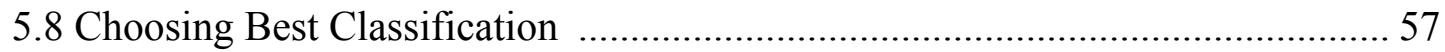

Chapter 6 Conclusions and Recommendations........................................................ 59

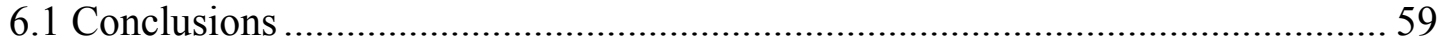

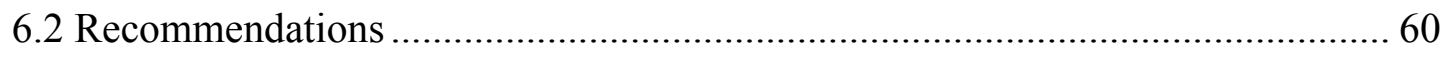

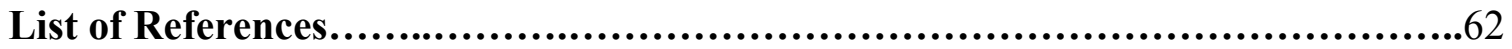

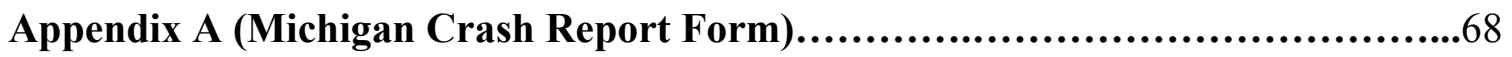

Appendix B (Results of the Neural Network)...................................... 71 


\section{List of Tables}

Table 3.1 Merging Instructions for the Data Set.............................................................. 24

Table 3.2 Definitions of Variables in Accident File ............................................................. 26

Table 3.3 Definition of Variables in Vehicle File................................................................ 27

Table 3.4 Definition of Variables in Occupant File........................................................... 27

Table 3.5 Guardrail Types in the Database....................................................................... 28

Table 3.6 Guardrail end types in the data base ...................................................... 29

Table 3.7 Definition of Variables in Guardrail File............................................................ 30

Table 3.8 Definition of Variables in Road File............................................................... 31

Table 4.1 Examples of Variables Checked from Different Files......................................... 41

Table 4.2 Examples of Variables Deleted Because of Missing Data ................................... 42

Table 4.3 Examples of Variables Unrelated to the Problem................................................. 42

Table 5.1 Result of Training with Input Road/Environment in ANN ............................ 47

Table 5.2 Result of Cross Validation with Input Road/Environment in ANN................. 48

Table 5.3 Result of Testing with Input Road/Environment in ANN .............................. 48

Table 5.4 Summary of the Results of Road/Environment Factors .................................. 54

Table 5.5 Result of Training with Input Human/Vehicle in ANN ................................. 55

Table 5.6 Result of Cross Validation with Input Human/Vehicle in ANN ....................... 55

Table 5.7 Result of Testing with Input Human/Vehicle in ANN ...................................... 55

Table 5.8 Summary of the Results of Human/Vehicle Factors ........................................... 57

Table 5.9 Result of Training with Input Human/Vehicle/Roadway Variables.................. 58

Table 5.10 Result of Cross Validation with Input Human/Vehicle/Roadway variables..58

Table 5.11 Result of Testing with Input Human/Vehicle/Roadway Variables. ............... 58 


\section{List of Figures}

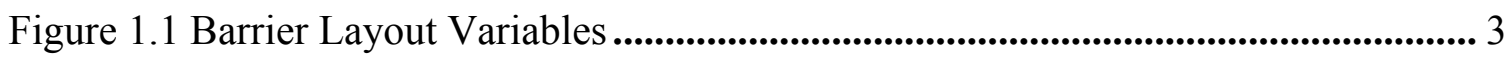

Figure 1.2 Distribution of Roadside Objects in Fatal Accidents. ..................................... 4

Figure 4.1 Schematic Representation of An Artificial Neural Network............................ 34

Figure 4.2 Sample of Neural Network.................................................................................... 34

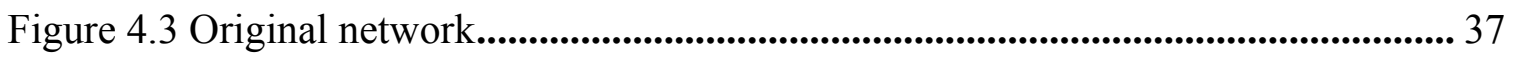

Figure 4.4 Dual network ............................................................................................... 37

Figure 4.5 Shape of Learning Curve...................................................................................... 45

Figure 5.1 Layout of the Breadboard of ANN .............................................................. 49

Figure 5.2 Percentage of Weighted Matrix Values for Eight Variables........................... 50

Figure 5.3 Percentage of Weighted Matrix Values for Seven Variables............................ 51

Figure 5.4 Percentage of Weighted Matrix Values for Six Variables ................................. 52

Figure 5.5 Percentage of Weighted Matrix Values for Five Variables............................... 53

Figure 5.6 Percentage of Weighted Matrix Values for Four Variables .............................. 53

Figure 5.7 Percentage of Weighted Matrix Values for Three Variables ............................ 54

Figure 5.8 Percentage of Weighted Matrix Values for Human/Vehicle variables ............ 56

Figure 5.9 Percentage of Weighted Matrix Values for Human/vehicle variables ............. 56

Figure 5.10 Percentage of Weighted Matrix Values for Human/vehicle of Three Variables 


\section{Chapter 1}

\section{Introduction}

\subsection{Background}

For many years, guardrails have been effectively used to shield motorists from roadside hazards. Despite their overall effectiveness, collisions with guardrails may result in significant property damage or injury, due to guardrail failure, post failure, soil settlement, or other condition resulting in the guardrail not performing its intended function. Over the years, design engineers have modified essentially every aspect of guardrails through different full-scale crash tests in an effort to improve their effectiveness and reduce the likelihood of serious property damage and injury. These standard crash testes were presented in National Cooperative Highway Research Program (NCHRP) Report Number 230 (1) which recommended two tests on standard sections of barriers: one with an $1800 \mathrm{lb}$. vehicle impacting at $60 \mathrm{~m} / \mathrm{h}$ speed at a 15 degree angle to evaluate the risk, and the other test with $4500 \mathrm{lb}$. vehicle impacting at $60 \mathrm{~m} / \mathrm{h}$ and at 25 degree angle to evaluate structural integrity of the barrier. These crash tests do not reflect all types of vehicles. NCHRP Report Number 350 (2) requires that testing be done with full-size pickup trucks to better accommodate the vehicle fleet on U.S. highways. In recent years, there has been a growth in sport utility vehicles and pickup trucks on U.S. highways, thus the need to increase their representation in standard guardrail tests. The report also requires testing with very light compact cars as well as heavy trucks for proper guardrail installation. The continued evolution of guardrail design will rely on an understanding of the crashes involving guardrails to determine if there is any action that 
could be taken to reduce their severity based on an understanding of the factors that affect the severity of crashes with guardrails.

In the 1988 edition of its Roadside Design Guide, the American Association of State Highway and Transportation Officials, AASHTO, (3) presented warrants for the installation of traffic barriers. A traffic barrier should be installed only if it reduces the severity of crash i.e. hitting the barrier will be less severe than negotiating the hazard. The selection criteria for roadside barriers depend on many factors:

1. Barriers must be structurally able to contain and redirect the design vehicle

2. Expected deflection of the barrier should not exceed available distance to deflect

3. Barriers must undergo routine maintenance and maintenance after collision

4. Simpler designs, besides costing less, are more likely to be reconstructed properly by field personnel.

The Roadside Design Guide (3) contains the variables that should be considered in designing guardrail; those variables are identified in Figure1.1 .Subsequently, the length of guardrail can be calculated using the following equation (1):

$$
\mathrm{X}=\mathrm{L}_{\mathrm{H}}+(\mathrm{b} / \mathrm{a})\left(\mathrm{L}_{1}\right)-\mathrm{L}_{2} /\left(\mathrm{b} / \mathrm{a}+\mathrm{L}_{\mathrm{H}}\right) / \mathrm{L}_{\mathrm{R}}
$$

The lateral offset $\mathrm{Y}$, which is defined as the horizontal distance from the edge of the road to the face of the guardrail can be calculated from the following equation (3):

$$
\mathrm{Y}=\mathrm{L}_{\mathrm{H}}-\mathrm{L}_{\mathrm{H}} / \mathrm{L}_{\mathrm{R}}(\mathrm{X})
$$

Although barriers are used to shield users from obstacles located along the roadway, serious problems still exist in the highway roadside due to fixed objects. 


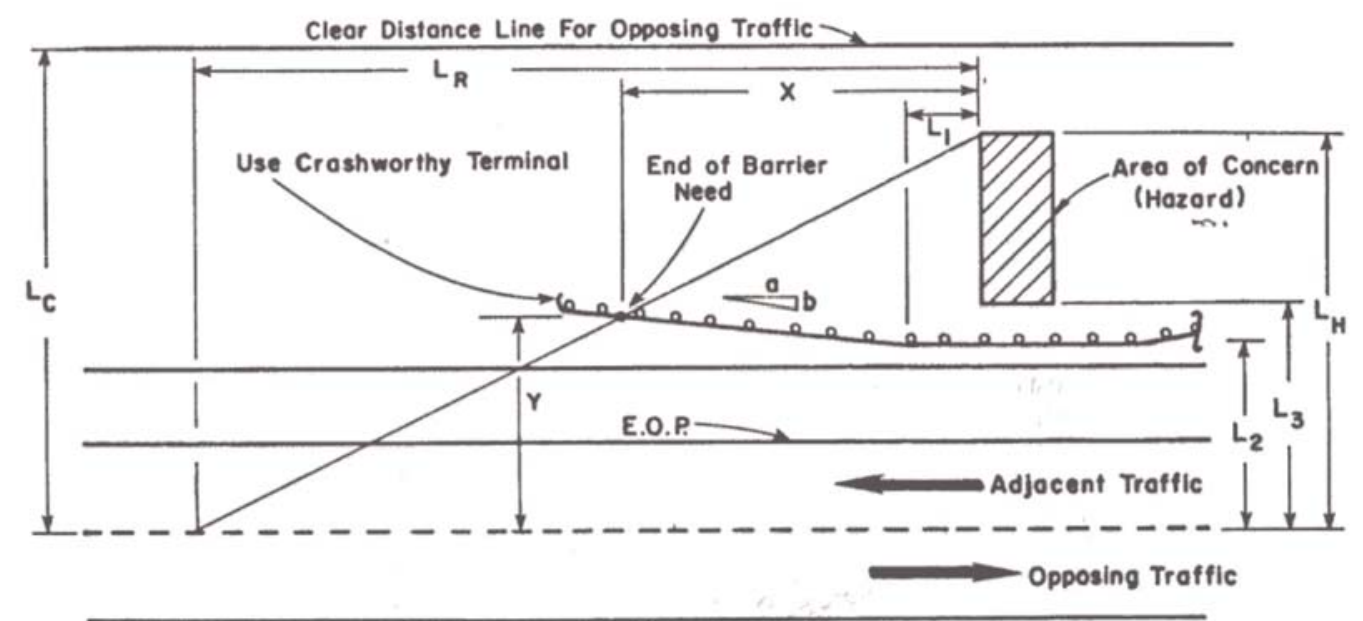

Figure 1.1 Barrier Layout Variables

$\mathrm{X}=$ Length of Need

$\mathrm{Y}=$ Lateral offset

$\mathrm{L}_{\mathrm{R}}=$ Runout Length

$\mathrm{L}_{\mathrm{H}}=$ Lateral Extent of the Hazard

$\mathrm{L}_{\mathrm{C}}=$ Clear Zone

$\mathrm{L}_{1}=$ Tangent Length of Barrier

Upstream from the Hazard

$\mathrm{L}_{2}=$ Lateral Distance of Guardrail

from the Edge of the Travel Way

Analysis of crash data indicates that more than $40 \%$ of all highway crashes involve vehicles colliding with fixed objects on the roadside. The distribution of fatal crashes with various types of fixed objects is shown in Figure 1.2.

As can be seen from the Figure 1.2, guardrails represent $12 \%$ of all fatalities involving fixed objects. Although guardrails are designed to protect motorists, the 


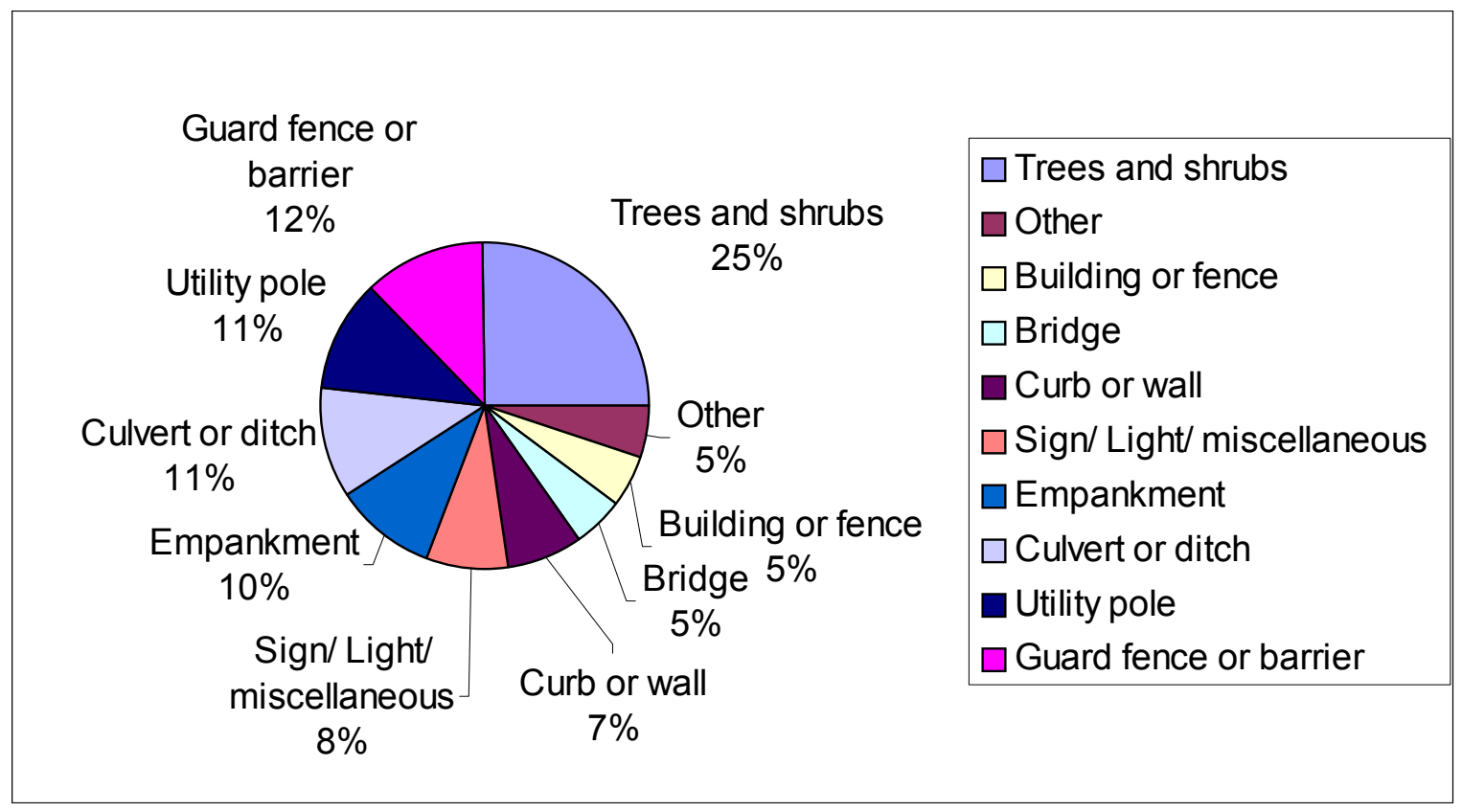

Figure 1.2 Distribution of Roadside Objects in Fatal Accidents (4).

statistics on fatalities suggest they can pose hazards. When a vehicle collides with a barrier it will result in an accident with a certain classification of severity ranging from property damage to fatality. The severity of a guardrail accident varies according to (among other things) the vehicle speed, angle of impact, and guardrail performance. This is not to suggest that guardrails are not a valuable asset to highway safety, but rather, an understanding of factors of crash severity involving guardrails could help make design and maintenance of the traffic barrier more effective.

The numerous variables and complex relationships between the driver, vehicle and roadway characteristics, guardrail design and crash severity require analytic approaches that are not conventional. This is because these factors are very different from one situation to another. For example, human factors vary from person to person due to age, gender, driver condition, reaction time and visibility. Vehicle factors are 
different due to the diverse nature of the vehicle fleet. The roadway contributions to the severity of traffic crashes severity varies from segment to segment due to changes in slope, design and maintenance of the roadway hardware or change in the lateral distance from the edge of the road, and other factors.

Identifying factors that map to some measure of crash severity requires special attention from the researcher in the field of transportation. Better information on the factors that affect crash severity, including the guardrail itself, could lead to modifying the design of the guardrails and as a consequence a reduction in property damage, injuries, and fatalities would result. Most of the existing work in analyzing guardrail crash data employs statistical analysis to measure the severity of crashes and, unfortunately, do not incorporate much information concerning factors related to the severity of guardrail crashes.

The limitation of available data and/or the traditional analytical techniques could be the reasons for the limited understanding of the distribution of severity levels. In a resent study, Michigan State developed and maintained a guardrail file up to 1992. In addition, the accident file and the road file can be merged with the guardrail file to generate variables that can be used in the artificial neural network model and identify the most important factors that can lead to a certain severity level in crashes with guardrails.

A novel approach to analyzing the relationship between the severity of collisions involving guardrails and the various roadway, driver, and vehicle factors, is the Artificial Neural Network. This method is unique because it gives engineers the ability to capture and represent input / output relationships to principal contributing factors that affect 
guardrail crashes. This thesis presents the workings of the artificial neural networks and its value to the safety of those using the highway system.

\subsection{Problem Statement}

Collisions with guardrails may result in significant property damage or injury. Crash tests have been conducted for many years to understand the performance of different barriers when hit by a vehicle. However, crash tests do not give an understanding of the severity level and do not consider other factors such as human factors. The object of this study is to explore the use of Artificial Neural Networks as an analysis technique for classifying different severity levels in crashes involving guardrails. Specifically, the work examines the ability of neural networks to successfully classify the severity of crashes involving guardrails with respect to human factors, roadway factors and vehicle characteristics. It is expected that neural networks, will be effective in correctly classifying the crash severity. The results could be used to provide guideline for future research on guardrail crashes.

\subsection{Research Objectives:}

Guardrails are a fundamental component of the roadside safety system throughout the US. Unfortunately, the circumstance by which guardrails may play a role in crash severity is not well understood. There are many possible roadway, vehicle, and driver characteristics along with guardrail factors that may, in some way, affect the safety and effectiveness of guardrails. Since guardrails are designed to protect road users from reaching hazards along the roadside it is also considered a fixed object. The 
shortcomings of detailed data and traditional analytical techniques could possibly be a reason for this lack of understanding. At the same time, Artificial Neural Networks have been very effective in classifying relationship between inputs and outputs, thus have emerged as an effective tool for solving problems involving complex relationships among variables.

The objective of this study is to explore the use of Artificial Neural Networks as an analysis technique for classifying different severity levels in crashes involving guardrails, and to identify the most important factors that could significantly affect their severity, specifically:

(1) To conduct a literature review on the factors which affect the severity of crashes;

(2) To analyze data obtained from the Highway Safety Information System which includes accident files, road files and guardrail files;

(3) To analyze data using Neuro Dimension software to find out the most important factors that can give the most accurate classification of severity levels in crashes with guardrail.

(4) To draw conclusions and recommendations based on the performance of the model used and its respective variables.

\subsection{Thesis Organization}

A review of the guardrail crashes and neural network literature is presented in Chapter 2. The sources of data collection and definition of variables are then represented in Chapter 3. Chapter 4 describes the Artificial Neural Network and analytical 
methodologies. Chapter 5 includes the results of the Neural Network analysis. The conclusions and recommendations from this study are presented in Chapter 6. Appendix A contains a copy of the Michigan Police crash report form. Appendix B contains results of testing and cross validation metrics produced by the neural networks that were used for calculating a weighted matrix. 


\section{Chapter 2}

\section{Literature Review}

Since the study purpose is to use the neural networks to classify severity levels in crashes with guardrails, the literature review focuses on guardrail crashes, the factors related to crash severity and application of neural networks in different areas of transportation.

\subsection{Guardrail Crashes}

Lee Jinsun and Fred L. Mannering (5) investigated the relationships among roadway geometry, roadside geometry, roadside characteristics and run-off-roadway crash frequency and severity. The aim is to provide a basis for identifying cost -effective ways to improve highway designs that will reduce the probability of vehicles leaving the roadway and the severity of crashes. The effects of roadside features on run-off-roadway crash severity were studied with a nested Logit model. One of the roadside features that was found to significantly affect the severity of run-off-roadway crashes was guardrails. Dangerous driver behaviors such as speeding, reckless driving and driving under the influence of alcohol or fatigue can significantly increase the risk of a severe crash. The severity distribution of guardrails were $73.7 \%$ property damage, $14.0 \%$ possible injury, $10.5 \%$ evident injury, $1.8 \%$ disabling injury and $0 \%$ fatality. The study found that widening lanes, relocating roadside fixed objects, flattening side slopes and maintenance of roadside is required to reduce run-of-road crashes. 
Michie and Bronstad (6) studied crashes involving guardrails. They concluded that up to $40 \%$ of guardrail crashes result in fatalities or injuries. Their conclusion was based on analysis done in New York Department of Transportation. Also, longitudinal barriers have been improperly given poor performance ratings based only on reported accident data. Using estimates of unreported accidents (90\%), the success rate of longitudinal barriers is at least 94 percent, considering all types of barriers in all kinds of conditions during impacts that are within and outside the normal performance range. Guardrails are designed to perform well in crash tests. Crash test depends on three factors, which are the weight of the vehicle, speed, and the angle of approach. If the impact condition exceeds the design capacity, then barrier performance will be outside the performance range, i.e. heavy trucks, high speed, and angles clearly beyond design range.

Jovanis and Chang (7) demonstrated that conventional linear regression models are not appropriate for modeling vehicle accident events on roadways, and test statistics from these models are often problematic. This is because of the relationships between the mean and variance of accident rates, non-negativity of dependent variables, and the invalidity of normal error term distribution assumption.

Hunter, Stewart, Eccles, Huang, Council and Harkey (8) evaluated the installation of cable median barrier in North Carolina, by using historical crash data. Their analysis indicated that several kinds of crashes increased after installing cable median barrier (ran- 
off-road, left hit, fixed object). However, these sections showed improved overall safety due to fewer serious fatal crashes. Overall severity values were reduced after installation.

Agent (9) found that crashes with guardrails on primary and secondary highways represent two percent of all crashes. This is less than that for interstates and parkways which are only 17 percent of all crashes. This may be due to a lack of reporting of lowseverity impacts in cases of primary and secondary highways, and also due to the higher exposure of freeway traffic to guardrails on interstates and parkways. However, the severity of guardrail crashes was higher on primary and secondary highways. The higher percentage of vehicles vaulting over the rail was found to be the causes for the high severity. A computer program was used to obtain the total number of accidents, injuries and fatalities which occurred on a road system during two-year period. Crashes were classified according to the number of lanes crossed before striking the guardrail to provide an estimate of the impact angle. Vehicle reaction upon impact was categorized and the severity of each category was determined by means of a severity index. The smallest possible value of the severity index is 1.00 corresponding to the case when all accidents involve only property damage, and the largest possible value is 9.5 corresponding to all accidents resulting in a fatal or injury type A. Agent also found that there is a direct proportion between the impact angle and severity. Vehicle penetration through guardrails was limited mostly to heavy trucks. During the study period, two types of end treatment were present, buried end (the end turned under the ground) and blunt (the end is exposed). The buried end treatment provides a significant improvement over the blunt guardrail end. 
. Costanzo Andrea, Luingi Cicinnati and Gennaro Orsi(10) analyzed the type and severity of injuries caused to the occupants of the vehicles involved in accidental impacts against guardrails. The results of the crash tests were carried out for different types of guardrails. Concerning the trajectory and the acceleration of the vehicle during the impact as well as the damage incurred to the vehicle itself do not allow establishing any precise element regarding the possible injuries to the occupants of the vehicle. They study of the relationship between the damage to the vehicle and the personal injuries, was performed in order to find out some new solutions for improving road safety in the field of impact against the guardrails.

Gattis, Vargheses, and Toothaker (11) document attributes associated with crashes in which vehicles struck the guardrail end. Their data included crashes at a variety of guardrail end types, but most ends were either exposed or turned down. They found that roughly one third of all guardrail end accidents involve an inattentive driver striking a guardrail end, the majority of the guardrail- end type crashes were property damage. For all end types combined, about one-sixth of the crashes were fatal or incapacitating injury (injury A). The severity associated with roll/vault crashes for both exposed and turned-down ends was significantly higher than severity associated with no roll/vault crashes. When a roll/vault did occur, the results were more severe with exposed ends than with turned- down ends, although the difference was not statistically significant. 
Viner (12) studied the risk of rollover in ran-off-road crashes. He explored the nature and importance of vehicle rollovers in run-off-road crashes by linking accident and roadway data. The risks of rollover in run-off-road crashes are compared by land use, road type and object struck. Side slopes and ditches were found to be the main vehicle tripping mechanism involved in rollovers while guardrails/barriers was the leading fixed object cause of rollover for rural areas.

Ray, and Weir (13) evaluated in-service performance of four types of guardrails in three states (Connecticut, Iowa, and North Carolina). The types of guardrails evaluated were cable guardrail, W-beam guardrail, and strong post guardrail. Data were collected for two years and the collision performance was measured in terms of occupant injury and barrier damage. Rail height was one of the factors affecting occupant injury. They discovered that almost $90 \%$ of the collisions with guardrails were unreported. The results showed there was no statistically significant difference between the performance of the guardrail in the three states.

\subsection{Factors that are related to Severity}

Many studies have been conducted to investigate the relationship between vehicle crash severity and factors that are related to severity.

Renski, Khattak and Council (14) studied the impact of speed limit on crash injury severity on interstate highways in North Carolina. Single vehicle crashes were examined because they constitute a large share of injuries. The most commonly struck fixed object was found to be the face of the guardrail. The study compared crash 
information collected on highway segments where speed limits were increased against similar highway segments versus segments where speed limits did not increase. The paired-comparison method and the ordered model showed an increased likelihood of Class B and Class C injuries on study segments where speed limits were increased by 10 mph, resulted in a higher probability of increased severity than those increased by $5 \mathrm{mph}$. No significant changes in injury severity were found for the comparison involving highway segments where speed limits were increased from 65 to $70 \mathrm{mph}$. Higher crash severity was observed when vehicles strike the face of the guardrail after speed limits were increased by $10 \mathrm{mph}$.

Council and Stewart (15) developed severity indices for various fixed objects that are struck when vehicles leave the roadway. The study suggested the need to develop a severity index based on an airbag-equipped fleet and also the need of having larger sample size.

Lassarre (16) developed time series modeling of monthly crashes totals and deaths in order to independently evaluate the effects of seat belts and speed limits on crash severity. The study found that seat belt use and average vehicle speed (of vehicles of equal mass) have only a small influence on safety.

Jones and Whitfield (17) analyzed data on accident severity with logistic regression. They explored the effects of car mass, age of the driver, and restraint use towards predicting the severity of crashes. Driver age, car mass, and restraint use were significant 
parameters for predicting severity. Data were collected through the New Car Assessment Program. The New Car Assessment Program was established by the National Highway Traffic Safety Administration in 1979 to provide consumers with comparisons of crash protection. During the test, an instrumented dummy wearing safety belts measure the force of impact to the chest, head, and leg. These readings are the basis of the rating. Results showed that chest deceleration was a better predictor of overall injury than head injury. Leg injury provided a significant predicting risk of injury for unrestrained occupants.

Lui, McGee, and Pollock (18) used a logistic regression approach to model the probability of fatalities conditioned on the occurrence of a crash. However, the analysis was limited to two-vehicle crashes with at least one death. The probability of a fatality was modeled as a function of driver age, driver gender, impact points, car deformation, driver safety belt status, and car mass. The results showed that males were at lower risk than females. Age had a strong positive effect on the risk. Drivers of heavy cars had a lower risk than drivers of light cars. Drivers of cars that were severely deformed in the accident were much higher risk than drivers of cars that suffered minor deformation.

Kockelman, and Kweon (19) investigated injury severity for all crashes, twovehicle crashes and single-vehicle crashes by using data from National Automotive Sampling System. The variables chosen were severity level, vehicle type, vehicle age, driver gender, and type of crash, number of occupants in the vehicle, light condition, and day of the week. They found that a variety of factors were affecting the severity of crashes: number of vehicles involved in the crash, driver gender, vehicle type and alcohol 
usage. In two-vehicle crashes, they found that manner of collisions and vehicle type were important factors affecting the severity.

Kim, Nitz, Richardson, and Li (20) focused on the relationships between alcohol and crash risk. A model was built to relate the type of crash to KABCO injury scale. The KABCO scale categorizes injuries into five levels, which are:

$\mathrm{K}=$ Fatality

A = Incapacitating Injury

$\mathrm{B}=$ Non- Incapacitating Injury

$\mathrm{C}=$ Possible Injury

$\mathrm{O}=$ No Injury

They found that crash type was a significant factor in determining the degree of injury. Also the effect of seat belt use was investigated and they found that seat belt usage has an effect on the level of injury.

A study done by McGinnis, Davis, and Hathaway (21) in longitudinal analysis of fatal Run- off -Road (ROR) crashes examined how driver characteristics such as gender, age, and alcohol relate to ROR crashes. Young drivers, male drivers, drivers over 70, utility vehicles, rollover and alcohol pose special challenge for roadside safety improvement efforts. The study showed that male drivers have higher ROR crash rates than females, even after adjusting for driving exposure. Males ages 20 to 24 have ROR crash rates 3.3 times more than females of the same age. This study showed that ROR rates for teenage males are 20 times higher than for teenage females. For drivers 70 and older, these ratios are 4.5 times higher for males and 4.0 for females. Alcohol 
involvement in ROR crashes is nearly $50 \%$ for male drivers ages 20 to 39 and is over $50 \%$ for all drivers during dark conditions. Not all factors affecting ROR crashes are included in the study, e.g. roadway geometry, traffic volume, and guardrail presence.

A study conducted by Shankar, Mannering and Barfield (22) employed a statistical model to examine numerous variables including roadway geometry, weather conditions, and driver characteristics. The set of data that includes information on the primary cause of the crash, time of the day, location of the crash (on or off roadway, curve or straight section or grade); roadway illumination, types of roadside objects involved in the collision, and crash type. Also, the data includes weather conditions (rainy, snowy, foggy) and roadway geometry (radii and length of horizontal curves). The data also includes pavement surface condition and vehicle data (type of vehicle, restraint system used by driver and occupants), and number of occupants. Information about the driver's age and gender was also included. Their results provided evidence on the effects of environmental condition, highway design, crash type, driver characteristics and vehicle attributes on crash severity. Four types of severity levels were used in this study: property damage, possible injury, evident injury and disabling injury.

Mercer (23) investigated the effects of human factors on crash severity. These factors were alcohol usage, restraint device, driver age and gender. The study found that driver age was the most significant factor. Younger drivers were at greater risk of being involved in casualty crashes than older drivers. 
Shibata and Fukuda (24) evaluated the effect of driving without a license, alcohol use, motor vehicle speed, seat belt use in the case of motor cars and helmet use in the case of motorcycles. Severity was divided into four categories, which are death, severe injury, slight injury, and uninjured. The results showed that unlicensed drivers seemed to have a higher risk in motor vehicle crash fatality, alcohol use was suggested to be a risk factor of fatality. Speed effect was significant and the effect was more critical for motorcycles. Seat belt and helmet use were found to prevent motor vehicle traffic crash fatalities among motorcar drivers and motorcyclists.

Viner (25) used economic measures to examine the objects struck in motor vehicle crashes, which are believed to cause injury or property damage. Comprehensive costs were used to combine data on fatalities, injuries and property damage. The study found that the use of comprehensive costs could reduce distortions that may occur in analysis.

\subsection{Artificial Neural Networks in Transportation $\left(\mathrm{ANN}_{\mathrm{s}}\right)$}

A neural network is a data-modeling tool able to capture and represent complex input/output relationships in manner similar to the human brain. Typical networks have three components input layer, an output layer, and a hidden layer. The input layer contains the data which the network must classify (or independent variables), an output layer contains the desired output (or dependent variables), and between these two layers are one or more hidden layers which do the processing. Each layer consists of neurons connected to every other neuron in the previous layer by a link that is representative of 
weight. Artificial neural networks have been demonstrated to be successful in solving engineering problems in the areas of classification, prediction, and function approximation. Subsequently, there are many transportation research problems that can potentially be solved with ANNs. For example, McFadden, Yang and Durrans (26) used an ANNs to predict speed on two-lane-rural highways. Data was collected for this study using a radar gun at the mid point of horizontal curves; these data were used to train the neural network model. The input consisted of geometric parameters (degree of curvature, length of curve, superelevation), and traffic parameters (lane width, total pavement width, annual average daily traffic). Their study found that ANNs offer predictive power superior to those of regression models.

Abdelwahab and Aty (27) developed an ANN model to predict driver injury severity in traffic accidents at signalized intersections. One year of crash data was used in this study and the analyses focused on two-vehicle crashes. The input data were driver age, driver gender, alcohol use, seat belt use, vehicle type ( passenger car, van, pickup), speed, point of impact, day of the crash ( weekday, weekend) area type ( rural, urban), time of the crash( off peak, peak), light condition (daylight, dusk, street light) and weather condition. The output was severity which the researchers classified it into three levels; no injury, minor injury, and severe injury. Results of the model showed that ANNs are a promising analytical tool in predicting the severity of crashes at signalized intersections. 
Sadek, and Mark (28) used ANNs for solving the inverse transportation planning problem. Their model was designed to predict zonal trip ends given the traffic volumes on the links of transportation network.

Yang, and Fengxiang (29) used ANNs pattern recognition to classify highway traffic states into some distinctive cluster centers.

Pant and Balakrishhan (30) developed a combination ANNs and a binary logit model to predict accepted or rejected gaps at rural low-volume two-way-stop controlled intersections. The results showed that ANNs can correctly predict a higher percentage of accepted or rejected gaps. ANNs has been also introduced to incident detection. Ishak and Ishak and Haitham (31) used Multi- layer and fuzzy system using real world data. These data were collected by traffic surveillance. ANN showed success over the traditional algorithms.

Teng. H, Martinelli.D.R, and Taggart.B.T (32) applied Neural Networks to traffic prediction incident detection, the results showed a good prediction model can improve the performance of incident detection. Further, ANNs have superior capabilities in emulating nonlinear systems.

\subsection{Remarks:}

Although there exists work that has proven reasonably successful in using traditional numerical and statistical techniques in assessing the severity of crashes, there 
are some studies that used human factors, others used roadway factors and some used vehicle factors. However, there was no study including all the factors that effect severity including the use of guardrails.

Very little attention has been paid to the relationships between run-off-road crashes and roadside features. Recent national statistics indicate that about one-third of fatal crashes are associated with vehicles running off the road (11). These statistics on run -off-roadway vehicular crashes indicate the continued need for research to reduce run-off -roadway crashes. Although run-off-road crashes can presented in many ways, one of the most effective forms is the use of guardrails. The data on guardrails is available for analytical study, at the same time, a promising methodology in artificial neural networks is available, presenting an opportunity to better understand the factors that most significantly affect severity in guardrail crashes. 


\section{Chapter 3}

\section{Data Collection}

This chapter presents a discussion of the Highway Safety Information System (HSIS) database and the Michigan State files that were utilized in analyzing guardrail crashes. The procedure used in preparing the crash database for analysis is also discussed.

\subsection{What is HSIS?}

Highway engineers are continually faced with decisions concerning the design and operation of highway systems. One of the important components of the decisionmaking process is the potential impact on the safety of highway users. The Federal Highway Administration developed HSIS in 1987 to help understand how highway safety is affected by the design of the roadway, selection and placement of roadside hardware, the use of traffic control measures, the size and performance capabilities of vehicles, and the needs and abilities of roadway users. This understanding can be developed through an analysis of information about crashes, roadway, traffic control devices and location of hardware and obstacles on the roadside.

The HSIS is a roadway-based system that provides data on numerous policereported crashes, roadway inventory, and traffic variables. The criterion for inclusion of a crash varies from state to state. The HSIS uses data routinely collected by states as part of the highway management system. Data is acquired annually from a select group of states, processed into a common computer format, documented, and prepared for 
analysis. At present, there are nine states participating in HSIS: California, Illinois, Maine, Michigan, Minnesota, North Carolina, Ohio, Utah, and Washington.

\subsection{Selecting a State}

The primary criteria used in selecting a state for HSIS data is the availability of a substantive inclusion of pertinent variables in reliable quantities. Choosing a state from the HSIS data files for safety analysis depends on the problem being studied and the availability of variables (in the state) that are essential for analysis. The present study requires the guardrail file to be merged with the crash file to address the severity of guardrail- related crashes.

Exploration into the availability of variables in the state database found that Michigan is the only state that had developed and maintained a separate guardrail inventory file for 1987, 1989, and 1992. Michigan Department of Transportation district offices maintained these files, and maintenance effort was stopped or greatly reduced after 1992. The guardrail file includes only guardrail factors and does not contain information on non-metal barriers such as concrete median barriers. Each record contains variables as guardrail length to the nearest foot, guardrail type (e.g. w-beam, cable barrier, etc), rail height, lateral offset from roadway edge, terminal type and flare, number of posts and post type. 


\subsection{Michigan Database}

The Michigan database consists of the following files: Accident, Roadway Segment, Guardrail Inventory, Cross-section, Intersection, Interchange Inventory, and Traffic Control Device Inventory. The following files were used in this study: Accident, Roadway Segment, and Guardrail Inventory. The files are discussed later in this chapter. Data from the HSIS are in separate files. In order to have all information about the variables, files have to be merged together with one or more variables common in these files. For example, the accident file and vehicle file have the same case number which should be matched to indicate the same crash. The first task was merging the data files; (data was represented from HSIS in five files). Table 3.1 represents the linking variable and merging instruction.

Table 3.1 Merging Instructions for the Data Set.

\begin{tabular}{|l|l|l|}
\hline FILES & $\begin{array}{l}\text { LINKING } \\
\text { VARIABLE } \\
\text { ACCIDENT }\end{array}$ & $\begin{array}{l}\text { MERGING INSTRUCTION } \\
\text { post, Control section }\end{array}$ \\
\hline VEHICLE & $\begin{array}{l}\text { Case number, Vehicle } \\
\text { number }\end{array}$ & Merge on Case number with accident file. \\
\hline OCCUPANT & $\begin{array}{l}\text { Case number, Vehicle } \\
\text { number }\end{array}$ & $\begin{array}{l}\text { Merge on Control section with Accident file, } \\
\text { case number and vehicle number with } \\
\text { vehicle file. }\end{array}$ \\
\hline ROADLOG & $\begin{array}{l}\text { Beginning milepost, } \\
\text { Ending milepost, } \\
\text { Control Section }\end{array}$ & $\begin{array}{l}\text { Merge on control section with Accident file } \\
\text { along with the following constraint, milepost } \\
\text { of Accident file should be between beginning } \\
\text { and ending milepost of Roadlog file. }\end{array}$ \\
\hline GUARDRAIL & $\begin{array}{l}\text { Beginning milepost, } \\
\text { Ending milepost, } \\
\text { Control Section }\end{array}$ & $\begin{array}{l}\text { Merge on control section with Accident file } \\
\text { satisfying the following constraint, milepost } \\
\text { of accident file should be between beginning } \\
\text { and ending milepost of Guardrail file. }\end{array}$ \\
\hline
\end{tabular}




\subsection{Description of Files}

\subsubsection{Accident Data Files}

This file consists of data collected by various police departments (city or village police and/or township police, state police, county Sheriff's department) across the state on standard statewide accident report forms and coded by the Michigan state police. (A copy of police crash reporting form is presented in appendix A. The accident file consists of three separate subfiles, the Accident, Vehicle, and Occupant. The accident subfile contains basic information on accident type, location, and types of injuries and environment. Information on each of the vehicles involved in the crash and the objects hit in the crash are presented in the vehicle subfile. The occupant subfile contains information on each injured occupant in each vehicle that was involved in the accident. Tables 3.2, 3.3, and 3.4 contain definitions of variables found in accident file, vehicle file and occupant file.

One year of accident data (1994) was considered for the present study. This was because the guardrail file was not available after 1992. The study assumed that there was no significant change in the guardrails between 1992 and 1994 
Table 3.2 Definitions of Variables in Accident File

\begin{tabular}{|c|c|}
\hline Variable & Definition \\
\hline Accident Type & $\begin{array}{l}\text { Type of crash: overturn, hit train, hit parked vehicle, } \\
\text { rear- end, head- on, sideswipe }\end{array}$ \\
\hline Accident investigated by & $\begin{array}{l}\text { The agency investigate the crash (state police, county } \\
\text { sheriff, township police or city village police) }\end{array}$ \\
\hline Year + Case number & $\begin{array}{l}\text { This is used for merging accident, vehicle and } \\
\text { occupant files }\end{array}$ \\
\hline Control Section & $\begin{array}{l}\text { This is used for merging variables and it is a code for } \\
\text { the portion of the trunk-line system where the crash } \\
\text { occurred }\end{array}$ \\
\hline County Number & Each county has number where the crash occurred \\
\hline Day of month & The day the crash happened \\
\hline $\begin{array}{l}\text { District + Control section } \\
\text { number }\end{array}$ & Used in linkage data with roadlog file \\
\hline Drinking in accident & Whether the driver had alcohol or not \\
\hline Hour of occurrence & The hour in which the crash occurred \\
\hline Highway area code & $\begin{array}{l}\text { codes to identify whether the crash occurred (within } \\
150 \mathrm{ft} \text { north or east of the intersection, within } 150 \mathrm{ft} \\
\text { south or west of the intersection, driveway related, at } \\
\text { grade crossing, median crossing related, unknown) }\end{array}$ \\
\hline Highway area code and type & Same as highway area code with more details \\
\hline Highway area type & $\begin{array}{l}\text { Interchange area (within ramp limits in all directions), } \\
\text { intersection area (with } 150 \text { feet in any direction from } \\
\text { the intersection), non-intersection/interchange area. } \\
\text { This variable changed in } 1993 \text { based on Michigan } \\
\text { staff inputs, it appears more accurate in earlier years. }\end{array}$ \\
\hline Light condition & $\begin{array}{l}\text { lighting condition at the time of the crash( day light, } \\
\text { dawn or dusk, darkness- street light, darkness- no } \\
\text { street light) }\end{array}$ \\
\hline Month of the accident & the month of the year in which the crash happened \\
\hline Number of lanes & Number of traffic lanes at the crash site \\
\hline Road surface condition & $\begin{array}{l}\text { Condition of road surface when the crash occurred } \\
\text { (dry, wet, snowy, icy, muddy, deberis) }\end{array}$ \\
\hline Roadway classification & Classification of roadway \\
\hline Severity of Accident & $\begin{array}{l}\text { Crash severity definition(Fatal, Incapacitating injury, } \\
\text { non-incapacitating injury, possible injury, property } \\
\text { damage) }\end{array}$ \\
\hline Speed limit in the crash site & The speed limit in the crash site \\
\hline Speed limit posted & Whether the speed limit was posted or not \\
\hline
\end{tabular}


Table 3.3 Definition of Variables in Vehicle File

\begin{tabular}{|c|c|}
\hline Variable & Description \\
\hline Vehicle object hit (object 1) & First object hit in the crash \\
\hline Gender of driver (drv-sex) & Gender of driver (male-female) \\
\hline Year + Case number & $\begin{array}{l}\text { Combination of crash year and case number } \\
\text { used in linkage of Accident, Vehicle, and } \\
\text { Occupants files }\end{array}$ \\
\hline Driver injury & Degree of injury cased to the driver \\
\hline Driver drinking information & $\begin{array}{l}\text { Whether driver was under influence of alcohol } \\
\text { or not }\end{array}$ \\
\hline Driver Hazardous action/ violation & Action of the driver which led to the crash \\
\hline Driver action prior to crash & Driver intent or action before the crash \\
\hline Vehicle harmful event number 1 & First event which happened in the crash \\
\hline Vehicle harmful event number 2 & $\begin{array}{l}\text { Second harmful event which happened in the } \\
\text { crash }\end{array}$ \\
\hline Vehicle harmful event number 3 & Third harmful event happened in the crash \\
\hline Vehicle harmful event number 4 & Fourth event which happened in the crash \\
\hline Driver age & Age of the driver \\
\hline Vehicle contribution circumstance & Contribution of driver and vehicle to the crash \\
\hline Vehicle impact code & Point on the vehicle suffering worst damage \\
\hline Vehicle condition & $\begin{array}{l}\text { Vehicle condition after the crash (This variable } \\
\text { is no longer accurately coded after 1991) }\end{array}$ \\
\hline Direction of vehicle traveling & $\begin{array}{l}\text { Direction in which each vehicle involved in the } \\
\text { crash was traveling }\end{array}$ \\
\hline Vehicle type & Type of vehicle involved in the crash \\
\hline Vehicle type 2 & $\begin{array}{l}\text { Weight of vehicle and type involved in the } \\
\text { crash(uncoded) }\end{array}$ \\
\hline
\end{tabular}

Table 3.4 Definition of Variables in Occupant File

\begin{tabular}{|l|l|}
\hline \multicolumn{1}{|c|}{ Variable } & \multicolumn{1}{c|}{ Description } \\
\hline Year + Case number & $\begin{array}{l}\text { Combination of crash year and case number } \\
\text { used in linkage files }\end{array}$ \\
\hline Number of occupants & Number of occupants involved in the crash \\
\hline Age & Age of injured occupant \\
\hline Age category & The category in which driver age lie. \\
\hline Occupant degree of injury & The severity level of occupant \\
\hline
\end{tabular}




\subsubsection{The Guardrail File}

The guardrail inventory file is a guardrail-based file consisting of 12,141 guardrail sections in Michigan, which are situated on either side of the road. The data is obtained from the guardrail installation forms submitted by the private construction and design firms hired by the Michigan Department of Transportation (MDOT). Initially, road construction plans are provided by MDOT to the firms. Accordingly, the contractors are required to submit forms in the event of new guardrail installation and also in case of guardrail maintenance and relocation. Along with the forms, the contractors are required to submit the plans containing sketches of the guardrails. State personnel feed this information into the database. The file contains information on guardrail face types, end treatment types, guardrail function, and roadway type. Tables 3.5 and 3.6 contain the guardrail types and end types found in the data, the definitions of variables of guardrail file are represented in Table 3.7.

\section{Table 3.5 Guardrail Types in the Database}

\begin{tabular}{|l|l|l|}
\hline Code & \multicolumn{1}{|c|}{ Face Type } & \multicolumn{1}{c|}{ Kind } \\
\hline AA & TYPE A & W_beam, no blockout \\
\hline AD & Type AD & Type A rail on both faces of posts \\
\hline BB & Type B & Type B w beam with blockout \\
\hline BD & Type BD & Type BD Type B rail on both faces of posts \\
\hline CC & Type C & $\begin{array}{l}\text { Two rail W-beam, top rail with blockout, lower rail } \\
\text { without blockout }\end{array}$ \\
\hline CD & Type CD & Type C rail on both faces of posts \\
\hline CA & & Cable barrier \\
\hline TT & & Thrie beam barrier \\
\hline EE & & Other \\
\hline TD & & Thrie beam on both faces of posts \\
\hline
\end{tabular}


Table 3.6 Guardrail end types in the data base

\begin{tabular}{|c|}
\hline Cable GR end \\
\hline Buffered cable terminal \\
\hline Buffered \\
\hline Curved End shoe \\
\hline Turned down \\
\hline Texas twist \\
\hline Anchored to bridge or barrier wall \\
\hline Expose ending \\
\hline Transition from another control section or ramp \\
\hline Intersection radius \\
\hline Minnesota bull nose \\
\hline Attenuator \\
\hline Terminal \\
\hline Terminal cable terminal \\
\hline Sentre \\
\hline
\end{tabular}


Table 3.7 Definition of Variables in Guardrail File

\begin{tabular}{|l|l|}
\hline Variable & Description \\
\hline Begin mile point & $\begin{array}{l}\text { Beginning mile point of guardrail run. Used in } \\
\text { linkage with other files }\end{array}$ \\
\hline Ending mile point & $\begin{array}{l}\text { Ending mile point of guardrail run. Used with } \\
\text { linkage with other files }\end{array}$ \\
\hline Control section & Variable used in linkage to other files \\
\hline Approach end type & Type of the end of guardrail \\
\hline Approach end flair & Whether the approach end is flared or not \\
\hline Guardrail location & $\begin{array}{l}\text { Location of the guardrail. right side, left side, } \\
\text { continuos median. }\end{array}$ \\
\hline Guardrail type & \begin{tabular}{l} 
Type of guardrail face \\
\hline Guardrail use
\end{tabular} \\
$\begin{array}{l}\text { Use of the guardrail with respect to the type of } \\
\text { road (Roadway, interchange, rest area, weight } \\
\text { station) }\end{array}$ \\
\hline Lateral distance & $\begin{array}{l}\text { Lateral distance of the guardrail face from the } \\
\text { roadway }\end{array}$ \\
\hline Number of posts & Number of posts in the guardrail \\
\hline Post type & Guardrail post type \\
\hline Rail material & Material of the rail ( Galvanized, rusty, cable) \\
\hline Rail height & Height of the guardrail face \\
\hline Roadway type & $\begin{array}{l}\text { Type of roadway. F = Freeway, N = Non } \\
\text { freeway }\end{array}$ \\
\hline
\end{tabular}

\subsubsection{The Roadway File}

This file contains characteristics for about 10,000 miles of roadway, which covers $8 \%$ of the highway miles in Michigan. The roadway file contains accurate information in terms of quality of data, because the data is obtained from the roadway plans and is less susceptible to human error. Table 3.8 contains variables and their definitions found in road file. 
Table 3.8 Definition of Variables in Road File

\begin{tabular}{|l|l|}
\hline Variable & Description \\
\hline AADT & Annual average daily traffic \\
\hline Beginning mile point of the segment & Beginning mile post of the roadway segment \\
\hline Ending mile point of segment & Ending milepost of the roadway segment \\
\hline Control section & Variable used in linkage to the other files \\
\hline Lane width & Average lane width \\
\hline Shoulder/curb type left & Type of shoulder in the left side \\
\hline Shoulder / curb type right & Type of shoulder in the right side \\
\hline Median type & $\begin{array}{l}\text { Type of median used (No median, concrete } \\
\text { barrier guardrail, raised island with curb, rumble } \\
\text { strip) }\end{array}$ \\
\hline Million vehicle miles traveled & $\begin{array}{l}\text { Million vehicle miles traveled on road segment } \\
\text { (created variable after 1999 for HSIS }\end{array}$ \\
\hline Number of lanes & Number of basic travel lanes \\
\hline Roadway type (oneway) & $\begin{array}{l}\text { Type of roadway( one way, two way, divided } \\
\text { highway, freeway) }\end{array}$ \\
\hline Paved shoulder width & width of the paved shoulder \\
\hline Roadside development code & For rural 1 and for urban 3 \\
\hline Calculated segment length & $\begin{array}{l}\text { Calculated segment length based on beginning } \\
\text { and ending mile posts. }\end{array}$ \\
\hline Posted speed limit & Speed limit set at the location in miles/hour \\
\hline Terrain type & Type of terrain which level or rolling \\
\hline Median width & Width of median measured in feet \\
\hline
\end{tabular}

\subsection{Codes of Crash Severity in Michigan Data:}

Each level of crash severity in the data set is identified by a code as follows:

$1=$ Fatality

$2=$ Incapacitating injury

$3=$ Non- incapacitating injury

$4=$ Possible injury

$5=$ Property damage 
The Vehicle subfile, object 1, which represents the first object struck, was chosen to extract data concerning the crashes with guardrails. All crashes which contain missing data were deleted. The cases of fatalities were very small in the main set of data (8 cases), and after eliminating all the missing information, Code 1 disappeared. Also, it was found that the data set does not contain any of Code 5 which is property damage, thus limiting the classification levels to 2,3 , and 4 . The variables that were chosen and the method of eliminating the data are presented in Chapter 4. 


\section{Chapter 4}

\section{Methodology}

\subsection{Artificial Neural Networks}

Artificial Neural Networks $\left(\mathrm{ANN}_{\mathrm{s}}\right)$ are a powerful data-modeling tool that are able to capture and represent complex input/output relationships. The motivation for the development of neural network technology stemmed from the desire to develop an artificial system that could perform intelligent tasks in a manner similar to that of the human brain. $\mathrm{ANN}_{\mathrm{s}}$ resemble the human brain in two ways:

(1) They acquire knowledge through learning.

(2) Their knowledge is stored within interneuron connection strengths known as synaptic weights. The true power and advantage of neural networks lies in their ability to learn these relationships directly from the data being modeled.

$\mathrm{ANN}_{\mathrm{s}}$ are adaptive, most often nonlinearly distributed systems. This pragmatic definition emphasizes the key features of the technology. $\mathrm{ANN}_{\mathrm{s}}$ are distributed, adaptive, generally nonlinear learning machines built from many different processing elements (PEs). Each PE receives connections from other $\mathrm{PEs}_{\mathrm{s}}$ and/or itself. The interconnectivity defines the topology (the way the $\mathrm{PE}_{\mathrm{s}}$ are connected together in a neural network).

The signals flowing on the connections are scaled by adjustable parameters called weights. The $\mathrm{PE}_{\mathrm{s}}$ sums all these contributions and produces an output that is a nonlinear function of the sum. The $\mathrm{PE}_{\mathrm{s}}$ outputs become either system outputs or sent to the same or other $\mathrm{PE}_{\mathrm{s}}$. $\mathrm{ANNs}_{\mathrm{s}}$ build discriminant functions from its $\mathrm{PE}_{\mathrm{s}}$. The placement of the 


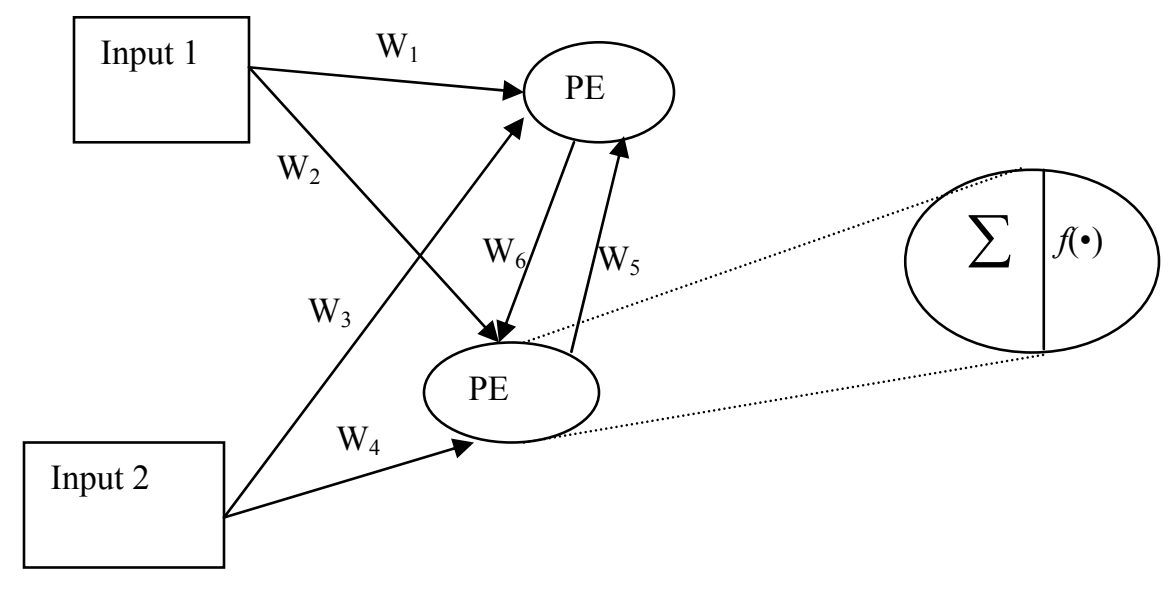

Figure 4.1 Schematic Representation of an Artificial Neural

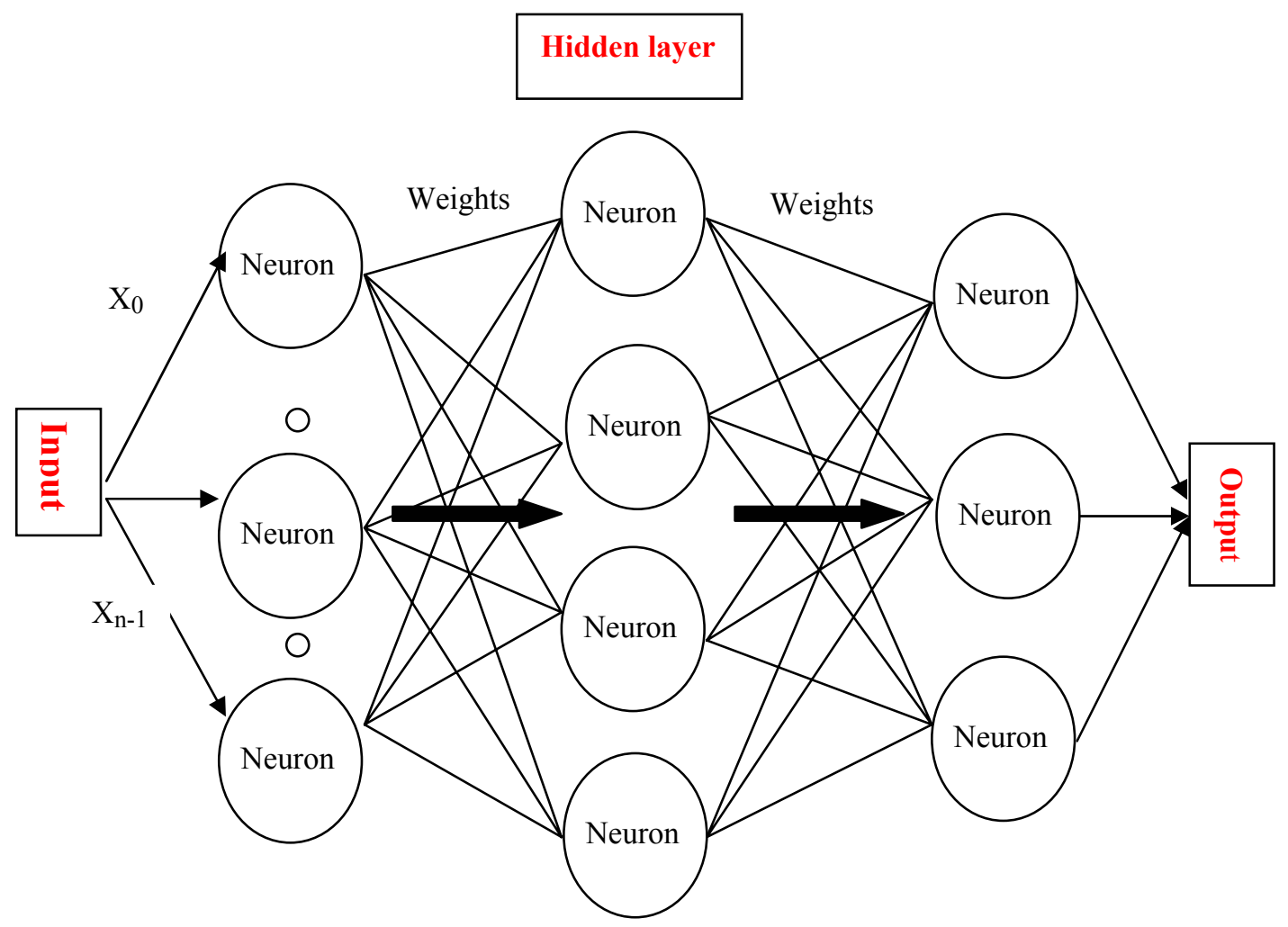

Figure 4.2 Sample of Neural Network

discriminant functions is controlled by the network weights. The weights are adjusted directly from the training data without any assumptions about statistical distribution of the data. Figure 4.1 presents a schematic of an Artificial Neural Network. Figure 4.2 
presents a neural network with a structure of three layers: the input layer, the hidden layer, and output layer. For the connection between neurons on the different layers, weights are assigned which can change during training. There are many different types of neural networks, differing with respect to their architecture and transfer function. In addition, neural networks can be classified by their learning algorithm which is usually either supervised or unsupervised. A supervised network has its output compared to known answers during training. The most common type of neural network model is the multi-layer perceptron (MLP). This type of network is known as the supervised network because it requires a desired output in order to learn. The goal of this type of network is to create a model that correctly maps the input to the output using historical data so that the model can be used to produce the output when the desired output is unknown. The main advantage is that they are easy to use, and they can approximate any input/output.

The key disadvantage is that they require a relatively large data set for training. A rule of thumb (33) states that $\mathrm{N}=10 \mathrm{~W}$, that is, the training set size, $\mathrm{N}$, should be 10 times larger than the number of network weights, W, to accurately classify. As mentioned before, a typical neural network can be viewed as a direct graph composed of nodes and connections (weights) between nodes. A set of vectors referred to as a training set is presented to the network one vector at a time. Each vector consists of input values and output values as shown in Figure 4.2. The inputs are $\mathrm{X}_{0}$ through $\mathrm{X}_{\mathrm{n}-1}$ and the output is $\mathrm{Y}$. The goal of any neural network is to characterize a relationship between the inputs and outputs. 


\subsection{Backpropagation}

The $\mathrm{MLP}_{\mathrm{s}}$ learn using an algorithm called backpropagation. Basically, backpropagation is a supervised learning scheme. With backpropagation, the input data is repeatedly presented to the neural network. With each presentation, the output of the neural network is compared to the desired output and an error is computed. This error is then fed back (backpropagated) to the neural network and used to adjust the weights such that the error decreases. Thus, at every component there is a local activity and a local error so that the weights of the network can be modified. Basically, there are two equations which are:

Forward equation: $\mathrm{y}_{\mathrm{i}}=f\left(\sum \mathrm{W}_{\mathrm{ij}} \mathrm{Y}_{\mathrm{j}}\right)+\mathrm{X}_{\mathrm{i}}$

$\mathrm{y}_{\mathrm{i}}=$ System output

$\mathrm{W}_{\mathrm{ij}}=$ weight

$\mathrm{X}_{\mathrm{i}}=$ Current input

Backward equation: $\mathrm{e}_{\mathrm{i}}=-\varepsilon_{\mathrm{i}}+\sum \mathrm{W}_{\mathrm{ij}} \delta_{\mathrm{j}}$

$\mathrm{e}_{\mathrm{i}}=$ Produced error

$\varepsilon_{\mathrm{i}}=$ Injected error

$\delta_{\mathrm{j}}=$ Error computes by topology

Figures 4.3 and 4.4 represent the flow calculations. In the forward pass, the network works with input data $\left(\mathrm{X}_{\mathrm{i}}\right)$ and produces activation $\mathrm{y}_{\mathrm{i}}$. The backward equation works with the injected error $\varepsilon_{i}$ and produces errors $e_{i}$. In more details at the ith PE the flow of activation $X_{i}$ in the original network topology is from left to right, while in the 
topology that computes the error $\delta_{\mathrm{j}}$, it is from right to left, i.e. inputs become outputs and outputs become inputs.

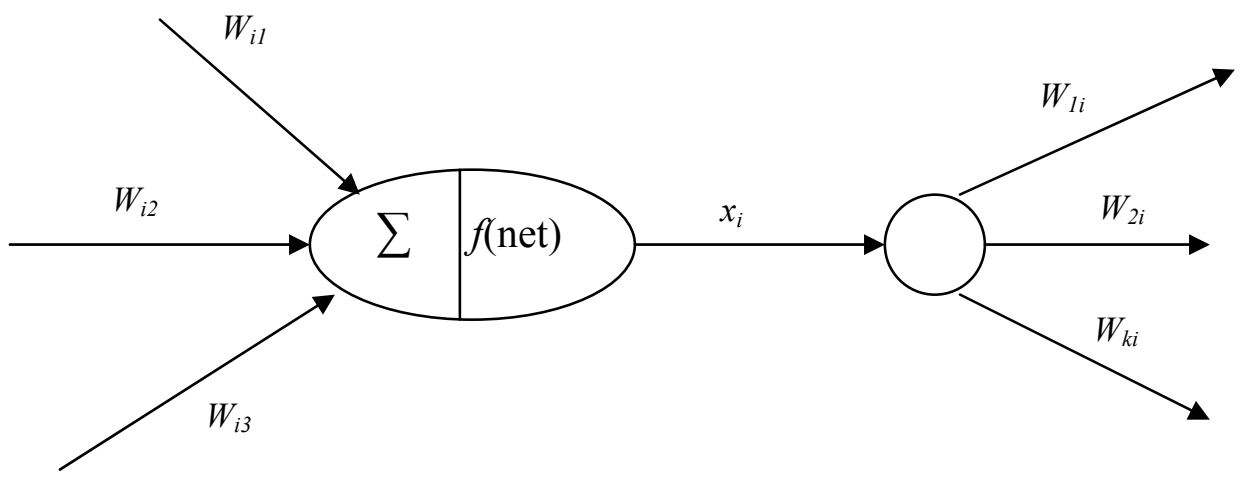

Figure 4.3 Original network

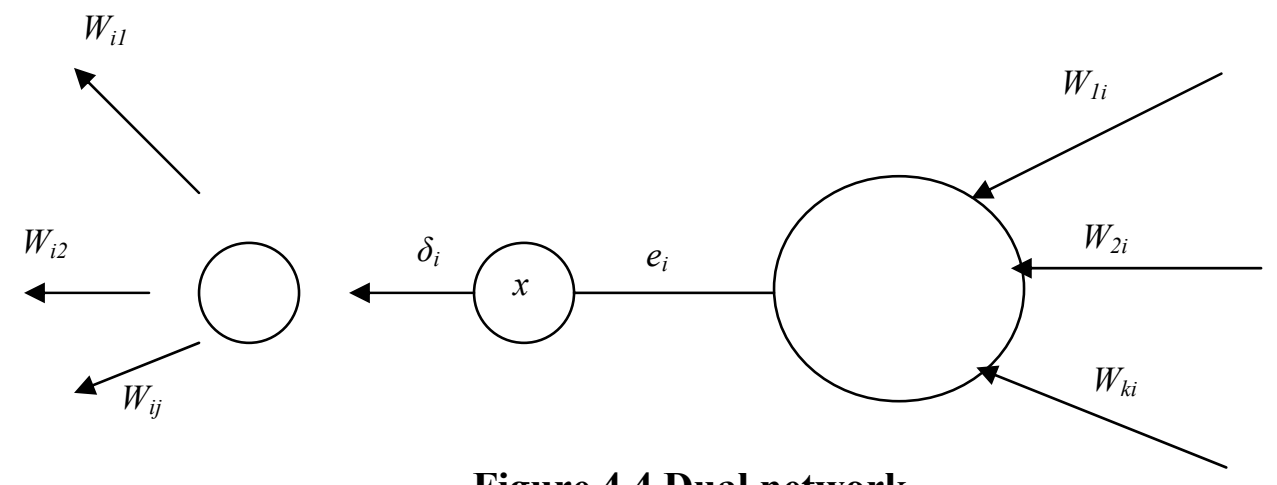

Figure 4.4 Dual network

\subsection{Advantages of $\mathrm{ANN}_{\mathrm{s}}$ for this Study}

According to Principe, Euliano, and Lefebvre (34) there are six primary justifications for using Neural Networks for the analysis of this type of data set:

(1) ANNs have a remarkable ability to derive meaning from complicated data and can be used to extract patterns that are complex.

(2) Traditional linear models are simply inadequate when it comes to modeling data that contains non-linear characteristics. 
(3) A trained $\mathrm{ANN}_{\mathrm{s}}$ can be thought of as a model of function domain that can map the input to map output regardless of function form, i.e., there are no assumptions of function form necessary and a spectrum of functional forms are inherently considered ( as opposed to one).

(4) An ability to learn how to do tasks based on the data given for training (adaptive learning).

(5) ANNs can be used when the data provided to solve the problem is complex and the exact mechanisms that generate the data are often unknown.

(6) ANNs are sufficiently powerful to create arbitrary discriminant functions. The ANN builds dicriminant functions from its processing elements. The ANN topology determines the number and shape of the discriminant functions. The shapes of the discriminant functions change with the topology so ANNs can achieve optimal classification. (33).

\subsection{How $\mathrm{ANN}_{\mathrm{s}}$ are used in this study}

There are many types of Neural Network software. While they do not differ significantly in their performance, they may differ with respect to the visualization of the problem. One of the latest software packages is Neuro Solutions (33). This software is advantageous because it contains a demo, which helps to understand the processing of the data. It also contains icons to visualize the processing of learning, cross validation and testing procedures. Especially in the classification problem, the designer can visualize whether the data is stuck in the local minimum or not. 
The Neural Expert has been used in this study. Neural Expert is a part of Neural Solution Software, which intelligently selects the network size and architecture that will most likely produce a good solution. The first step in building a neural network with the Neural Expert is to select the problem type. The classification problem has been chosen in this project since the objective is to classify crash severity. The second step is to notify the network of the location of the input file that must be in text format. The next step in constructing the neural model is to tag the input columns. The tag input columns panel is where the designer specifies which data he would like to feed into the neural network. After that, the designer has to select the desired output data. In this step, the designer can randomize the data set.

The following step is to tag the desired output columns, which for this study is severity. Then the designer shows the network which columns represent symbolic data. Finally, the designer chooses the level of generalization protection, to ensure that the network performs well on data that it has not been trained on. The standard method to ensure good generalization is to divide the data set into three types of data. These are:

- Training set

- Cross validation set

a Testing set

(1) Training Set is the portion of the data used to actually train the network. This is normally the largest portion of the data and can be taken as $50 \%$ of the data set. The process of learning consists of showing to the neural network examples of input data and 
expected output. The synaptic weights adjust themselves until error between the output generated by network and real output reaches a desired level as mentioned before.

(2) Cross validation set is the data set aside to test the network during training.

(3) Testing set is used to further validate the results of a trained network.

\subsection{Experimental design}

Two steps were used for the design of the experiment

(1) Reduce the number of variables for the model from 74 variables to 13 variables based on the logic of the problem and availability of data.

(2) Reduce the number of variables for the model from 13 variables to 6 variables based on model performance under different combinations of these variables.

These two steps helped retain the variables that best explain severity of crashes by eliminating the redundant variables and the variables containing missing data. This guarantees the efficiency of the processed data, hence produces a more useful and robust model.

\subsubsection{Criteria for logic-based reduction of variables}

In the Vehicle subfile, OBJECT1, that represents the first object struck, was chosen to extract data concerning the crashes with guardrails. Then three steps were followed to get an uncontaminated data set:

(1) Reduce the number of variables for the model from 74 variables to 13 variables by the following procedure:

(a) Variables, which are the same, are checked from two files or more. Some of the variables that are checked are presented in Table 4.1 
(b) Some variables were deleted because of missing data. Some of the variables are presented in Table 4.2

(c) Some variables were deleted because of unrelated to the problem. Examples of such variables are represented in Table 4.3

(2) Reduce the number of variables for the model from 13 variables to 6 variables based on model performance under different combinations of these variables.

\section{Table 4.1 Examples of Variables Checked from Different Files}

\begin{tabular}{|c|c|c|}
\hline Variable symbol & Variable name & Files contain the variable \\
\hline DWI & $\begin{array}{l}\text { Driving under influence of } \\
\text { alcohol }\end{array}$ & Accident file \\
\hline INTOX & Driver drinking & Vehicle file \\
\hline Drv_sex & Driver gender & $\begin{array}{l}\text { Vehicle file and Occupant } \\
\text { file }\end{array}$ \\
\hline Sev & Severity & $\begin{array}{l}\text { Accident file and Occupant } \\
\text { file }\end{array}$ \\
\hline Drv_ag & Driver age & $\begin{array}{l}\text { Vehicle file and occupant } \\
\text { file }\end{array}$ \\
\hline Speed & $\begin{array}{l}\text { Posted Speed at the crash } \\
\text { location }\end{array}$ & $\begin{array}{l}\text { Accident file and roadway } \\
\text { file }\end{array}$ \\
\hline
\end{tabular}


Table 4.2 Examples of Variables Deleted Because of Missing Data

\begin{tabular}{|c|c|c|}
\hline Variable symbol & Variable name & Files contain the variable \\
\hline hwy_cod & Highway code & Accident file \\
\hline Tot-no & $\begin{array}{c}\text { Numbers of persons } \\
\text { uninjured }\end{array}$ & Accident file \\
\hline Rd-loc & Relationship to roadway & Accident file \\
\hline hwy-tycd & Highway area code and type & Roadway file \\
\hline vehcond 1 & $\begin{array}{c}\text { Vehicle condition } \\
\text { circumstance }\end{array}$ & Vehicle file \\
\hline veh-face & vehicle file \\
\hline vision & Harmful events & vehicle file \\
\hline event1,event2,event3,event4 & Vehicle type & vehicle file \\
\hline veh-typ & Defect of vehicle & vehicle file \\
\hline defect & Lane width & vehicle file \\
\hline lanwid & &
\end{tabular}

Table 4.3 Examples of Variables Unrelated to the Problem

\begin{tabular}{|c|c|c|}
\hline Variable symbol & Variable name & Files contain the variable \\
\hline Acc-loc & Accident location & Accident file \\
\hline agency & $\begin{array}{c}\text { Agency investigate the } \\
\text { accident }\end{array}$ & Accident file \\
\hline Nbr-lane & $\begin{array}{c}\text { Number of lanes } \\
\text { Speed limit posted } \\
\text { wheteter the speed posted } \\
\text { or not) }\end{array}$ & Accident file \\
\hline spdpost & Direction of travel & vehicle \\
\hline Dir-trv & Average daily traffic & Road file \\
\hline aadt & Segment length & Road file \\
\hline Seg-lng & Median wide & Road file \\
\hline medwid & Shoulder type & Guardrail file \\
\hline Sld-typ & Rail material & Guardrail file \\
\hline Rail-mat & Guardrail length & Guardrail file \\
\hline Grd-lngt & &
\end{tabular}


Based on this study and typical studies employing neural networks, the input variables play a critical role in achieving a good performance of classification.

Identifying the most important inputs, which have great contributions and effects on the output, is the main key to produce a good classification.

To do so, the data was divided into two groups.

The first group of data contains Roadway Characteristics/Environment, which are:

a Light condition

a Road surface condition

- Type of the end of guardrail

a Flared end of guardrail

- Guardrail type

- Post type

a Rail height

a Lateral distance from the edge of the road to the Guardrail

The second group of data contains:

口 Speed limit

- Driver age

- Driving under influence of alcohol

- Vehicle impact

口 Number of occupants 
The Neuro-solution software was used in the experiment and a total of 53 neural networks were developed to identify the best factors that can classify the levels of severity with minimum error. As mentioned before, the data was divided into two sets. The first set was Roadway/Environment and this set contains:

Light condition, road surface condition, type of the end of guardrail, type of guardrail, flared end of guardrail, type of post, height of rail, and lateral distance from the edge of the road to the guardrail. All of these variables were chosen as input for the neural network, and the output was the severity.

The second set of data contained Human/Vehicle data and this set contains:

Driving under influence of alcohol, speed limit, driver age, vehicle impact and number of occupants.

\subsubsection{Measuring Performance of Classification:}

Performance of classification was measured by:

๑ Learning curve

- Confusion matrix for training

a Confusion matrix for cross validation

The learning curve is the plot of the mean squared error (MSE) of the network after each epoch of data. Figure 4.5 represents the shape of learning curve produced by the ANNs of the first run. The $\mathrm{X}$-axis represents the epoch number and the $\mathrm{Y}$-axis represents the (MSE). The MSE of the training set is shown in red, and the MSE of the cross validation is shown in blue. A network that is training well should have a constantly 


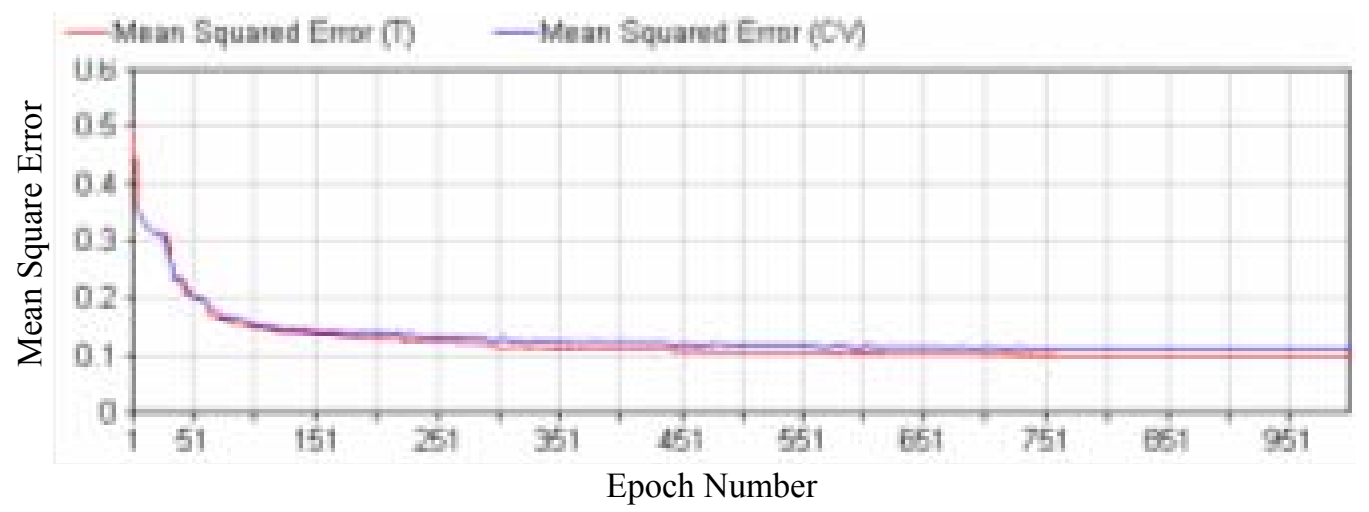

Figure 4.5 Shape of Learning Curve.

decreasing slope of the training MSE. As long as the training set learning curve is decreasing, the network is still training.

If the training set learning curve is increasing or noisy (jumping up and down), this means the network is probably not training well.

Data were examined with 672 records, but the performance of the network was very poor. The learning curve indicated that the network did not train well with the data because of lack of the quantity of data. To avoid this problem, data in an Excel spreadsheet were repeated 10 times the data set (copy, paste). Then the data became 6720 records. The neural net examined the new data and the performance of the learning curve was very good.

The confusion matrix for training and cross validation is a matrix used in classification problems to determine the number of correct and incorrect classifications by the network. The diagonal values of this matrix indicate the true classification. The off-diagonal values indicate where the neural network has been confused in classification. 
Therefore, correct classifications are contained on the diagonal of the matrix [position $(2,2),(3,3),(4,4)]$. All other entries are incorrect classifications, but also indicate where the network was confused. Each matrix shows a percentage, but can also show absolute numbers.

The cross validation matrix is transferred into one number using the following formula:

Weighted Matrix $=$

\% of cases $(2,2) \times$ total \# of cases $2+\%$ of cases $(3,3) \times$ total \# of cases $3+\%$ of cases $(4,4) \times$ total \# of cases 4 Total \# of cases $2,3 \& 4$

The effect of eliminating each variable is discussed in chapter 5 . 


\section{Chapter 5}

\section{Results}

\subsection{Input for Roadway/Environment Factors}

The first experiment was to input the identified roadway/environment factors, which are light condition, road surface condition, end type, approach end, guardrail type, post type, rail height, and lateral distance, (8 factors) and classify the severity as output. The cross validation matrix was transferred to one number.

\subsubsection{Output for Roadway/Environment}

The output of the network is in the form of a matrix as mentioned before, this matrix is used in classification problems to determine the number of correct and incorrect classifications by the network. The horizontal axis indicates the true class of the input and the vertical axis indicates the network's prediction of the class. Therefore, correct classifications are contained on the diagonal of the matrix [position $(2,2),(3,3)$, $(4,4)$ ],which are 80.4 for level 2, 83.7 for severity level 3 and 93.06 for severity level 4 . All other entries are incorrect classifications, but also indicate where the network was confused. Tables 5.1, 5.2, and 5.3 represents the output of the neural network.

Table 5.1 Result of Training with Input Road/Environment in ANN

\begin{tabular}{|l|l|l|l|}
\hline Training & 2 & 3 & 4 \\
\hline 2 & 80.408165 & 6.857143 & 12.734694 \\
\hline 3 & 5.486399 & 83.725220 & 10.788382 \\
\hline 4 & 2.110023 & 4.822909 & 93.067070 \\
\hline
\end{tabular}


Table 5.2 Result of Cross Validation with Input Road/Environment in ANN.

\begin{tabular}{|l|l|l|l|}
\hline Cross Validation & 2 & 3 & 4 \\
\hline 2 & 80.140190 & 2.102804 & 17.757010 \\
\hline 3 & 3.621170 & 80.22839 & 16.155989 \\
\hline 4 & 1.724138 & 1.724138 & 96.551727 \\
\hline
\end{tabular}

Table 5.3 Result of Testing with Input Road/Environment in ANN.

\begin{tabular}{|l|l|l|l|}
\hline Testing & 2 & 3 & 4 \\
\hline 2 & 75.539566 & 8.153478 & 16.3069 \\
\hline 3 & 1.923077 & 92.170326 & 5.906593 \\
\hline 4 & 2.755454 & 2.640643 & 94.603905 \\
\hline
\end{tabular}

\subsection{Calculation of weighted matrices}

The results presented above are obtained after several runs until getting the best shape of the learning curve. To have good judgment in which factor should be eliminated, the cross validation matrix is transferred into one number using the following formula:

Weighted Matrix =

$\%$ of cases $(2,2) \times$ total \# of cases $2+\%$ of cases $(3,3) \times$ total $\#$ of cases $3+\%$ of cases $(4,4) \times$ total \# of cases 4 Total \# of cases 2, 3 \& 4

That is:

Weighted Matrix $=\frac{80.14 \times 1380+80.2 \times 2410+96.5 \times 2930}{(1380+2410+2930)}=87.294672$

Figure 5.1 is a copy of the first neural network to illustrate the learning curve, matrix of training and matrix of cross validation. The mean square error for this run was 0.109990 


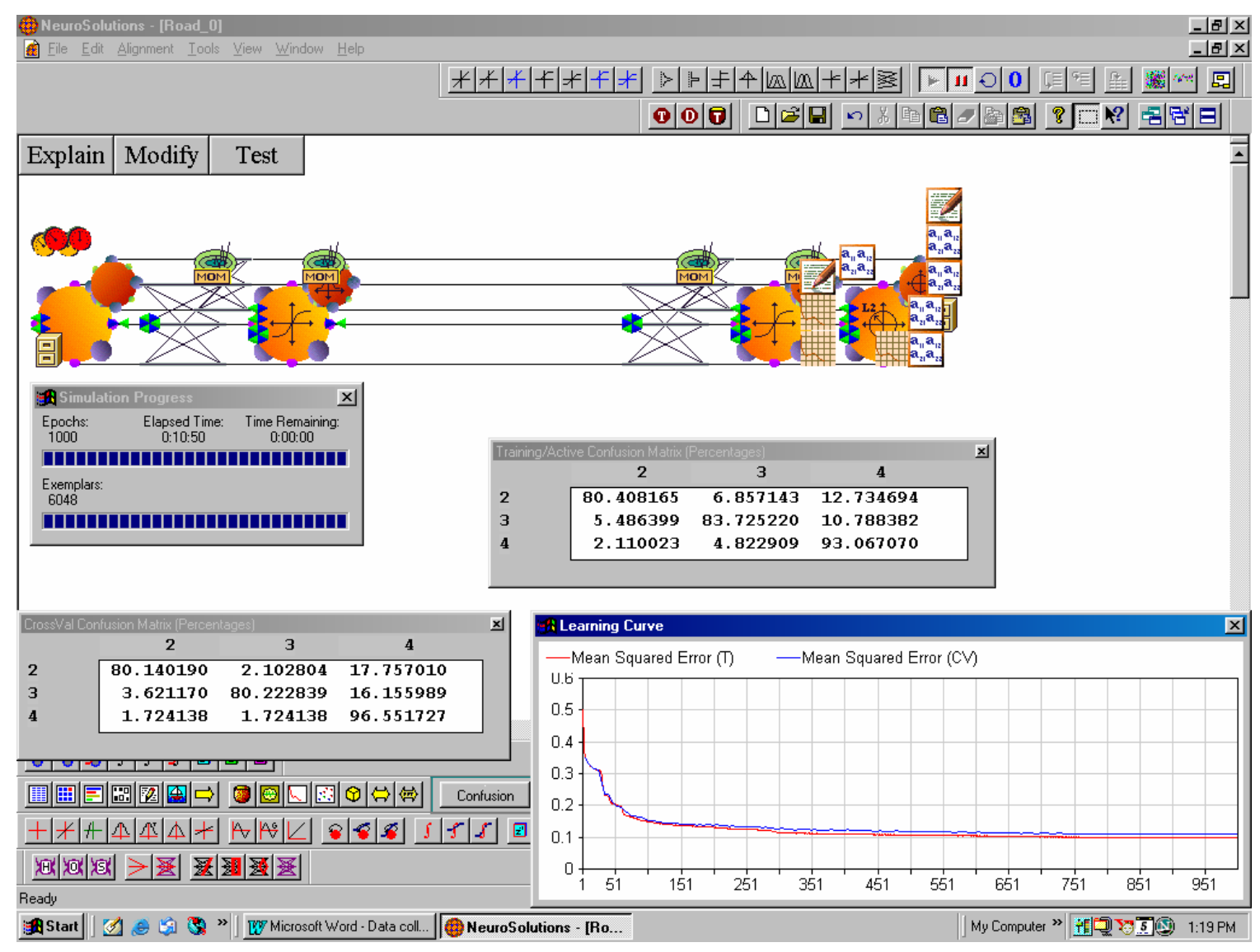

Figure 5.1 Layout of the Breadboard of ANN

\subsection{Method of Modifying the Input}

After this test was completed, and after taking out one variable from the data set, the network modified data was then rerun. Classification results were then obtained from the cross validation matrix. Then, the weighted matrix was calculated to indicate the effect of the deleted variable. Next, the variable that was deleted was put back and another variable was deleted. Calculation for the weighted matrix will indicate which variable has no significant effect on classification. 
A total of nine neural networks were developed to conclude that the end flared variable seems to have no effect on classification. Graphical presentation of ( 8 variables) the results of the calculated weighted matrix are shown in Figure 5.2

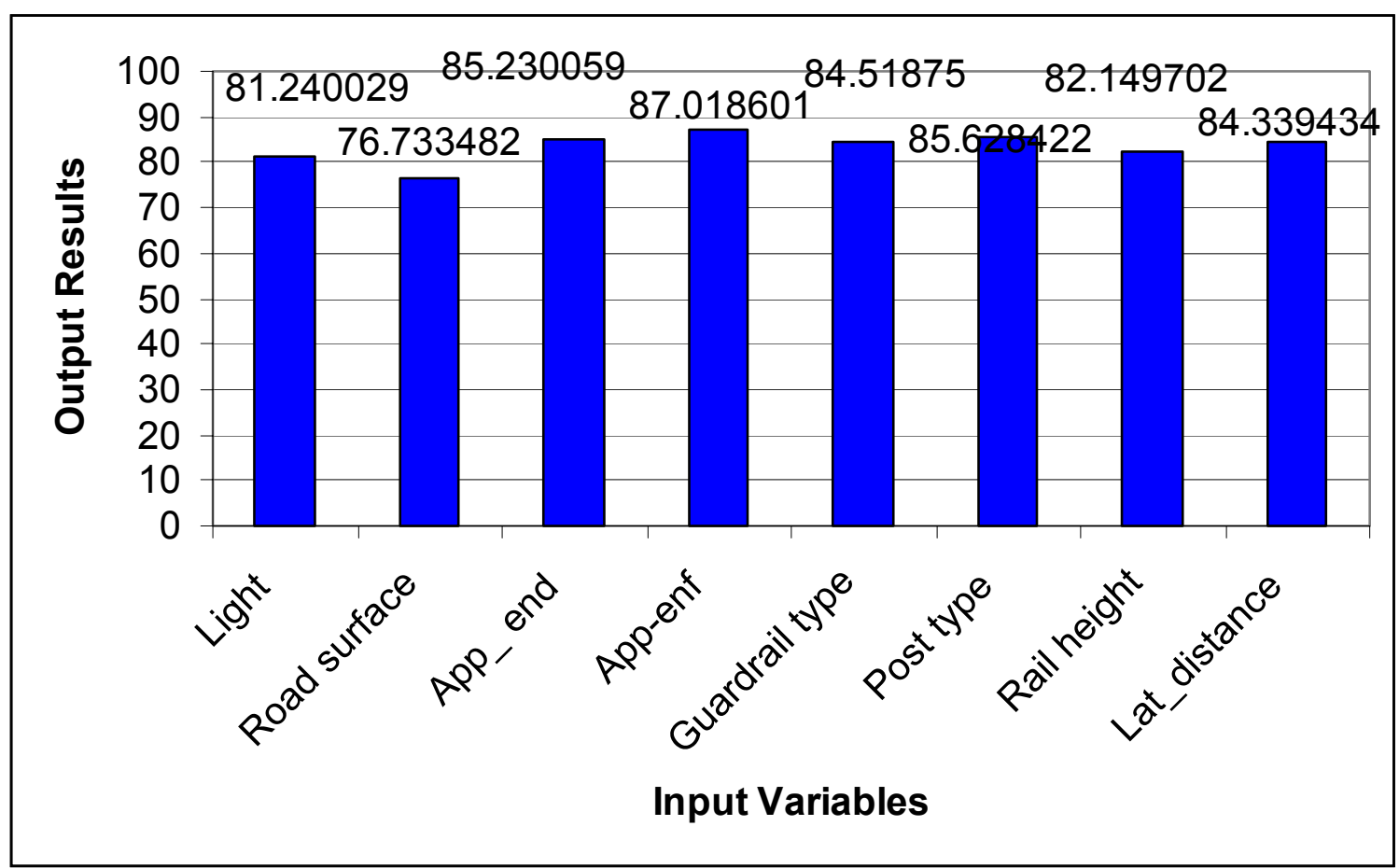

Figure 5.2 Percentage of Weighted Matrix Values for Eight Variables.

The bar chart in Figure 5.2 shows the percentage of weighted matrix values for eight variables under considerations. The chart indicates that the end-flared of the guardrail gives the highest value (87.018601). Therefore, this variable can be eliminated since it has no significant impact on the classification. 
Then, data was modified. Seven variables were used in the model as input, and severity was output. The weighted matrix then was calculated. This operation was repeated to all the variables to decide which variable we have to eliminate.

Figure 5.3 presents the results of the weighted matrix which was calculated from cross validation matrix that were produced by neural networks.

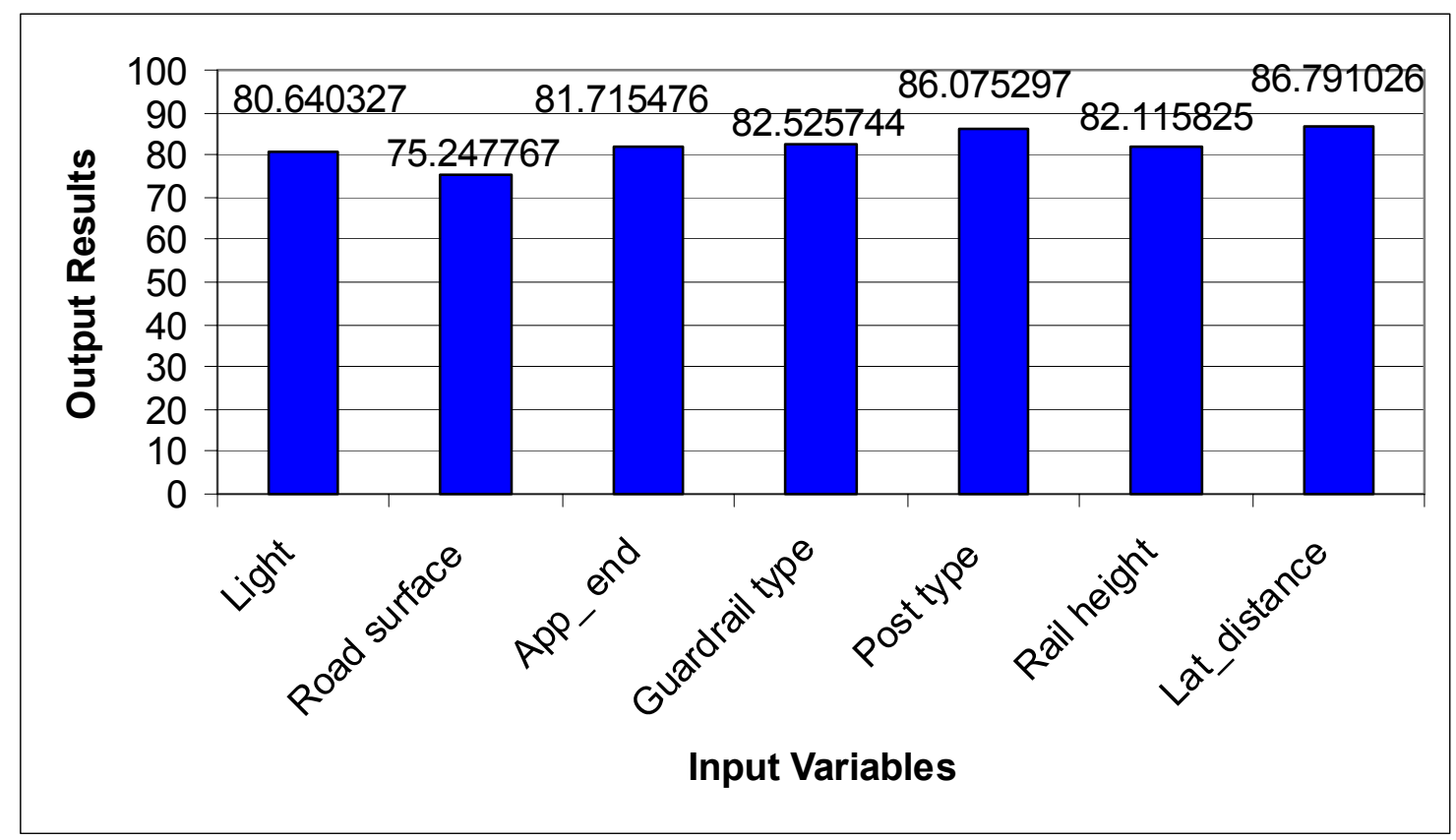

Figure 5.3 Percentage of Weighted Matrix Values for Seven Variables

From the graph, it was found that the lateral distance had no effect on severity, so this variable was deleted. The rest of variables were used in a new run. It has to be mentioned that from an engineering point of view, although lateral distance is an important factor, it seems to not be affecting the classification. Possibly, if the data included another factor it could work well to prove that the lateral distance is important. 
The process was started again and the weighted matrix was calculated. The aim was to eliminate another variable. The result showed that post type has no effect on the severity. Figure 5.4 presents the weighted matrix that was calculated indicating that post type has no effect on severity.

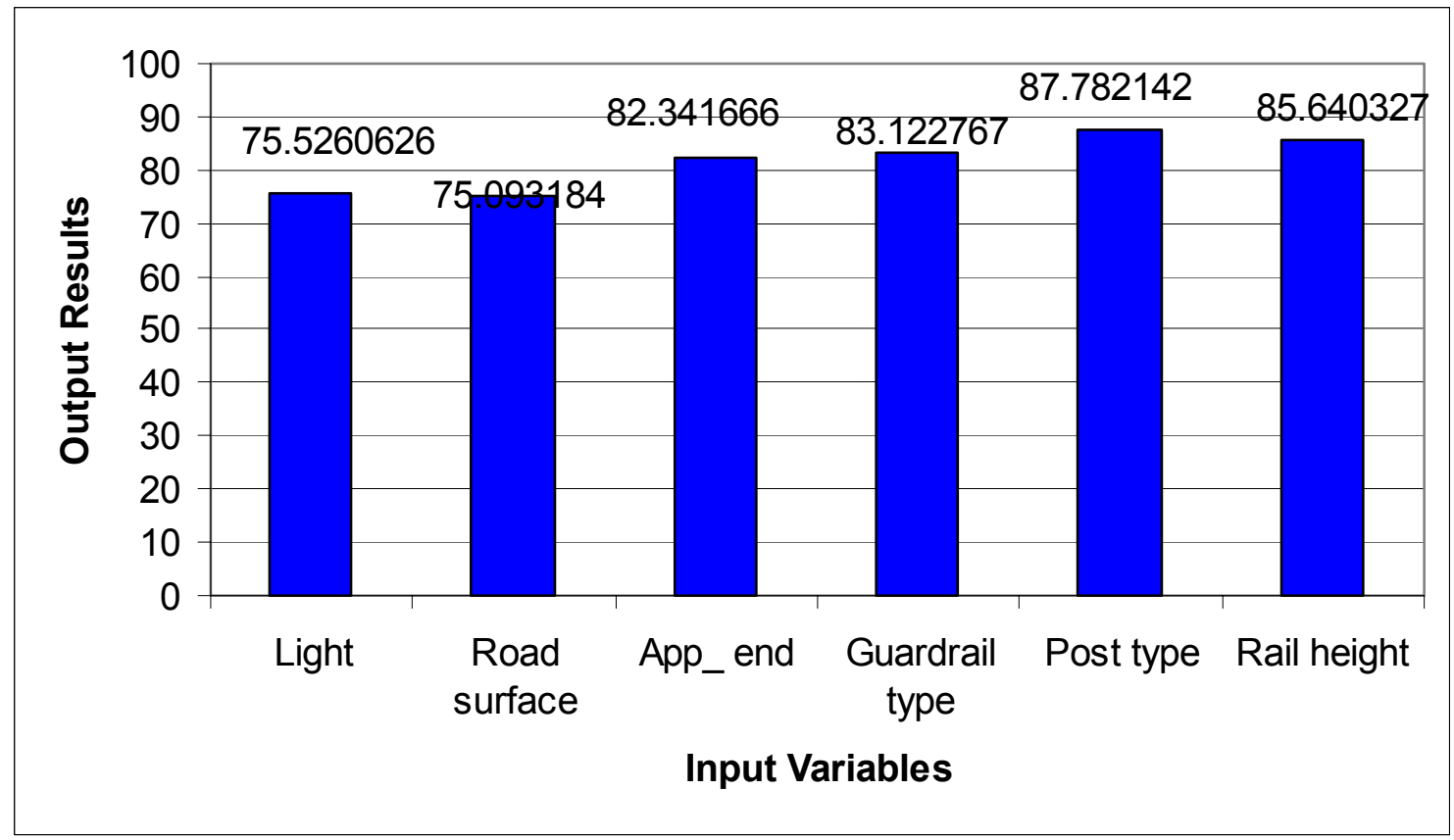

Figure 5.4 Percentage of Weighted Matrix Values for Six Variables

After eliminating post type, five variables remained. The same process was done for the remaining variables and the results are shown in Figures 5.5, 5.6 and 5.7. To reach the last results, a total of 39 Neural Networks were done. All the results can be viewed the summary presented in Table 5.4. 


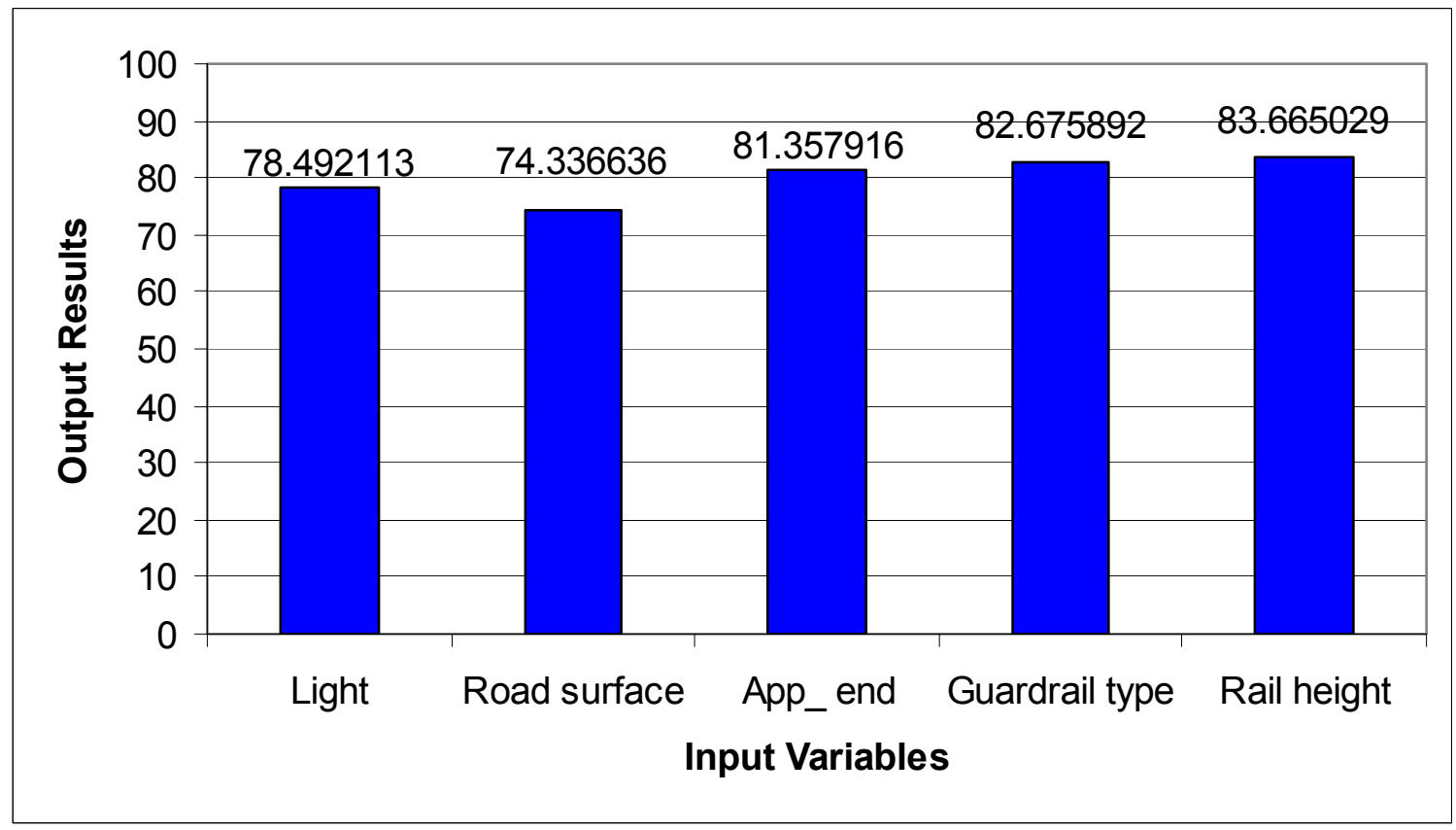

Figure 5.5 Percentage of Weighted Matrix Values for Five Variables

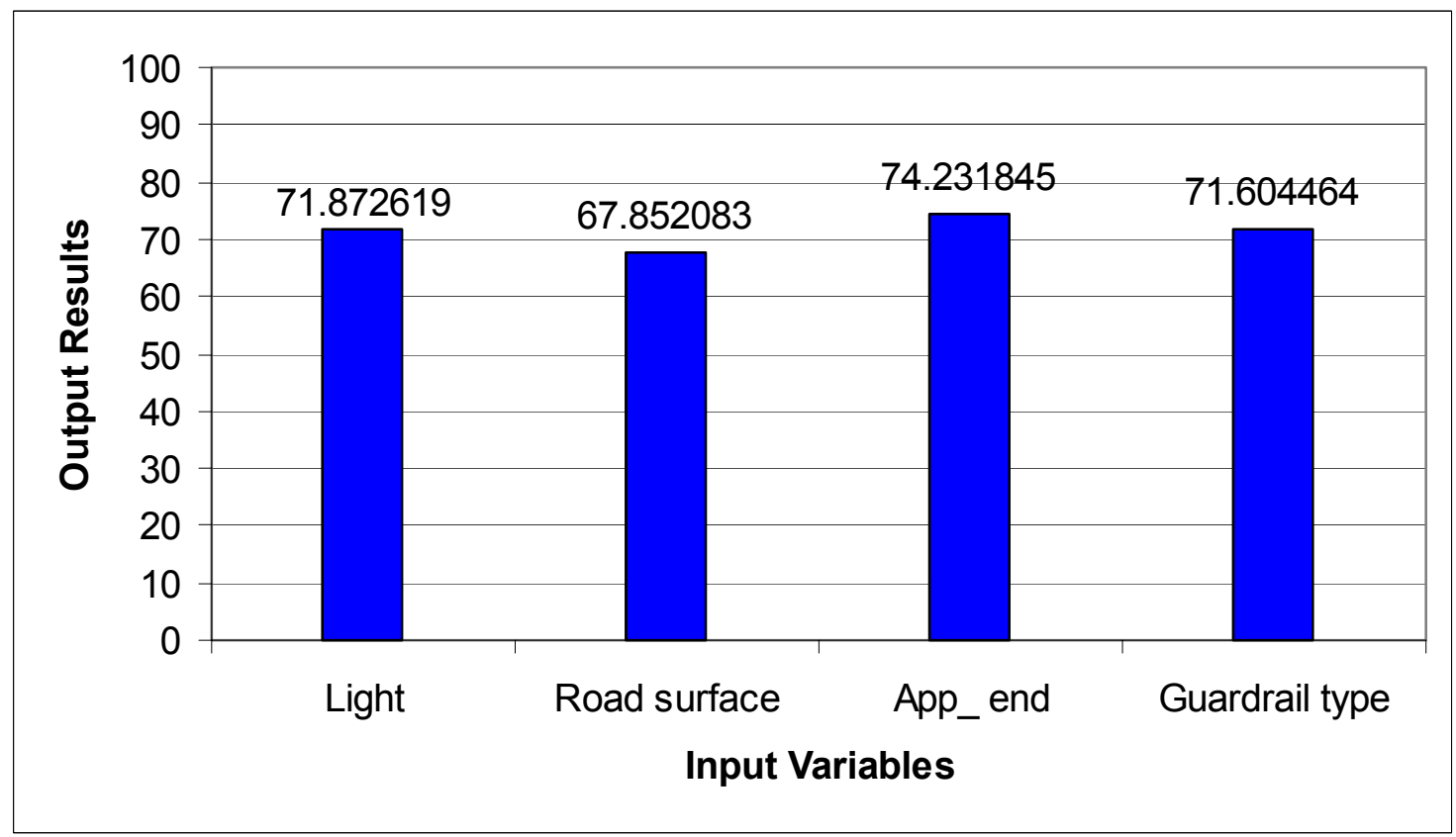

Figure 5.6 Percentage of Weighted Matrix Values for Four Variables. 


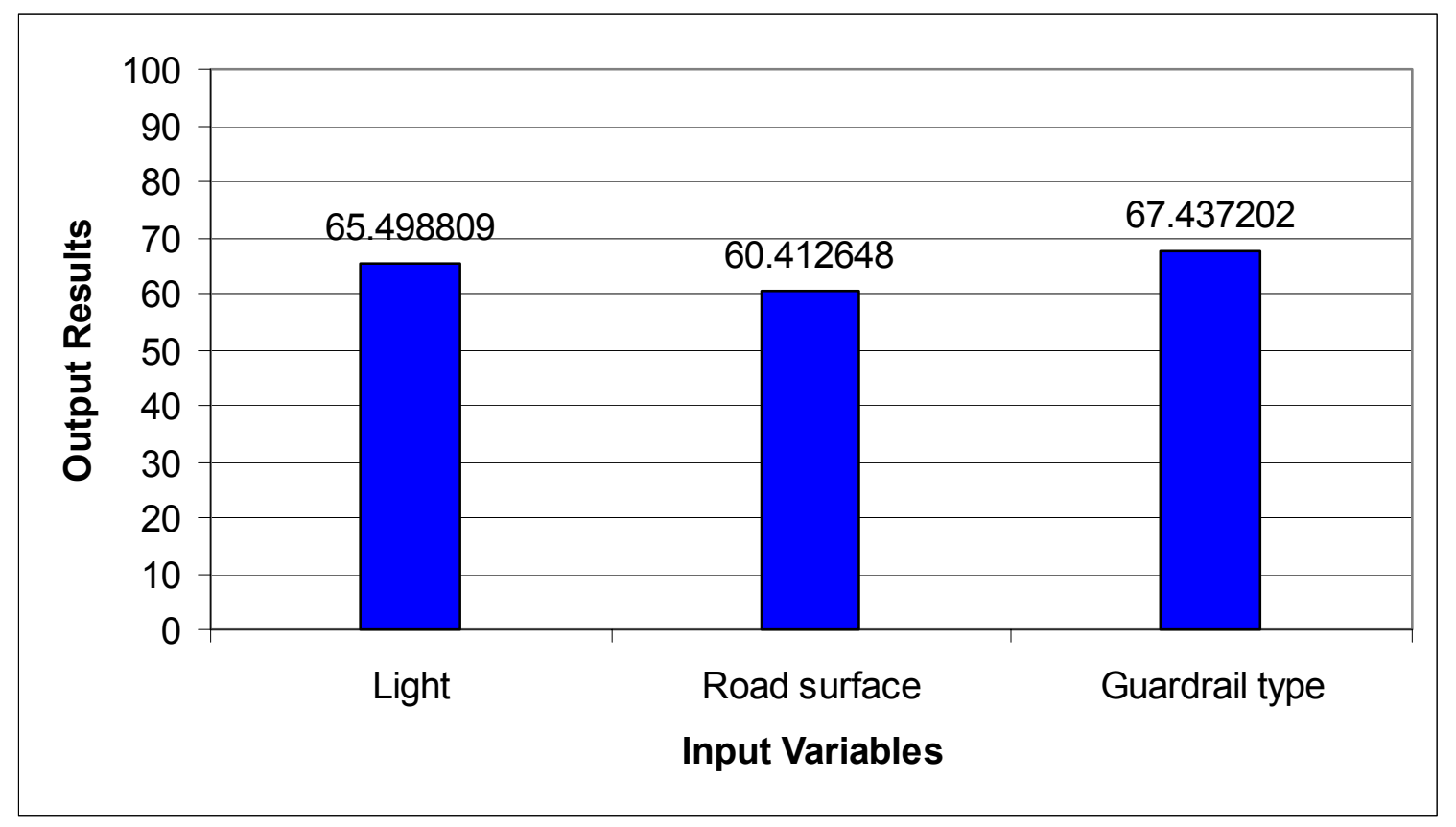

Figure 5.7 Percentage of Weighted Matrix Values for Three Variables.

Table 5.4 Summary of the Results of Road/Environment Factors

\begin{tabular}{|c|c|c|c|c|c|c|c|c|c|}
\hline All & $\begin{array}{l}\frac{0}{0} \\
\frac{\pi}{\tilde{a}} \\
\frac{\pi}{>}\end{array}$ & Light & $\begin{array}{l}\text { Road } \\
\text { surface }\end{array}$ & App-end & App-enf & $\begin{array}{l}\text { Guard- } \\
\text { type }\end{array}$ & Post -type & $\begin{array}{c}\text { Rail } \\
\text { height }\end{array}$ & Lat. Dist. \\
\hline \multicolumn{2}{|c|}{87.294672} & 81.240029 & 76.733482 & 85.230059 & 87.018601 & 84.51875 & 85.628422 & 82.149702 & 84.339434 \\
\hline \multicolumn{2}{|c|}{83.3375} & 80.640327 & 75.247767 & 81.715476 & & 82.525744 & 86.075297 & 82.115625 & 86.791026 \\
\hline \multicolumn{2}{|c|}{86.791026} & 75.526026 & 75.093184 & 82.341666 & & 83.122767 & 87.782142 & 85.640327 & \\
\hline \multicolumn{2}{|c|}{87.782142} & 78.492113 & 74.336636 & 81.357916 & & 82.675892 & & 83.665029 & \\
\hline \multicolumn{2}{|c|}{83.175} & 71.872619 & 67.852083 & 74.231845 & & 71.604464 & & & \\
\hline \multicolumn{2}{|c|}{74.358779} & 65.498809 & 60.412648 & & & 67.437202 & & & \\
\hline
\end{tabular}




\subsection{Input for Vehicle/Human Factors}

After processes were completed with the first set of data, the second set of data, which includes the vehicle factors and human factors, was prepared for the second cluster to identify the best factors which can be used in the model. These factors are driving under influence of alcohol, speed limit, driver age, vehicle impact and number of occupants. It has to be mentioned that the driver and the vehicle have a great impact in classification of the severity. Results for training, cross validation and testing are represented Tables 5.5, 5.6 and 5.7. The result of MSE was 0.078636.

Table 5.5 Result of Training with Input Human/Vehicle in ANN

\begin{tabular}{|c|c|c|c|}
\hline Training & 2 & 3 & 4 \\
\hline 2 & 82.285713 & 11.673470 & 6.040816 \\
\hline 3 & 1.844168 & 88.197327 & 9.958507 \\
\hline 4 & 0.602864 & 2.712886 & 96.684250 \\
\hline
\end{tabular}

Table 5.6 Result of Cross Validation with Input Human/Vehicle in ANN

\begin{tabular}{|c|c|c|c|}
\hline Cross validation & 2 & 3 & 4 \\
\hline 2 & 83.411217 & 10.280374 & 6.308411 \\
\hline 3 & 1.949861 & 90.250694 & 7.799443 \\
\hline 4 & 0.919540 & 2.988506 & 96.091957 \\
\hline
\end{tabular}

Table 5.7 Result of Testing with Input Human/Vehicle in ANN

\begin{tabular}{|c|c|c|c|}
\hline Testing & 2 & 3 & 4 \\
\hline 2 & 82.733810 & 5.995204 & 11.270983 \\
\hline 3 & 4.807693 & 80.357140 & 14.835165 \\
\hline 4 & 0.574053 & 1.492537 & 97.933411 \\
\hline
\end{tabular}

The neural network was able to classify the different levels of severity with more than $80 \%$ accuracy. The weighted matrix was calculated and the result was 91.41 . Then, the same operation was applied on vehicle/human factors to choose the best factors by eliminating variables. The results are presented in Figures 5.8, 5.9, and 5.10. 


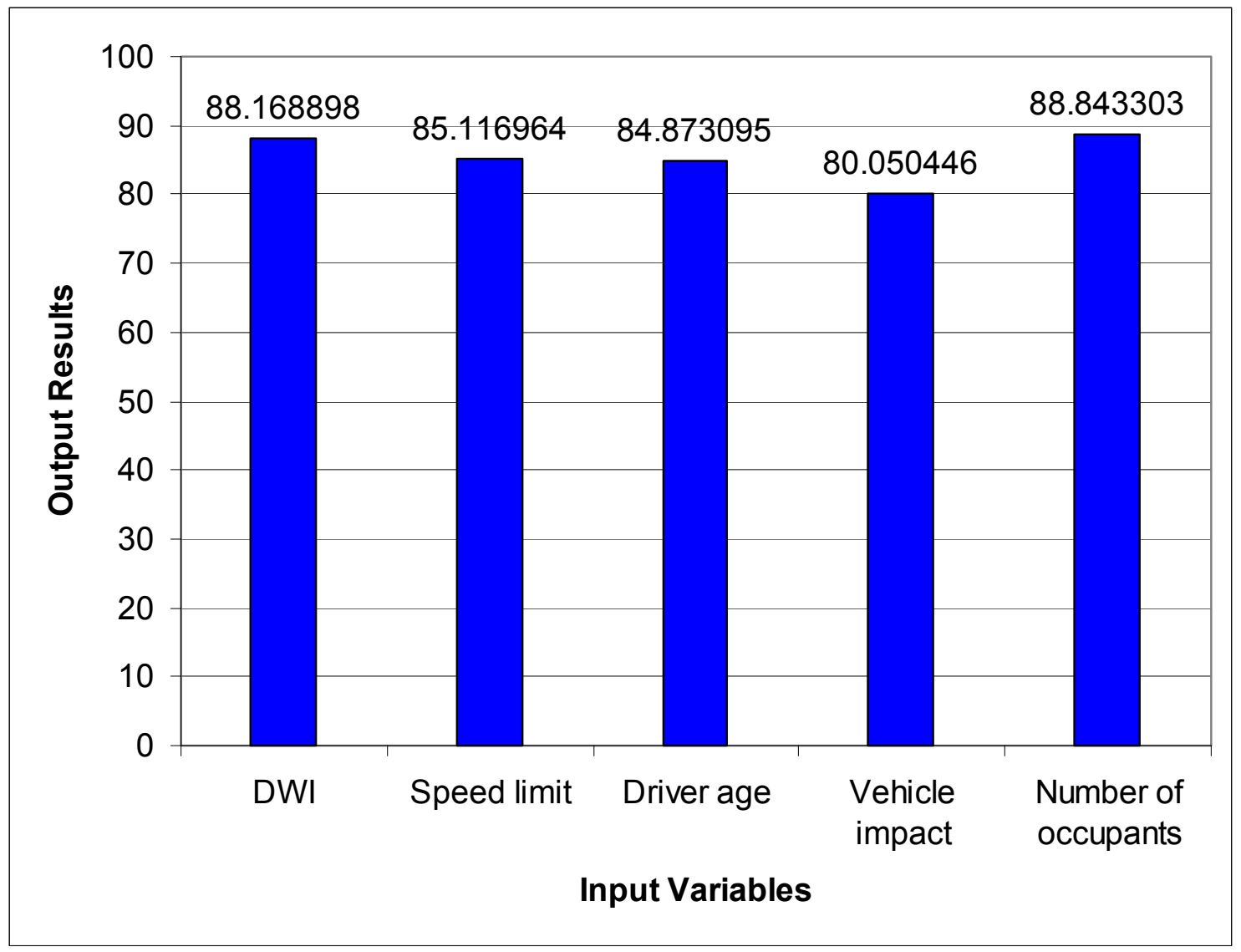

Figure 5.8 Percentage of Weighted Matrix Values for Human/Vehicle variables

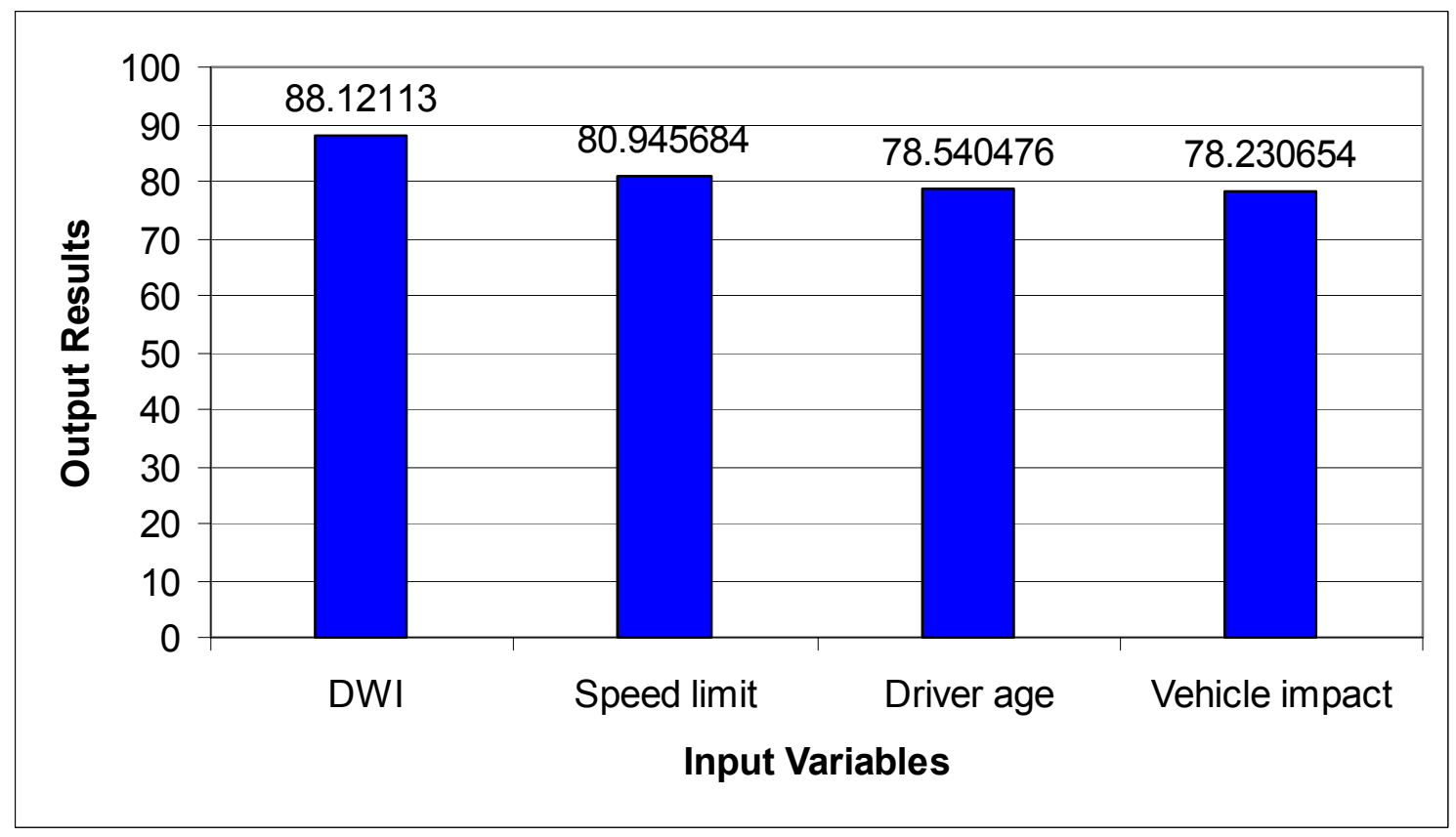

Figure 5.9 Percentage of Weighted Matrix Values for Human/vehicle variables 


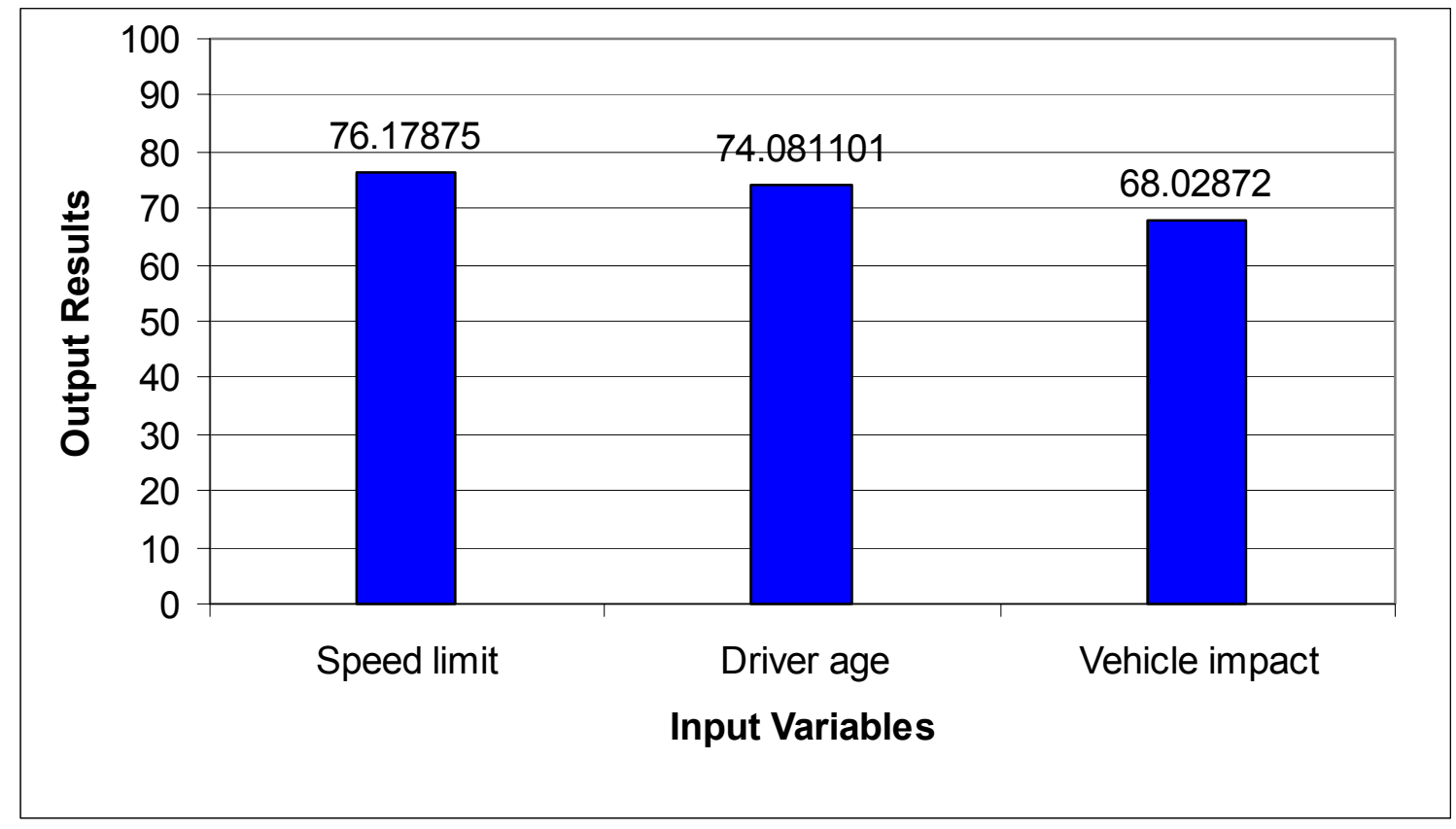

Figure 5.10 Percentage of Weighted Matrix Values for Human/vehicle of Three Variables

Three factors were eliminated in the last three figures. These factors were number of occupants, driving under influence of alcohol, and speed limit. It was found that the driver's age, speed limit, and vehicle impact have a significant effect on severity. Vehicle point of impact was found to be significant because the point of impact determines the amount of energy observed and physics of crash response. Results are summarized in Table 5.8.

Table 5.8 Summary of the Results of Human/Vehicle Factors

\begin{tabular}{|l|l|l|l|l|l|}
\hline & DWI & Speed limit & Driver age & Vehicle impact & Numb.of occ. \\
\hline 91.411904 & 88.168898 & 85.116964 & 84.873095 & 80.050446 & 88.843303 \\
\hline 88.508377 & 84.12113 & 80.945684 & 78.540476 & 78.230654 & \\
\hline 84.12113 & & 76.17875 & 74.081101 & 68.02872 & \\
\hline
\end{tabular}

\subsection{Choosing the Best Classification}

Two neural networks were developed looking for best results of classification. Input variables for the first network were: Driver age, vehicle impact, light condition, 
road surface, and guardrail type. Input variables for the second network were: driver age, vehicle impact, light condition, road surface, end type of guardrail and the type of guardrail.

The performance of the second network was good in classification with MSE $=.027089$.

The results of training, cross validation and testing are illustrated in Tables 5.9, 5.10, and

5.11Classification of severity Level \# 2 was (93.525177\%), severity Level \#3

(96.428574\%) and severity Level \# 4 was (97.244545\%), indicating very good performance of the neural network.

Table 5.9 Result of Training with Input Human/Vehicle/Roadway Variables

\begin{tabular}{|c|c|c|c|}
\hline Training & 2 & 3 & 4 \\
\hline 2 & 96.261681 & 2.102804 & 1.635514 \\
\hline 3 & 0.835655 & 96.796654 & 2.367688 \\
\hline 4 & 0.229885 & 1.954023 & 97.816093 \\
\hline
\end{tabular}

Table 5.10 Result of Cross Validation with Input Human/Vehicle/Roadway variables.

\begin{tabular}{|c|c|c|c|}
\hline Cross validation & 2 & 3 & 4 \\
\hline 2 & 96.261681 & 2.102804 & 1.635514 \\
\hline 3 & 0.835655 & 96.796654 & 2.367688 \\
\hline 4 & 0.229885 & 1.954023 & 97.816093 \\
\hline
\end{tabular}

Table 5.11 Result of Testing with Input Human/Vehicle/Roadway Variables.

\begin{tabular}{|c|c|c|c|}
\hline Testing & 2 & 3 & 4 \\
\hline 2 & 93.525177 & 3.35314 & 3.117506 \\
\hline 3 & 0.961538 & 96.428574 & 2.609890 \\
\hline 4 & 0.459242 & 2.296211 & 97.244545 \\
\hline
\end{tabular}




\section{Chapter 6}

\section{Conclusions and Recommendations}

\subsection{Conclusions}

The objective of this research has been to explore the use of Artificial Neural Networks as an analytical technique for classifying severity levels in crashes involving guardrails and to identify the most significant factors that contribute to the severity of such crashes. The major finding of this research is that ANNs performs well on both objectives. From this study the following conclusions can be made:

1. In testing the performance of the ANNs developed in this investigation, it was found that the successful classification was as follows:

a. $93.5 \%$ for classification severity level 2 (Incapacitating injury),

b. $96.4 \%$ for classification severity level 3 (Non-incapacitating injury), and

c. $97.2 \%$ for classification level 4 (Possible injury).

The above classification performance indicates that the ANNs was successful in capturing the relationship between the different variables and the severity of crash cases used in testing the performance of the network.

2. For an input of human factors (driver's age and driving under the influence of alcohol) and the vehicle factors (point of impact and speed), the ANN classification performance was $80 \%$. This indicates that those factors have a significant effect on the classification of severity level.

3. During the process of data reduction and classification, some factors were deleted because they seemed to have little or no effect on the crash severity level. One 
such factor is the lateral distance from the road edge to the guardrail. From an engineering point of view, this factor is important since the lateral distance allows room for the driver of an out of control vehicle to place it under control before the vehicle hits the guard rail.

4. Including guardrail type and the type of the guardrail end in the input of the ANNs model showed that these factors have a significant effect on the classification of crash severity.

5. Lighting condition (daylight, dawn, or darkness) is one of the important factors that influence the severity of guardrails crashes. Under poor lightening conditions, the driver's ability to respond quickly to road hazards is reduced. The driver is also less able to maneuver his vehicle to avoid hitting a guardrail especially if he cannot see it because of poor lightning condition. The ANNs developed in this study indicated the significance of road lightning condition on the severity classification performance.

\subsection{Recommendations}

From the study performed in this thesis, we recommend the following:

1. The present study made use of only one year of crash data because this was the only available data that could be used. However, ANNs are likely to be even more effective when larger data sets are used for training. It is recommended that all states collect crash data with guardrail inventory file and accumulate it in a national database to use for safety analysis. 
2. As mentioned before, the data were collected from police crash reports that are subject to human error or missing parameters, these parameters are important in the safety analysis, so there is a need for a software package to be used in collecting the crash data properly. The package should be simple to use, with easy data entry, and logical checking to ensure that the data is as accurate as possible when entered without any missing parameters

3. The police officer decides at the seen, as much a possible, the degree of injury and puts it in the crash report form. Results of injury versus -non injury crashes will be more robust if police officers receive comprehensive training in collecting and documenting crash data on site. 


\section{$\underline{\text { List of References }}$}

1. National Council Highway Research Program (1980) "Guardrail and Median Barrier Crashworthiness" NCHRP Report No. 230

2. Ross, H. E., D. L. Sicking, and R. A. Zimmer (1993). Recommended Procedures for the Safety Performance Evaluation of Highway Features. NCHRP Report No. 350, National Cooperation Highway Research Program, Transportation Research Board, Washington, D.C.

3. American Association of State Highway and Transportation Officials, Road Design Guide, Washington, D.C.,1988.

4. Ogden, K.W. (1995). Safer Roads: A Guide to Road Safety Engineering. Ashgate Pub Co Avebury, Burlington, Vermont.

5. Lee, Jinusun and Fred L. Mannering, Analysis of Roadside Accident Frequency and Severity and Roadside Safety. Washington State Department of Transportation Center Report no. WA-RD 475.1 December 1999

6. Michie, Jarvis D. and Maurice E.Bronstad (1994) Highway Guardrails: Safety Features or Roadside Hazard? Transportation Research Record 1468,PP. 1-9 
7. Jovanis, Paul P. and Hsin_Li Chang (1986) Modeling the Relationship of Accidents to Miles Traveled, Transportation Research Record 1068, 42-51

8. Hunter.William.W.,J.Richard.Stewart.,Kimberly.A.Eccles.,Herman.F.Huang.,Forr est.M.Council.,and David.L.Harkey,(2001) “Three-Strand Cable Median Barrier In North Carolina: An In-Service Evaluation", Transportation Research Record 1743, PP.97-103

9. Agent, K.R.,(1976) Guardrail performance: An Analysis of Accident Records, Commonwealth of Kentuky, DOT, Research Report No. 442, Lexington, KY, March 1976

10. Andrea Costanzo, Luigi Cicinati and Gennaro Orsi An Injury Severity Comparison On Side Impact Crashes, paper number 98_S8_W_15 http://www.nhtsa.dot.gov/esv/16198s8w15.pdf accessed on 2/16/03

11. Gattis, J.L. John P. Varghese and Larry E. Toothaker (1993) Analysis of Guardrail-end Accidents in Oklahoma, Transportation Research Record 1419, PP.52-62

12. Viner, John G.(1995)" Risk of Rollover in Ran-off-Road crashes", Transportation Research Record 1500,PP. 112-118 
13. Ray, Malcolm. H. and Jennifer A. Weir (2001) "Unreported Collisions With Postand-Beam Guardrails in Connecticut, Iowa And North Carolina", Transportation Research Record 1743,PP. 111-119

14. Renski, Henry, Khattak. J. Asad and Council. M Forrest (1999) "Impact of Speed Limit Increases on Crash Injury Severity: Analysis of Single-Vehicle Crashes on North Carolina Interstate Highways" Paper represented in $78^{\text {th }}$ Annual meeting Transportation Research Board Washington D.C. January 1999.

15. Council, Forrest M. and J. Richard Stewart (1996) "Severity Indexes for Roadside Objects' Transportation Research Record 1528, PP.87-96.

16. Lassarre, S. (1986) The Introduction of the Variables "Traffic volume, Speed and Belt Wearing" Into A Predictive Model of the Severity of Accidents, Accident Analysis and Prevention, Vol. 18 No. 2,PP. 129-134

17. Jones, Ian S. and R.A. Whitfield (1988) Predicting Injury Risk with New Car Assessment Program "Crashworthiness Ratings, Accident Analysis and Prevention, Vol. 20, No. 6 411-419

18. Lui, K. J, Daniel McGee, Phil Rhodes. and Daniel Pollock (1988) "An Application of a Conditional Logistic Safety Belts, Principal Impact Points, and 
Car Weights on Driver's Fatalities" Journal of Safety Research, Vol. 19, 1988, PP. $187-203$

19. Kockelman,K.M., and Young-Jun Kweon (2002)'Driver Injury Severity: An Application of Ordered Probit Models" Accident Analysis and Prevention, Vol. 34, No: 3, pp. 313-321

20. Kim, Karl, Lawrence Nitz, James Richardson and lei Li (1995) “Analyzing the Relationship Between Crash Types and Injuries in Motor Vehicle Collisions in Hawaii”, Transportation Research Record 1467,PP. 9-13

21. McGinnis Richard. G, Matthew J. Daves and Eric A. Hathaway (2001) Longitudinal Analysis of Fatal Run-off Road Crashes ,Transportation Research Record 1746,PP. 47-58

22. Shankar, Venkataraman, Fred L. Mannering and Woodrow Barfield (1996) "Statistical Analysis of Accident Severity on Rural Freeways" Accident Analysis and Prevention, Vol. 28, No. 3, PP.391-401

23. Mercer, G. William (1987) Influence on Passenger Vehicle Casualty Accident Frequency and Severity: Unemployment, Driver Gender, Driver Age, Drinking While Driving and Restraint Device Use, Accident Analysis and Prevention, vol. 19, No. 3, 231-236 
24. Shibata, Akira and Katsuhiro Fukuda (1994) Risk Factors of Fatality in Motor Vehicle Traffic Accidents, Accident Analysis and Prevention, vol. 26, No. 3, PP. $391-397$

25. Viner, John G. (1993) Harmful Events in Crashes, Accident Analysis and Prevention, Vol. 25 No.2 PP.139-145

26. McFadden John, Tai Yang. W, and Durrans Rocky.S (2000) "Application of Artificial Neural Networks to Predict Speeds on Two-Lane Rural Highways", Transportation Research Record, 1751,pp9-17

27. Abedelwahab .H and Abdel-Aty. M. A, (2001) Development of Artificial Neural Networks Models To Predict Driver Injury Severity in Traffic Accidents at Signalized Intersections, Transportation Research Board $80^{\text {th }}$ annual meeting, Paper No. 01-2234 Jan. 2001 Washington D.C.

28. Sadek. A. W and Mark .C,(2003) "Modular Artificial Neural Networks for Solving the Inverse Transportation Planning Problem", Transportation Research Board $82^{\text {nd }}$ Annual Meeting Washington D.C. 2003 
29. Yang, H. and Fengxiang. Q(1998)"Neural Network Approach to Classification of Traffic Flow States" Journal of Transportation Engineering, ASCE Vol. 124,No.6,PP.521-525

30. Pant. P. D., and Purushothaman. B (1994) “ Neural Network for Gap Acceptance at Stop-Controlled Intersections" Journal of Transportation Engineering, ASCE Vol. 120,No.3,PP.432-446

31. Ishak. S. and Haitham Al-Deek (1999) " Performance of Automatic ANN- Based Incident Detection on Freeways" Journal of Transportation Engineering, ASCE Vol. 125,No.4,PP.281-290

32. Teng. H., David. R. Martinelli, and Benjamin. T. (1999) “ Incorporating Neural Network Traffic Prediction into Freeway Incident Detection" Transportation Research Board, No 1679,PP. 101-110

33. Neuro Dimensions, Inc. (2001). Neuro Solutions On-Line Manual, Version 4.1. Gainesville, Florida.

34. Principe, J.C., N. W. Euliano, and W. C. Lefebrvre. (2000). Neural and Adaptive Systems: Fundamentals through Simulations. John Wiley \& Sons, Inc. 


\section{Appendix A}

Michigan Crash Report Form 


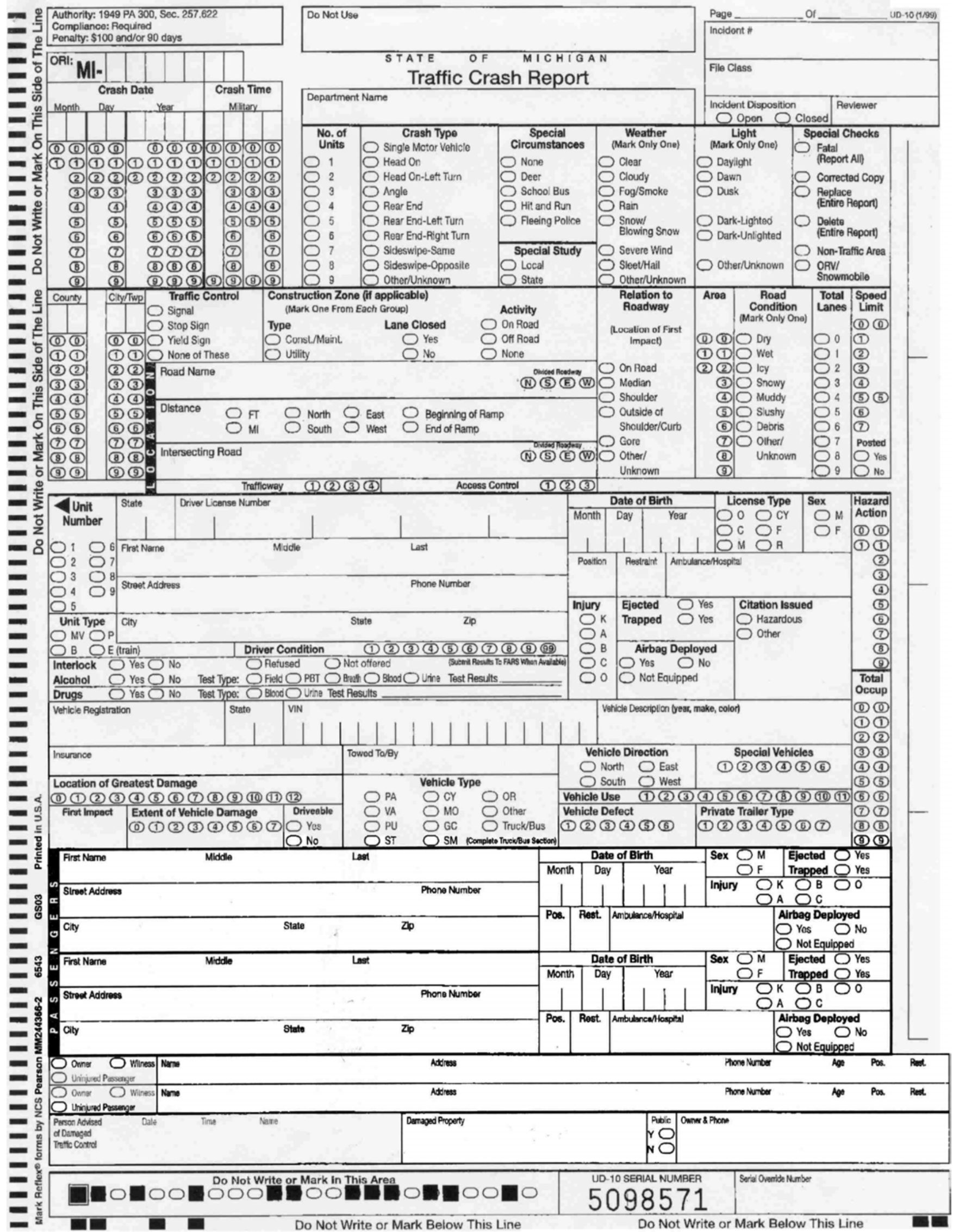


01/29/2004 17:53 FAX $517 \quad 322 \quad 5385$

Michigan State Police

003

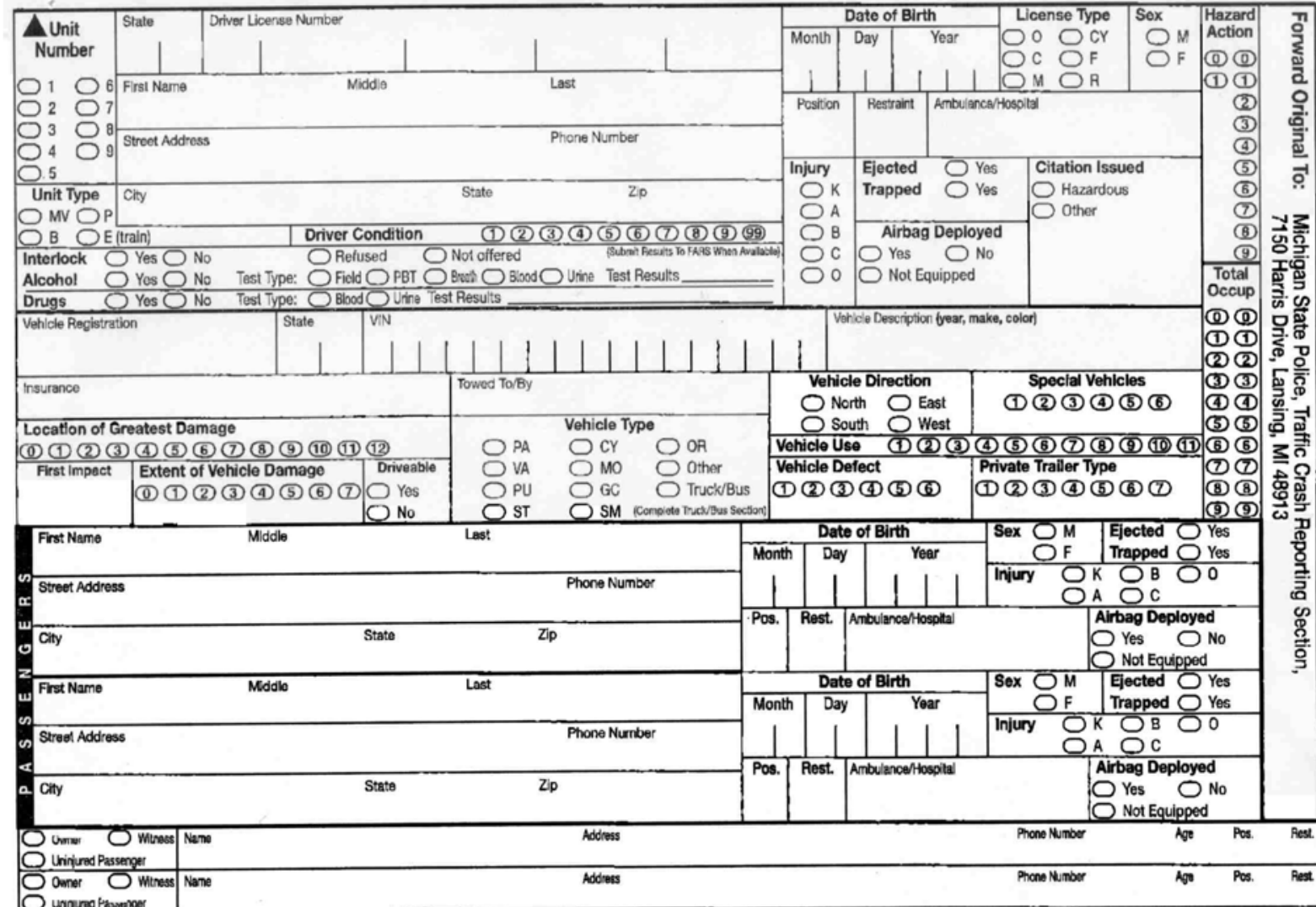

\begin{tabular}{|c|c|c|c|c|}
\hline \multicolumn{5}{|c|}{ Unit Reported on Front } \\
\hline \multirow{2}{*}{$\begin{array}{l}\text { Action } \\
\text { Prior }\end{array}$} & \multicolumn{4}{|c|}{ Sequence of Events } \\
\hline & First & Socons & & Fourth \\
\hline (6) (6) & (4) & (ब) & DQ8 & \\
\hline & & & & \\
\hline (3) & & (3) $\mathrm{C}$ & D(3) & (3) (3) \\
\hline & & (4) & (1) (4) & (4) (4) \\
\hline (5) & (5) & (5) & (5) & (5) \\
\hline & 8 & (7) & (7) & (7) \\
\hline & (8) & (8) & (8) & (8) \\
\hline & & & & \\
\hline
\end{tabular}

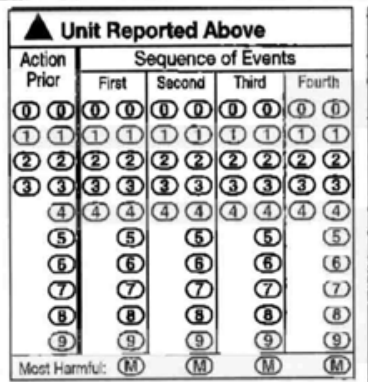

Unit No. (1) (2) (3) (4) (5) (6) (7) (8) (9)

Carier Name (1) (2) (3) (4) (5) (6) (1) (8) 9

Addrese

City

Carrier Source

Papers $\bigcirc$ Log Book ICCMC

USDOT

MPSC

Stato

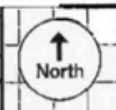

Crash Dlagram and Remarks

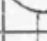




\section{Appendix B}

Results of training and cross validation metrics 


\section{First: Road/Environment}

(1)

\begin{tabular}{|l|l|l|l|l|l|l|l|}
\hline Input & $\begin{array}{l}\text { Road } \\
\text { surface }\end{array}$ & $\begin{array}{l}\text { App- } \\
\text { End }\end{array}$ & $\begin{array}{l}\text { App- } \\
\text { Enf }\end{array}$ & $\begin{array}{l}\text { Guardrail } \\
\text { type }\end{array}$ & $\begin{array}{l}\text { Post } \\
\text { type }\end{array}$ & $\begin{array}{l}\text { Rail } \\
\text { height }\end{array}$ & $\begin{array}{l}\text { Lateral } \\
\text { distance }\end{array}$ \\
\hline Training & 2 & 3 & 4 \\
\hline 2 & 67.020409 & 19.918367 & 13.061225 \\
\hline 3 & 0.783771 & 92.485016 & 6.731213 \\
\hline 4 & 2.411454 & 13.564431 & 84.024117 \\
\hline
\end{tabular}

\begin{tabular}{|l|l|l|l|}
\hline Cross Validation & 2 & 3 & 4 \\
\hline 2 & 65.420563 & 17.056074 & 17.523365 \\
\hline 3 & 1.114206 & 88.857941 & 10.027855 \\
\hline 4 & 3.333333 & 14.252873 & 82.413795 \\
\hline
\end{tabular}

(2)

\begin{tabular}{|l|l|l|l|l|l|l|l|}
\hline Input & $\begin{array}{l}\text { Light } \\
\text { condition }\end{array}$ & $\begin{array}{l}\text { App- } \\
\text { End }\end{array}$ & $\begin{array}{l}\text { App- } \\
\text { Enf }\end{array}$ & $\begin{array}{l}\text { Guardrail } \\
\text { type }\end{array}$ & $\begin{array}{l}\text { Post } \\
\text { type }\end{array}$ & $\begin{array}{l}\text { Rail } \\
\text { height }\end{array}$ & $\begin{array}{l}\text { Lateral } \\
\text { distance }\end{array}$ \\
\hline
\end{tabular}

\begin{tabular}{|l|l|l|l|}
\hline Training & 2 & 3 & 4 \\
\hline 2 & 73.224487 & 6.775510 & 20.0000 \\
\hline 3 & 5.855233 & 78.699860 & 15.444905 \\
\hline 4 & 14.845516 & 7.347400 & 77.807083 \\
\hline
\end{tabular}

\begin{tabular}{|l|l|l|l|}
\hline Cross Validation & 2 & 3 & 4 \\
\hline 2 & 81.542053 & 1.869159 & 16.588785 \\
\hline 3 & 8.774373 & 78.272980 & 12.952646 \\
\hline 4 & 20.0000 & 6.781609 & 73.218391 \\
\hline
\end{tabular}


(3)

\begin{tabular}{|c|c|c|c|c|c|c|c|}
\hline Input & $\begin{array}{l}\text { Light } \\
\text { condition }\end{array}$ & $\begin{array}{l}\text { Road } \\
\text { surface }\end{array}$ & $\begin{array}{l}\text { App- } \\
\text { Enf }\end{array}$ & $\begin{array}{l}\text { Guardrail } \\
\text { type }\end{array}$ & Post type & $\begin{array}{l}\text { Rail } \\
\text { height }\end{array}$ & $\begin{array}{l}\text { Lateral } \\
\text { distance }\end{array}$ \\
\hline \multicolumn{2}{|c|}{ Training } & \multicolumn{2}{|l|}{2} & \multicolumn{2}{|l|}{3} & \multicolumn{2}{|l|}{4} \\
\hline \multicolumn{2}{|c|}{2} & \multicolumn{2}{|c|}{70.448982} & \multicolumn{2}{|c|}{11.428572} & \multicolumn{2}{|c|}{18.122450} \\
\hline \multicolumn{2}{|l|}{3} & \multicolumn{2}{|c|}{3.411711} & \multicolumn{2}{|c|}{89.764870} & \multicolumn{2}{|c|}{6.823421} \\
\hline \multicolumn{2}{|l|}{4} & \multicolumn{2}{|c|}{2.486812} & \multicolumn{2}{|c|}{6.895252} & \multicolumn{2}{|c|}{90.617935} \\
\hline
\end{tabular}

\begin{tabular}{|l|l|l|l|}
\hline Cross Validation & 2 & 3 & 4 \\
\hline 2 & 72.196259 & 6.542056 & 21.261683 \\
\hline 3 & 4.596100 & 87.465179 & 7.938719 \\
\hline 4 & 2.413793 & 8.045977 & 89.540230 \\
\hline
\end{tabular}

(4)

\begin{tabular}{|l|l|l|l|l|l|l|l|}
\hline Input & $\begin{array}{l}\text { Light } \\
\text { condition }\end{array}$ & $\begin{array}{l}\text { Road } \\
\text { surface }\end{array}$ & $\begin{array}{l}\text { App- } \\
\text { End }\end{array}$ & $\begin{array}{l}\text { Guardrail } \\
\text { type }\end{array}$ & Post type & $\begin{array}{l}\text { Rail } \\
\text { height }\end{array}$ & $\begin{array}{l}\text { Lateral } \\
\text { distance }\end{array}$ \\
\hline
\end{tabular}

\begin{tabular}{|l|l|l|l|}
\hline Training & 2 & 3 & 4 \\
\hline 2 & 69.224487 & 7.020408 & 23.755102 \\
\hline 3 & 0.599355 & 90.640846 & 8.759797 \\
\hline 4 & 2.712886 & 4.973625 & 92.313492 \\
\hline
\end{tabular}

\begin{tabular}{|l|l|l|l|}
\hline Cross Validation & 2 & 3 & 4 \\
\hline 2 & 69.859710 & 4.672897 & 25.467289 \\
\hline 3 & 0.139276 & 90.389969 & 9.470752 \\
\hline 4 & 2.643678 & 5.057471 & 92.298851 \\
\hline
\end{tabular}


(5)

\begin{tabular}{|l|l|l|l|l|l|l|l|}
\hline Input & $\begin{array}{l}\text { Light } \\
\text { condition }\end{array}$ & $\begin{array}{l}\text { Road } \\
\text { surface }\end{array}$ & $\begin{array}{l}\text { App- } \\
\text { End }\end{array}$ & $\begin{array}{l}\text { App- } \\
\text { Enf }\end{array}$ & Post type & $\begin{array}{l}\text { Rail } \\
\text { height }\end{array}$ & $\begin{array}{l}\text { Lateral } \\
\text { distance }\end{array}$ \\
\hline
\end{tabular}

\begin{tabular}{|l|l|l|l|}
\hline Training & 2 & 3 & 4 \\
\hline 2 & 62.183674 & 9.061225 & 27.755102 \\
\hline 3 & 2.120793 & 84.555092 & 13.324113 \\
\hline 4 & 1.469480 & 4.483798 & 94.046722 \\
\hline
\end{tabular}

\begin{tabular}{|l|l|l|l|}
\hline Cross Validation & 2 & 3 & 4 \\
\hline 2 & 60.514019 & 7.242990 & 32.242992 \\
\hline 3 & 0.835655 & 84.818939 & 14.345404 \\
\hline 4 & 1.379310 & 2.988506 & 95.632187 \\
\hline
\end{tabular}

(6)

\begin{tabular}{|l|l|l|l|l|l|l|l|}
\hline Input & $\begin{array}{l}\text { Light } \\
\text { condition }\end{array}$ & $\begin{array}{l}\text { Road } \\
\text { surface }\end{array}$ & $\begin{array}{l}\text { App- } \\
\text { End }\end{array}$ & $\begin{array}{l}\text { App- } \\
\text { Enf }\end{array}$ & $\begin{array}{l}\text { Guardrai } \\
1 \text { type }\end{array}$ & $\begin{array}{l}\text { Rail } \\
\text { height }\end{array}$ & $\begin{array}{l}\text { Lateral } \\
\text { distance }\end{array}$ \\
\hline
\end{tabular}

\begin{tabular}{|l|l|l|l|}
\hline Training & 2 & 3 & 4 \\
\hline 2 & 77.714287 & 4.734694 & 17.551020 \\
\hline 3 & 1.152605 & 82.388199 & 16.459198 \\
\hline 4 & 3.240392 & 4.10708 & 92.652603 \\
\hline
\end{tabular}

\begin{tabular}{|l|l|l|l|}
\hline Cross Validation & 2 & 3 & 4 \\
\hline 2 & 77.803741 & 3.504673 & 18.691589 \\
\hline 3 & 1.114206 & 82.033424 & 16.852367 \\
\hline 4 & 2.988506 & 4.712644 & 92.298851 \\
\hline
\end{tabular}


(7)

\begin{tabular}{|c|c|c|c|c|c|c|c|}
\hline Input & $\begin{array}{l}\text { Light } \\
\text { condition }\end{array}$ & $\begin{array}{l}\text { Road } \\
\text { surface }\end{array}$ & $\begin{array}{l}\text { App- } \\
\text { End }\end{array}$ & $\begin{array}{l}\text { App- } \\
\text { Enf }\end{array}$ & $\begin{array}{l}\text { Guardrai } \\
1 \text { type }\end{array}$ & Post type & $\begin{array}{l}\text { Lateral } \\
\text { distance }\end{array}$ \\
\hline \multicolumn{2}{|c|}{ Training } & \multicolumn{2}{|l|}{2} & \multicolumn{2}{|l|}{3} & \multicolumn{2}{|l|}{4} \\
\hline \multicolumn{2}{|c|}{2} & \multicolumn{2}{|c|}{70.775513} & \multicolumn{2}{|c|}{18.775511} & \multicolumn{2}{|l|}{10.448979} \\
\hline \multicolumn{2}{|l|}{3} & \multicolumn{2}{|c|}{2.858460} & \multicolumn{2}{|c|}{86.583679} & \multicolumn{2}{|l|}{10.557860} \\
\hline \multicolumn{2}{|l|}{4} & \multicolumn{2}{|c|}{2.486812} & \multicolumn{2}{|c|}{10.926903} & \multicolumn{2}{|l|}{86.586282} \\
\hline
\end{tabular}

\begin{tabular}{|l|l|l|l|}
\hline Cross Validation & 2 & 3 & 4 \\
\hline 2 & 66.121498 & 18.691589 & 15.186916 \\
\hline 3 & 2.089127 & 85.236771 & 12.674095 \\
\hline 4 & 1.494253 & 11.264368 & 87.241379 \\
\hline
\end{tabular}

(8)

\begin{tabular}{|l|l|l|l|l|l|l|l|}
\hline Input & $\begin{array}{l}\text { Light } \\
\text { condition }\end{array}$ & $\begin{array}{l}\text { Road } \\
\text { surface }\end{array}$ & $\begin{array}{l}\text { App- } \\
\text { End }\end{array}$ & $\begin{array}{l}\text { App- } \\
\text { Enf }\end{array}$ & $\begin{array}{l}\text { Guardrai } \\
1 \text { type }\end{array}$ & Post type & $\begin{array}{l}\text { Rail } \\
\text { height }\end{array}$ \\
\hline
\end{tabular}

\begin{tabular}{|l|l|l|l|}
\hline Training & 2 & 3 & 4 \\
\hline 2 & 76.326530 & 7.020408 & 16.653061 \\
\hline 3 & 3.596127 & 83.310280 & 13.093592 \\
\hline 4 & 3.579503 & 4.709872 & 91.710625 \\
\hline
\end{tabular}

\begin{tabular}{|l|l|l|l|}
\hline Cross Validation & 2 & 3 & 4 \\
\hline 2 & 73.364487 & 6.308411 & 20.327103 \\
\hline 3 & 3.064067 & 83.565460 & 13.370474 \\
\hline 4 & 4.022988 & 5.862069 & 90.114944 \\
\hline
\end{tabular}




\section{(9) All Factors after eliminating App- enf}

\begin{tabular}{|l|l|l|l|l|l|l|l|}
\hline Input & $\begin{array}{l}\text { Light } \\
\text { condition }\end{array}$ & $\begin{array}{l}\text { Road } \\
\text { surface }\end{array}$ & $\begin{array}{l}\text { App- } \\
\text { End }\end{array}$ & $\begin{array}{l}\text { Guardrai } \\
1 \text { type }\end{array}$ & Post type & $\begin{array}{l}\text { Rail } \\
\text { height }\end{array}$ & $\begin{array}{l}\text { Lateral } \\
\text { distance }\end{array}$ \\
\hline
\end{tabular}

\begin{tabular}{|l|l|l|l|}
\hline Training & 2 & 3 & 4 \\
\hline 2 & 64.816330 & 11.510204 & 23.673470 \\
\hline 3 & 1.383126 & 87.229141 & 11.387736 \\
\hline 4 & 2.637528 & 5.124341 & 92.238129 \\
\hline
\end{tabular}

\begin{tabular}{|l|l|l|l|}
\hline Cross Validation & 2 & 3 & 4 \\
\hline 2 & 61.682243 & 7.476635 & 30.841122 \\
\hline 3 & 0.696379 & 86.350975 & 12.952646 \\
\hline 4 & 2.873563 & 6.436781 & 90.689651 \\
\hline
\end{tabular}

(10)

\begin{tabular}{|l|l|l|l|l|l|l|}
\hline Input & $\begin{array}{l}\text { Road } \\
\text { surface }\end{array}$ & $\begin{array}{l}\text { App- } \\
\text { End }\end{array}$ & $\begin{array}{l}\text { Guardrail } \\
\text { type }\end{array}$ & Post type & $\begin{array}{l}\text { Rail } \\
\text { height }\end{array}$ & $\begin{array}{l}\text { Lateral } \\
\text { distance }\end{array}$ \\
\hline
\end{tabular}

\begin{tabular}{|l|l|l|l|}
\hline Training & 2 & 3 & 4 \\
\hline 2 & 66.285713 & 21.306122 & 12.408163 \\
\hline 3 & 0.691563 & 92.300598 & 7.007838 \\
\hline 4 & 2.901281 & 16.390354 & 80.708366 \\
\hline
\end{tabular}

\begin{tabular}{|l|l|l|l|}
\hline Cross Validation & 2 & 3 & 4 \\
\hline 2 & 63.551403 & 20.327103 & 16.121496 \\
\hline 3 & 0.696379 & 93.036209 & 6.267409 \\
\hline 4 & 2.988506 & 18.505747 & 78.505745 \\
\hline
\end{tabular}


(11)

\begin{tabular}{|c|c|c|c|c|c|c|}
\hline Input & $\begin{array}{l}\text { Light } \\
\text { condition }\end{array}$ & $\begin{array}{l}\text { App- } \\
\text { End }\end{array}$ & $\begin{array}{l}\text { Guardrail } \\
\text { type }\end{array}$ & Post type & $\begin{array}{l}\text { Rail } \\
\text { height }\end{array}$ & $\begin{array}{l}\text { Lateral } \\
\text { distance }\end{array}$ \\
\hline \multicolumn{2}{|c|}{ Training } & \multicolumn{2}{|l|}{2} & \multicolumn{2}{|l|}{3} & 4 \\
\hline \multicolumn{2}{|c|}{2} & \multicolumn{2}{|c|}{60.081635} & \multicolumn{2}{|l|}{11.020409} & 28.897959 \\
\hline \multicolumn{2}{|l|}{3} & \multicolumn{2}{|c|}{1.244813} & \multicolumn{2}{|l|}{78.192719} & 20.562471 \\
\hline \multicolumn{2}{|l|}{4} & \multicolumn{2}{|c|}{11.793519} & \multicolumn{2}{|l|}{8.703843} & 79.502640 \\
\hline
\end{tabular}

\begin{tabular}{|l|l|l|l|}
\hline Cross Validation & 2 & 3 & 4 \\
\hline 2 & 66.822433 & 7.009346 & 26.168224 \\
\hline 3 & 1.114206 & 79.944290 & 18.941504 \\
\hline 4 & 14.137931 & 10.459770 & 75.402298 \\
\hline
\end{tabular}

(12)

\begin{tabular}{|l|l|l|l|l|l|l|}
\hline Input & $\begin{array}{l}\text { Light } \\
\text { condition }\end{array}$ & $\begin{array}{l}\text { Road } \\
\text { surface }\end{array}$ & $\begin{array}{l}\text { Guardrail } \\
\text { type }\end{array}$ & Post type & $\begin{array}{l}\text { Rail } \\
\text { height }\end{array}$ & $\begin{array}{l}\text { Lateral } \\
\text { distance }\end{array}$ \\
\hline
\end{tabular}

\begin{tabular}{|l|l|l|l|}
\hline Training & 2 & 3 & 4 \\
\hline 2 & 49.142857 & 13.061225 & 37.795918 \\
\hline 3 & 0.875980 & 86.721992 & 12.402029 \\
\hline 4 & 1.657875 & 6.141673 & 92.200455 \\
\hline
\end{tabular}

\begin{tabular}{|l|l|l|l|}
\hline Cross Validation & 2 & 3 & 4 \\
\hline 2 & 50.000 & 12.149532 & 37.850468 \\
\hline 3 & 0.835655 & 86.350975 & 12.813371 \\
\hline 4 & 0.919540 & 6.321839 & 92.758621 \\
\hline
\end{tabular}


(13)

\begin{tabular}{|c|c|c|c|c|c|c|}
\hline Input & $\begin{array}{l}\text { Light } \\
\text { condition }\end{array}$ & $\begin{array}{l}\text { Road } \\
\text { surface }\end{array}$ & $\begin{array}{l}\text { App- } \\
\text { End }\end{array}$ & Post type & $\begin{array}{l}\text { Rail } \\
\text { height }\end{array}$ & $\begin{array}{l}\text { Lateral } \\
\text { distance }\end{array}$ \\
\hline \multicolumn{2}{|c|}{ Training } & \multicolumn{2}{|l|}{2} & \multicolumn{2}{|l|}{3} & 4 \\
\hline \multicolumn{2}{|c|}{2} & \multicolumn{2}{|c|}{66.857140} & \multicolumn{2}{|l|}{4.408163} & 28.734694 \\
\hline \multicolumn{2}{|l|}{3} & \multicolumn{2}{|c|}{5.394191} & \multicolumn{2}{|l|}{80.497925} & 14.107883 \\
\hline \multicolumn{2}{|l|}{4} & \multicolumn{2}{|c|}{1.620196} & \multicolumn{2}{|l|}{5.011304} & 93.368500 \\
\hline
\end{tabular}

\begin{tabular}{|l|l|l|l|}
\hline Cross Validation & 2 & 3 & 4 \\
\hline 2 & 64.485985 & 2.570093 & 32.943924 \\
\hline 3 & 4.456824 & 80.919220 & 14.623956 \\
\hline 4 & 1.379310 & 6.206897 & 92.413795 \\
\hline
\end{tabular}

(14)

\begin{tabular}{|l|l|l|l|l|l|l|}
\hline Input & $\begin{array}{l}\text { Light } \\
\text { condition }\end{array}$ & $\begin{array}{l}\text { Road } \\
\text { surface }\end{array}$ & $\begin{array}{l}\text { App- } \\
\text { End }\end{array}$ & $\begin{array}{l}\text { Guardrai } \\
1 \text { type }\end{array}$ & $\begin{array}{l}\text { Rail } \\
\text { height }\end{array}$ & $\begin{array}{l}\text { Lateral } \\
\text { distance }\end{array}$ \\
\hline
\end{tabular}

\begin{tabular}{|l|l|l|l|}
\hline Training & 2 & 3 & 4 \\
\hline 2 & 72.326530 & 10.285714 & 17.387754 \\
\hline 3 & 0.461042 & 92.669434 & 6.869525 \\
\hline 4 & 2.637528 & 6.631500 & 90.730972 \\
\hline
\end{tabular}

\begin{tabular}{|l|l|l|l|}
\hline Cross Validation & 2 & 3 & 4 \\
\hline 2 & 69.158882 & 9.345795 & 21.495327 \\
\hline 3 & 0.557103 & 88.857941 & 10.584958 \\
\hline 4 & 1.724138 & 6.551724 & 91.724136 \\
\hline
\end{tabular}


(15)

\begin{tabular}{|c|c|c|c|c|c|c|}
\hline Input & $\begin{array}{l}\text { Light } \\
\text { condition }\end{array}$ & $\begin{array}{l}\text { Road } \\
\text { surface }\end{array}$ & $\begin{array}{l}\text { App- } \\
\text { End }\end{array}$ & $\begin{array}{l}\text { Guardrai } \\
1 \text { type }\end{array}$ & Post type & $\begin{array}{l}\text { Lateral } \\
\text { distance }\end{array}$ \\
\hline \multicolumn{2}{|c|}{ Training } & \multicolumn{2}{|l|}{2} & \multicolumn{2}{|l|}{3} & 4 \\
\hline \multicolumn{2}{|c|}{2} & \multicolumn{2}{|c|}{66.612244} & \multicolumn{2}{|c|}{13.632653} & 19.755102 \\
\hline \multicolumn{2}{|l|}{3} & \multicolumn{2}{|c|}{2.305210} & \multicolumn{2}{|c|}{81.143387} & 16.551407 \\
\hline \multicolumn{2}{|l|}{4} & \multicolumn{2}{|c|}{2.411454} & \multicolumn{2}{|c|}{6.556142} & 91.032402 \\
\hline
\end{tabular}

\begin{tabular}{|l|l|l|l|}
\hline Cross Validation & 2 & 3 & 4 \\
\hline 2 & 62.383179 & 10.514019 & 27.102804 \\
\hline 3 & 1.810585 & 79.526459 & 18.662952 \\
\hline 4 & 1.034483 & 5.287356 & 93.678162 \\
\hline
\end{tabular}

(16)

\begin{tabular}{|l|l|l|l|l|l|l|}
\hline Input & $\begin{array}{l}\text { Light } \\
\text { condition }\end{array}$ & $\begin{array}{l}\text { Road } \\
\text { surface }\end{array}$ & $\begin{array}{l}\text { App- } \\
\text { End }\end{array}$ & $\begin{array}{l}\text { Guardrai } \\
1 \text { type }\end{array}$ & Post type & $\begin{array}{l}\text { Rail } \\
\text { height }\end{array}$ \\
\hline
\end{tabular}

\begin{tabular}{|l|l|l|l|}
\hline Training & 2 & 3 & 4 \\
\hline 2 & 78.040817 & 8.897959 & 13.061225 \\
\hline 3 & 2.305210 & 92.070076 & 5.624712 \\
\hline 4 & 3.579503 & 7.121326 & 89.299171 \\
\hline
\end{tabular}

\begin{tabular}{|l|l|l|l|}
\hline Cross Validation & 2 & 3 & 4 \\
\hline 2 & 75.700935 & 8.644860 & 15.654205 \\
\hline 3 & 2.506964 & 89.972145 & 7.520891 \\
\hline 4 & 2.873563 & 7.701149 & 89.425285 \\
\hline
\end{tabular}


(17) All Variables after Eliminating Lateral distance

\begin{tabular}{|c|c|c|c|c|c|c|}
\hline Input & $\begin{array}{l}\text { Light } \\
\text { condition }\end{array}$ & $\begin{array}{l}\text { Road } \\
\text { surface }\end{array}$ & $\begin{array}{l}\text { App- } \\
\text { End }\end{array}$ & $\begin{array}{l}\text { Guardrail } \\
\text { type }\end{array}$ & Post type & $\begin{array}{l}\text { Rail } \\
\text { height }\end{array}$ \\
\hline \multicolumn{2}{|c|}{ Training } & \multicolumn{2}{|l|}{2} & \multicolumn{2}{|l|}{3} & 4 \\
\hline \multicolumn{2}{|c|}{2} & \multicolumn{2}{|c|}{78.040817} & \multicolumn{2}{|c|}{8.897959} & 13.061225 \\
\hline \multicolumn{2}{|l|}{3} & \multicolumn{2}{|c|}{2.305210} & \multicolumn{2}{|c|}{92.070076} & 5.624712 \\
\hline \multicolumn{2}{|l|}{4} & \multicolumn{2}{|c|}{3.579503} & \multicolumn{2}{|c|}{7.121326} & 89.299171 \\
\hline
\end{tabular}

\begin{tabular}{|l|l|l|l|}
\hline Cross Validation & 2 & 3 & 4 \\
\hline 2 & 75.700935 & 8.644860 & 15.654205 \\
\hline 3 & 2.506964 & 89.972145 & 7.520891 \\
\hline 4 & 2.873563 & 7.701149 & 89.425285 \\
\hline
\end{tabular}

(18)

\begin{tabular}{|l|l|l|l|l|l|}
\hline Input & $\begin{array}{l}\text { Road } \\
\text { surface }\end{array}$ & $\begin{array}{l}\text { App- } \\
\text { End }\end{array}$ & $\begin{array}{l}\text { Guardrai } \\
1 \text { type }\end{array}$ & Post type & $\begin{array}{l}\text { Rail } \\
\text { height }\end{array}$ \\
\hline
\end{tabular}

\begin{tabular}{|l|l|l|l|}
\hline Training & 2 & 3 & 4 \\
\hline 2 & 52.816326 & 24.489796 & 22.693878 \\
\hline 3 & 0.645459 & 88.151222 & 11.203320 \\
\hline 4 & 1.733233 & 17.746798 & 80.519966 \\
\hline
\end{tabular}

\begin{tabular}{|l|l|l|l|}
\hline Cross Validation & 2 & 3 & 4 \\
\hline 2 & 50.934578 & 17.757010 & 31.308411 \\
\hline 3 & 0.696379 & 81.754875 & 17.548746 \\
\hline 4 & 1.609195 & 16.436781 & 81.954025 \\
\hline
\end{tabular}


(19)

\begin{tabular}{|l|l|l|l|l|l|}
\hline Input & $\begin{array}{l}\text { Light } \\
\text { condition }\end{array}$ & $\begin{array}{l}\text { App- } \\
\text { End }\end{array}$ & $\begin{array}{l}\text { Guardrai } \\
1 \text { type }\end{array}$ & Post type & $\begin{array}{l}\text { Rail } \\
\text { height }\end{array}$ \\
\hline
\end{tabular}

\begin{tabular}{|l|l|l|l|}
\hline Training & 2 & 3 & 4 \\
\hline 2 & 65.714287 & 13.387755 & 20.897959 \\
\hline 3 & 1.383126 & 82.526512 & 16.090364 \\
\hline 4 & 13.677468 & 13.187641 & 73.134888 \\
\hline
\end{tabular}

\begin{tabular}{|l|l|l|l|}
\hline Cross Validation & 2 & 3 & 4 \\
\hline 2 & 72.897194 & 11.682243 & 15.420561 \\
\hline 3 & 0.974930 & 85.097496 & 13.927577 \\
\hline 4 & 16.206896 & 15.862069 & 67.931038 \\
\hline
\end{tabular}

(20)

\begin{tabular}{|l|l|l|l|l|l|}
\hline Input & $\begin{array}{l}\text { Light } \\
\text { condition }\end{array}$ & $\begin{array}{l}\text { Road } \\
\text { surface }\end{array}$ & $\begin{array}{l}\text { Guardrail } \\
\text { type }\end{array}$ & Post type & $\begin{array}{l}\text { Rail } \\
\text { height }\end{array}$ \\
\hline
\end{tabular}

\begin{tabular}{|l|l|l|l|}
\hline Training & 2 & 3 & 4 \\
\hline 2 & 59.836735 & 11.346939 & 28.816326 \\
\hline 3 & 2.443522 & 84.140160 & 13.416321 \\
\hline 4 & 4.107008 & 8.138659 & 87.754333 \\
\hline
\end{tabular}

\begin{tabular}{|l|l|l|l|}
\hline Cross Validation & 2 & 3 & 4 \\
\hline 2 & 59.112148 & 7.242990 & 33.644859 \\
\hline 3 & 0.557103 & 83.286911 & 16.155989 \\
\hline 4 & 2.068965 & 5.402299 & 92.528732 \\
\hline
\end{tabular}


(21)

\begin{tabular}{|l|l|l|l|l|l|}
\hline Input & $\begin{array}{l}\text { Light } \\
\text { condition }\end{array}$ & $\begin{array}{l}\text { Road } \\
\text { surface }\end{array}$ & $\begin{array}{l}\text { App- } \\
\text { End }\end{array}$ & Post type & $\begin{array}{l}\text { Rail } \\
\text { height }\end{array}$ \\
\begin{tabular}{|l|l|l|l|}
\hline Training & 2 & 3 & 4 \\
\hline 2 & 74.612244 & 5.551021 & 19.836735 \\
\hline 3 & 4.933149 & 82.710930 & 12.355925 \\
\hline 4 & 3.956292 & 6.706858 & 89.336853 \\
\hline
\end{tabular}
\end{tabular}

\begin{tabular}{|l|l|l|l|}
\hline Cross Validation & 2 & 3 & 4 \\
\hline 2 & 69.392525 & 4.906542 & 25.700935 \\
\hline 3 & 3.064067 & 84.261841 & 12.674095 \\
\hline 4 & 2.758621 & 8.505747 & 88.735634 \\
\hline
\end{tabular}

(22)

\begin{tabular}{|l|l|l|l|l|l|}
\hline Input & $\begin{array}{l}\text { Light } \\
\text { condition }\end{array}$ & $\begin{array}{l}\text { Road } \\
\text { surface }\end{array}$ & $\begin{array}{l}\text { App- } \\
\text { End }\end{array}$ & $\begin{array}{l}\text { Guardrai } \\
1 \text { type }\end{array}$ & $\begin{array}{l}\text { Rail } \\
\text { height }\end{array}$ \\
\hline
\end{tabular}

\begin{tabular}{|l|l|l|l|}
\hline Training & 2 & 3 & 4 \\
\hline 2 & 78.285713 & 5.959184 & 15.755102 \\
\hline 3 & 1.936376 & 87.275246 & 10.788382 \\
\hline 4 & 2.373775 & 5.162020 & 92.464203 \\
\hline
\end{tabular}

\begin{tabular}{|l|l|l|l|}
\hline Cross Validation & 2 & 3 & 4 \\
\hline 2 & 75.233643 & 4.672897 & 20.093458 \\
\hline 3 & 1.810585 & 88.440109 & 9.749304 \\
\hline 4 & 2.183908 & 4.597701 & 93.218391 \\
\hline
\end{tabular}


(23)

\begin{tabular}{|l|l|l|l|l|l|}
\hline Input & $\begin{array}{l}\text { Light } \\
\text { condition }\end{array}$ & $\begin{array}{l}\text { Road } \\
\text { surface }\end{array}$ & $\begin{array}{l}\text { App- } \\
\text { End }\end{array}$ & $\begin{array}{l}\text { Guardrail } \\
\text { type }\end{array}$ & Post type \\
\hline
\end{tabular}

\begin{tabular}{|l|l|l|l|}
\hline Training & 2 & 3 & 4 \\
\hline 2 & 77.142860 & 7.428571 & 15.428572 \\
\hline 3 & 3.550023 & 84.094055 & 12.355925 \\
\hline 4 & 3.504145 & 7.385079 & 89.110779 \\
\hline
\end{tabular}

\begin{tabular}{|l|l|l|l|}
\hline Cross Validation & 2 & 3 & 4 \\
\hline 2 & 77.803741 & 5.607477 & 16.588785 \\
\hline 3 & 3.064067 & 84.122566 & 12.813371 \\
\hline 4 & 3.448276 & 5.977012 & 90.574715 \\
\hline
\end{tabular}

\section{(24) All Variables after Eliminating Post Type}

\begin{tabular}{|l|l|l|l|l|l|}
\hline Input & $\begin{array}{l}\text { Light } \\
\text { condition }\end{array}$ & $\begin{array}{l}\text { Road } \\
\text { surface }\end{array}$ & $\begin{array}{l}\text { App- } \\
\text { End }\end{array}$ & $\begin{array}{l}\text { Guardrail } \\
\text { type }\end{array}$ & $\begin{array}{l}\text { Rail } \\
\text { height }\end{array}$ \\
\hline
\end{tabular}

\begin{tabular}{|l|l|l|l|}
\hline Training & 2 & 3 & 4 \\
\hline 2 & 78.285713 & 5.959184 & 15.755102 \\
\hline 3 & 1.936376 & 87.275246 & 10.788382 \\
\hline 4 & 2.373775 & 5.162020 & 92.464203 \\
\hline
\end{tabular}

\begin{tabular}{|l|l|l|l|}
\hline Cross Validation & 2 & 3 & 4 \\
\hline 2 & 75.233643 & 4.672897 & 20.093458 \\
\hline 3 & 1.810585 & 88.440109 & 9.749304 \\
\hline 4 & 2.183908 & 4.597701 & 93.218391 \\
\hline
\end{tabular}


(25)

\begin{tabular}{|l|l|l|l|l|}
\hline Input & $\begin{array}{l}\text { Road } \\
\text { surface }\end{array}$ & $\begin{array}{l}\text { App- } \\
\text { End }\end{array}$ & $\begin{array}{l}\text { Guardrai } \\
1 \text { type }\end{array}$ & $\begin{array}{l}\text { Rail } \\
\text { height }\end{array}$ \\
\hline
\end{tabular}

\begin{tabular}{|l|l|l|l|}
\hline Training & 2 & 3 & 4 \\
\hline 2 & 59.346939 & 26.693878 & 13.959184 \\
\hline 3 & 0.783771 & 89.488243 & 9.727985 \\
\hline 4 & 2.260739 & 17.445366 & 80.293900 \\
\hline
\end{tabular}

\begin{tabular}{|l|l|l|l|}
\hline Cross Validation & 2 & 3 & 4 \\
\hline 2 & 58.177570 & 23.598131 & 18.224298 \\
\hline 3 & 0.974930 & 88.440109 & 10.584958 \\
\hline 4 & 2.183908 & 17.931034 & 79.885056 \\
\hline
\end{tabular}

(26)

\begin{tabular}{|l|l|l|l|l|}
\hline Input & $\begin{array}{l}\text { Light } \\
\text { condition }\end{array}$ & $\begin{array}{l}\text { App- } \\
\text { End }\end{array}$ & $\begin{array}{l}\text { Guardrail } \\
\text { type }\end{array}$ & $\begin{array}{l}\text { Rail } \\
\text { height }\end{array}$ \\
\hline
\end{tabular}

\begin{tabular}{|l|l|l|l|}
\hline Training & 2 & 3 & 4 \\
\hline 2 & 64.653061 & 11.591837 & 23.755102 \\
\hline 3 & 2.305210 & 76.579071 & 21.115721 \\
\hline 4 & 14.770158 & 12.773172 & 72.456673 \\
\hline
\end{tabular}

\begin{tabular}{|l|l|l|l|}
\hline Cross Validation & 2 & 3 & 4 \\
\hline 2 & 73.130844 & 8.177570 & 18.691589 \\
\hline 3 & 0.974930 & 82.729805 & 16.295265 \\
\hline 4 & 16.551723 & 15.402299 & 68.045975 \\
\hline
\end{tabular}


(27)

\begin{tabular}{|c|c|c|c|c|c|}
\hline Input & $\begin{array}{l}\text { Light } \\
\text { condition }\end{array}$ & $\begin{array}{l}\text { Road } \\
\text { surface }\end{array}$ & $\begin{array}{l}\text { Guardrail } \\
\text { type }\end{array}$ & $\begin{array}{l}\text { Rail } \\
\text { height }\end{array}$ & \\
\hline \multicolumn{2}{|c|}{ Training } & \multicolumn{2}{|l|}{2} & 3 & 4 \\
\hline \multicolumn{2}{|c|}{2} & \multicolumn{2}{|c|}{64.816330} & 12.081633 & 23.102041 \\
\hline \multicolumn{2}{|l|}{3} & \multicolumn{2}{|c|}{1.890272} & 84.555092 & 13.554633 \\
\hline \multicolumn{2}{|l|}{4} & \multicolumn{2}{|c|}{4.822909} & 8.440090 & 86.737000 \\
\hline
\end{tabular}

\begin{tabular}{|l|l|l|l|}
\hline Cross Validation & 2 & 3 & 4 \\
\hline 2 & 65.654205 & 7.943925 & 26.401869 \\
\hline 3 & 2.506964 & 82.172699 & 15.320334 \\
\hline 4 & 5.057471 & 6.896552 & 88.045975 \\
\hline
\end{tabular}

(28)

\begin{tabular}{|c|c|c|c|c|c|}
\hline Input & $\begin{array}{l}\text { Light } \\
\text { condition }\end{array}$ & $\begin{array}{l}\text { Road } \\
\text { surface }\end{array}$ & $\begin{array}{l}\text { App- } \\
\text { End }\end{array}$ & $\begin{array}{l}\text { Rail } \\
\text { height }\end{array}$ & \\
\hline \multicolumn{2}{|c|}{ Training } & \multicolumn{2}{|l|}{2} & 3 & 4 \\
\hline \multicolumn{2}{|c|}{2} & \multicolumn{2}{|c|}{68.571426} & 4.906542 & 26.448980 \\
\hline \multicolumn{2}{|l|}{3} & \multicolumn{2}{|c|}{2.996773} & 79.299217 & 17.704012 \\
\hline \multicolumn{2}{|l|}{4} & \multicolumn{2}{|c|}{1.582517} & 5.614167 & 92.803314 \\
\hline
\end{tabular}

\begin{tabular}{|l|l|l|l|}
\hline Cross Validation & 2 & 3 & 4 \\
\hline 2 & 66.121498 & 4.906542 & 28.971962 \\
\hline 3 & 2.785515 & 78.412254 & 18.802229 \\
\hline 4 & 1.494253 & 4.482759 & 94.022987 \\
\hline
\end{tabular}


(29)

\begin{tabular}{|c|c|c|c|c|c|}
\hline Input & $\begin{array}{l}\text { Light } \\
\text { condition }\end{array}$ & $\begin{array}{l}\text { Road } \\
\text { surface }\end{array}$ & $\begin{array}{l}\text { App- } \\
\text { End }\end{array}$ & $\begin{array}{l}\text { Guardrail } \\
\text { type }\end{array}$ & \\
\hline \multicolumn{2}{|c|}{ Training } & \multicolumn{2}{|l|}{2} & 3 & 4 \\
\hline \multicolumn{2}{|c|}{2} & \multicolumn{2}{|c|}{72.653061} & 8.816326 & 18.530613 \\
\hline \multicolumn{2}{|l|}{3} & \multicolumn{2}{|c|}{3.227294} & 81.420006 & 15.352697 \\
\hline \multicolumn{2}{|l|}{4} & \multicolumn{2}{|c|}{4.446119} & 7.008289 & 88.545593 \\
\hline
\end{tabular}

\begin{tabular}{|l|l|l|l|}
\hline Cross Validation & 2 & 3 & 4 \\
\hline 2 & 68.925232 & 6.775701 & 24.299065 \\
\hline 3 & 2.506964 & 81.476326 & 16.016712 \\
\hline 4 & 1.494253 & 6.091954 & 92.413795 \\
\hline
\end{tabular}

(30) All Variables after Eliminating Rail Height

\begin{tabular}{|c|c|c|c|c|c|}
\hline Input & $\begin{array}{l}\text { Light } \\
\text { condition }\end{array}$ & $\begin{array}{l}\text { Road } \\
\text { surface }\end{array}$ & $\begin{array}{l}\text { App- } \\
\text { End }\end{array}$ & $\begin{array}{l}\text { Guardrail } \\
\text { type }\end{array}$ & \\
\hline \multicolumn{2}{|c|}{ Training } & \multicolumn{2}{|l|}{2} & 3 & 4 \\
\hline \multicolumn{2}{|c|}{2} & \multicolumn{2}{|c|}{69.061226} & 8.163265 & 22.775511 \\
\hline \multicolumn{2}{|l|}{3} & \multicolumn{2}{|c|}{2.166897} & 82.388199 & 15.444905 \\
\hline \multicolumn{2}{|l|}{4} & \multicolumn{2}{|c|}{2.373775} & 7.535795 & 90.090431 \\
\hline
\end{tabular}

\begin{tabular}{|l|l|l|l|}
\hline Cross Validation & 2 & 3 & 4 \\
\hline 2 & 67.523361 & 7.943925 & 24.532711 \\
\hline 3 & 2.228412 & 81.337044 & 16.434540 \\
\hline 4 & 1.839080 & 6.091954 & 92.068962 \\
\hline
\end{tabular}


(31)

\begin{tabular}{|l|l|l|l|}
\hline Input & $\begin{array}{l}\text { Road } \\
\text { surface }\end{array}$ & $\begin{array}{l}\text { App- } \\
\text { End }\end{array}$ & $\begin{array}{l}\text { Guardrail } \\
\text { type }\end{array}$ \\
\hline
\end{tabular}

\begin{tabular}{|l|l|l|l|}
\hline Training & 2 & 3 & 4 \\
\hline 2 & 59.102039 & 24.816326 & 16.081633 \\
\hline 3 & 3.135085 & 81.327805 & 15.537114 \\
\hline 4 & 4.521477 & 22.155237 & 73.323282 \\
\hline
\end{tabular}

\begin{tabular}{|l|l|l|l|}
\hline Cross Validation & 2 & 3 & 4 \\
\hline 2 & 57.710281 & 23.831776 & 18.457945 \\
\hline 3 & 2.228412 & 81.894150 & 15.877438 \\
\hline 4 & 4.942529 & 24.712645 & 70.344826 \\
\hline
\end{tabular}

(32)

\begin{tabular}{|l|l|l|l|}
\hline Input & $\begin{array}{l}\text { Light } \\
\text { condition }\end{array}$ & $\begin{array}{l}\text { App- } \\
\text { End }\end{array}$ & $\begin{array}{l}\text { Guardrai } \\
1 \text { type }\end{array}$ \\
\hline
\end{tabular}

\begin{tabular}{|l|l|l|l|}
\hline Training & 2 & 3 & 4 \\
\hline 2 & 56.734695 & 10.530612 & 32.734695 \\
\hline 3 & 4.518211 & 75.472565 & 20.009220 \\
\hline 4 & 15.523738 & 16.164280 & 68.311981 \\
\hline
\end{tabular}

\begin{tabular}{|l|l|l|l|}
\hline Cross Validation & 2 & 3 & 4 \\
\hline 2 & 73.364487 & 5.841122 & 20.794392 \\
\hline 3 & 9.888579 & 74.094711 & 16.016712 \\
\hline 4 & 22.643679 & 17.241379 & 60.114941 \\
\hline
\end{tabular}


(33)

\begin{tabular}{|l|l|l|l|}
\hline Input & $\begin{array}{l}\text { Light } \\
\text { condition }\end{array}$ & $\begin{array}{l}\text { Road } \\
\text { surface }\end{array}$ & $\begin{array}{l}\text { Guardrail } \\
\text { type }\end{array}$ \\
\hline
\end{tabular}

\begin{tabular}{|l|l|l|l|}
\hline Training & 2 & 3 & 4 \\
\hline 2 & 56.816326 & 13.877551 & 29.306122 \\
\hline 3 & 4.057169 & 67.680962 & 28.261871 \\
\hline 4 & 4.182366 & 8.854559 & 86.963074 \\
\hline
\end{tabular}

\begin{tabular}{|l|l|l|l|}
\hline Cross Validation & 2 & 3 & 4 \\
\hline 2 & 53.971962 & 13.084112 & 32.943924 \\
\hline 3 & 3.899721 & 69.498604 & 26.601671 \\
\hline 4 & 2.873563 & 9.425287 & 87.701149 \\
\hline
\end{tabular}

(34)

\begin{tabular}{|l|l|l|l|}
\hline Input & $\begin{array}{l}\text { Light } \\
\text { condition }\end{array}$ & $\begin{array}{l}\text { Road } \\
\text { surface }\end{array}$ & $\begin{array}{l}\text { App- } \\
\text { End }\end{array}$ \\
\hline
\end{tabular}

\begin{tabular}{|l|l|l|l|}
\hline Training & 2 & 3 & 4 \\
\hline 2 & 35.265305 & 17.959183 & 46.775509 \\
\hline 3 & 4.379899 & 72.936836 & 22.683264 \\
\hline 4 & 3.315750 & 8.929917 & 87.754333 \\
\hline
\end{tabular}

\begin{tabular}{|l|l|l|l|}
\hline Cross Validation & 2 & 3 & 4 \\
\hline 2 & 33.644859 & 11.915888 & 54.439251 \\
\hline 3 & 4.456824 & 75.487465 & 20.055710 \\
\hline 4 & 3.103448 & 10.574713 & 86.321838 \\
\hline
\end{tabular}


(35) All Variables after Eliminating App End

\begin{tabular}{|l|l|l|l|}
\hline Input & $\begin{array}{l}\text { Light } \\
\text { condition }\end{array}$ & $\begin{array}{l}\text { Road } \\
\text { surface }\end{array}$ & $\begin{array}{l}\text { Guardrail } \\
\text { type }\end{array}$ \\
\hline
\end{tabular}

\begin{tabular}{|l|l|l|l|}
\hline Training & 2 & 3 & 4 \\
\hline 2 & 54.612244 & 17.306122 & 28.081633 \\
\hline 3 & 3.411711 & 69.571228 & 27.017059 \\
\hline 4 & 4.408440 & 10.550113 & 85.041451 \\
\hline
\end{tabular}

\begin{tabular}{|l|l|l|l|}
\hline Cross Validation & 2 & 3 & 4 \\
\hline 2 & 51.168224 & 15.887851 & 32.943924 \\
\hline 3 & 1.949861 & 71.448471 & 26.601671 \\
\hline 4 & 2.643678 & 9.655172 & 87.701149 \\
\hline
\end{tabular}

(36)

\begin{tabular}{|l|l|l|}
\hline Input & $\begin{array}{l}\text { Road } \\
\text { surface }\end{array}$ & $\begin{array}{l}\text { Guardrail } \\
\text { type }\end{array}$ \\
\hline
\end{tabular}

\begin{tabular}{|l|l|l|l|}
\hline Training & 2 & 3 & 4 \\
\hline 2 & 47.510204 & 34.285713 & 18.204082 \\
\hline 3 & 2.166897 & 77.823883 & 20.009220 \\
\hline 4 & 4.107008 & 30.972118 & 64.920876 \\
\hline
\end{tabular}

\begin{tabular}{|l|l|l|l|}
\hline Cross Validation & 2 & 3 & 4 \\
\hline 2 & 47.897198 & 33.411217 & 18.691589 \\
\hline 3 & 1.253482 & 72.980499 & 25.766016 \\
\hline 4 & 2.873563 & 29.425287 & 67.701149 \\
\hline
\end{tabular}


(37)

\begin{tabular}{|l|l|l|}
\hline Input & $\begin{array}{l}\text { Light } \\
\text { condition }\end{array}$ & $\begin{array}{l}\text { Guardrail } \\
\text { type }\end{array}$ \\
\hline
\end{tabular}

\begin{tabular}{|l|l|l|l|}
\hline Training & 2 & 3 & 4 \\
\hline 2 & 44.73495 & 11.346939 & 43.918365 \\
\hline 3 & 4.840940 & 60.811436 & 34.347626 \\
\hline 4 & 12.999247 & 17.370008 & 69.630745 \\
\hline
\end{tabular}

\begin{tabular}{|l|l|l|l|}
\hline Cross Validation & 2 & 3 & 4 \\
\hline 2 & 44.626167 & 10.981308 & 44.392525 \\
\hline 3 & 4.038997 & 66.155991 & 29.805014 \\
\hline 4 & 13.563218 & 23.333334 & 63.103447 \\
\hline
\end{tabular}

(38)

\begin{tabular}{|l|l|l|}
\hline Input & $\begin{array}{l}\text { Light } \\
\text { condition }\end{array}$ & $\begin{array}{l}\text { Road } \\
\text { surface }\end{array}$ \\
\hline
\end{tabular}

\begin{tabular}{|l|l|l|l|}
\hline Training & 2 & 3 & 4 \\
\hline 2 & 50.12248 & 8.408163 & 41.469387 \\
\hline 3 & 8.944214 & 60.488705 & 30.567081 \\
\hline 4 & 6.518463 & 9.984928 & 83.496613 \\
\hline
\end{tabular}

\begin{tabular}{|l|l|l|l|}
\hline Cross Validation & 2 & 3 & 4 \\
\hline 2 & 47.429905 & 9.579439 & 42.990654 \\
\hline 3 & 10.584958 & 62.256268 & 27.158773 \\
\hline 4 & 7.586207 & 11.264368 & 81.149422 \\
\hline
\end{tabular}




\section{Second Human/Vehicle}

(1)

\begin{tabular}{|l|l|l|l|l|l|}
\hline Input & D w i & $\begin{array}{l}\text { Speed } \\
\text { limit }\end{array}$ & $\begin{array}{l}\text { Driver } \\
\text { age }\end{array}$ & $\begin{array}{l}\text { Vehicle } \\
\text { impact }\end{array}$ & $\begin{array}{l}\text { Number of } \\
\text { Occupants }\end{array}$ \\
\hline
\end{tabular}

\begin{tabular}{|l|l|l|l|}
\hline Training & 2 & 3 & 4 \\
\hline 2 & 82.285713 & 11.673470 & 6.040816 \\
\hline 3 & 1.844168 & 88.197327 & 9.958507 \\
\hline 4 & 0.602864 & 2.712886 & 96.684250 \\
\hline
\end{tabular}

\begin{tabular}{|l|l|l|l|}
\hline Cross Validation & 2 & 3 & 4 \\
\hline 2 & 83.411217 & 10.280374 & 6.308411 \\
\hline 3 & 1.949861 & 90.250694 & 7.799443 \\
\hline 4 & 0.919540 & 2.988506 & 96.091957 \\
\hline
\end{tabular}

(2)

\begin{tabular}{|l|l|l|l|l|}
\hline Input & $\begin{array}{l}\text { Speed } \\
\text { limit }\end{array}$ & $\begin{array}{l}\text { Driver } \\
\text { age }\end{array}$ & $\begin{array}{l}\text { Vehicle } \\
\text { impact }\end{array}$ & $\begin{array}{l}\text { Number of } \\
\text { Occupants }\end{array}$ \\
\hline
\end{tabular}

\begin{tabular}{|l|l|l|l|}
\hline Training & 2 & 3 & 4 \\
\hline 2 & 73.061226 & 14.448979 & 12.489796 \\
\hline 3 & 0.0 & 85.615494 & 14.384509 \\
\hline 4 & 0.263753 & 4.634514 & 95.101730 \\
\hline
\end{tabular}

\begin{tabular}{|l|l|l|l|}
\hline Cross Validation & 2 & 3 & 4 \\
\hline 2 & 71.728973 & 13.551402 & 14.719626 \\
\hline 3 & 0.0 & 88.161560 & 11.838440 \\
\hline 4 & 0.689655 & 3.333333 & 95.977013 \\
\hline
\end{tabular}


(3)

\begin{tabular}{|l|l|l|l|l|}
\hline Input & D w i & $\begin{array}{l}\text { Driver } \\
\text { age }\end{array}$ & $\begin{array}{l}\text { Vehicle } \\
\text { impact }\end{array}$ & $\begin{array}{l}\text { Number of } \\
\text { Occupants }\end{array}$ \\
\hline
\end{tabular}

\begin{tabular}{|l|l|l|l|}
\hline Training & 2 & 3 & 4 \\
\hline 2 & 81.306122 & 11.020409 & 7.673470 \\
\hline 3 & 5.117566 & 77.132317 & 17.750114 \\
\hline 4 & 0.979653 & 7.686511 & 91.333839 \\
\hline
\end{tabular}

\begin{tabular}{|l|l|l|l|}
\hline Cross Validation & 2 & 3 & 4 \\
\hline 2 & 81.074768 & 9.813084 & 9.112149 \\
\hline 3 & 4.874652 & 79.944290 & 15.181059 \\
\hline 4 & 0.114943 & 8.620689 & 91.264366 \\
\hline
\end{tabular}

(4)

\begin{tabular}{|l|l|l|l|l|}
\hline Input & D w i & $\begin{array}{l}\text { Speed } \\
\text { limit }\end{array}$ & $\begin{array}{l}\text { Vehicle } \\
\text { impact }\end{array}$ & $\begin{array}{l}\text { Number } \\
\text { of } \\
\text { Occupants }\end{array}$ \\
\hline
\end{tabular}

\begin{tabular}{|l|l|l|l|}
\hline Training & 2 & 3 & 4 \\
\hline 2 & 77.142860 & 12.897959 & 9.959184 \\
\hline 3 & 4.103273 & 69.064087 & 26.832642 \\
\hline 4 & 0.414469 & 2.185380 & 97.400154 \\
\hline
\end{tabular}

\begin{tabular}{|l|l|l|l|}
\hline Cross Validation & 2 & 3 & 4 \\
\hline 2 & 78.738319 & 13.317757 & 7.943925 \\
\hline 3 & 4.038997 & 72.423401 & 23.537605 \\
\hline 4 & 0.459770 & 1.494253 & 98.045975 \\
\hline
\end{tabular}


(5)

\begin{tabular}{|c|c|c|c|c|c|}
\hline Input & Dw i & $\begin{array}{l}\text { Speed } \\
\text { limit }\end{array}$ & $\begin{array}{l}\text { Driver } \\
\text { age }\end{array}$ & $\begin{array}{l}\text { Number of } \\
\text { Occupants }\end{array}$ & \\
\hline \multicolumn{2}{|c|}{ Training } & \multicolumn{2}{|l|}{2} & 3 & 4 \\
\hline \multicolumn{2}{|c|}{2} & \multicolumn{2}{|c|}{61.877552} & 20.163265 & 17.959183 \\
\hline \multicolumn{2}{|l|}{3} & \multicolumn{2}{|l|}{0.0} & 72.153069 & 27.846933 \\
\hline \multicolumn{2}{|l|}{4} & \multicolumn{2}{|l|}{0.0} & 7.611153 & 92.388847 \\
\hline
\end{tabular}

\begin{tabular}{|l|l|l|l|}
\hline Cross Validation & 2 & 3 & 4 \\
\hline 2 & 62.383179 & 19.626167 & 17.990654 \\
\hline 3 & 0.0 & 74.930359 & 25.069637 \\
\hline 4 & 0.0 & 7.356322 & 92.64367 \\
\hline
\end{tabular}

(6)

\begin{tabular}{|l|l|l|l|l|}
\hline Input & D w i & $\begin{array}{l}\text { Speed } \\
\text { limit }\end{array}$ & $\begin{array}{l}\text { Driver } \\
\text { age }\end{array}$ & $\begin{array}{l}\text { Vehicle } \\
\text { impact }\end{array}$ \\
\hline
\end{tabular}

\begin{tabular}{|l|l|l|l|}
\hline Training & 2 & 3 & 4 \\
\hline 2 & 82.367348 & 8.244898 & 9.387755 \\
\hline 3 & 4.702628 & 81.143387 & 14.153988 \\
\hline 4 & 0.226074 & 2.675207 & 97.098717 \\
\hline
\end{tabular}

\begin{tabular}{|l|l|l|l|}
\hline Cross Validation & 2 & 3 & 4 \\
\hline 2 & 90.420563 & 1.635514 & 7.943925 \\
\hline 3 & 8.635098 & 78.412254 & 12.952646 \\
\hline 4 & 0.459770 & 2.873563 & 96.666664 \\
\hline
\end{tabular}


(7) All Variables after Eliminating Number of Occupants

\begin{tabular}{|c|c|c|c|c|c|}
\hline Input & $\mathrm{DW} \mathrm{i}$ & $\begin{array}{l}\text { Speed } \\
\text { limit } \\
\end{array}$ & $\begin{array}{l}\text { Driver } \\
\text { age }\end{array}$ & $\begin{array}{l}\text { Vehicle } \\
\text { impact }\end{array}$ & \\
\hline \multicolumn{2}{|c|}{ Training } & \multicolumn{2}{|l|}{2} & 3 & 4 \\
\hline \multicolumn{2}{|c|}{2} & \multicolumn{2}{|c|}{79.591835} & 11.428572 & 8.979591 \\
\hline \multicolumn{2}{|l|}{3} & \multicolumn{2}{|c|}{2.904564} & 79.990776 & 17.104656 \\
\hline \multicolumn{2}{|l|}{4} & \multicolumn{2}{|c|}{0.715901} & 3.202713 & 96.081390 \\
\hline
\end{tabular}

\begin{tabular}{|l|l|l|l|}
\hline Cross Validation & 2 & 3 & 4 \\
\hline 2 & 81.308411 & 11.682243 & 7.009346 \\
\hline 3 & 2.089137 & 82.311981 & 15.598886 \\
\hline 4 & 0.459770 & 2.528736 & 97.011497 \\
\hline
\end{tabular}

(8)

\begin{tabular}{|l|l|l|l|}
\hline Input & $\begin{array}{l}\text { Speed } \\
\text { limit }\end{array}$ & $\begin{array}{l}\text { Driver } \\
\text { age }\end{array}$ & $\begin{array}{l}\text { Vehicle } \\
\text { impact }\end{array}$ \\
\hline
\end{tabular}

\begin{tabular}{|l|l|l|l|}
\hline Training & 2 & 3 & 4 \\
\hline 2 & 82.285713 & 9.795918 & 7.918367 \\
\hline 3 & 4.794837 & 78.653755 & 16.551407 \\
\hline 4 & 1.281085 & 8.703843 & 90.015068 \\
\hline
\end{tabular}

\begin{tabular}{|l|l|l|l|}
\hline Cross Validation & 2 & 3 & 4 \\
\hline 2 & 85.046730 & 7.943925 & 7.009346 \\
\hline 3 & 6.267409 & 77.158775 & 16.573816 \\
\hline 4 & 0.689655 & 9.885057 & 89.425285 \\
\hline
\end{tabular}


(9)

\begin{tabular}{|l|l|l|l|}
\hline Input & D W i & $\begin{array}{l}\text { Driver } \\
\text { age }\end{array}$ & $\begin{array}{l}\text { Vehicle } \\
\text { impact }\end{array}$ \\
\hline
\end{tabular}

\begin{tabular}{|l|l|l|l|}
\hline Training & 2 & 3 & 4 \\
\hline 2 & 75.510201 & 7.591837 & 16.897959 \\
\hline 3 & 7.330567 & 72.752419 & 19.917013 \\
\hline 4 & 6.857574 & 5.990957 & 87.151466 \\
\hline
\end{tabular}

\begin{tabular}{|l|l|l|l|}
\hline Cross Validation & 2 & 3 & 4 \\
\hline 2 & 82.242989 & 2.570093 & 15.186916 \\
\hline 3 & 10.445683 & 70.752090 & 18.802229 \\
\hline 4 & 5.862069 & 5.402299 & 88.735634 \\
\hline
\end{tabular}

(10)

\begin{tabular}{|l|l|l|l|}
\hline Input & D W i & $\begin{array}{l}\text { Speed } \\
\text { limit }\end{array}$ & $\begin{array}{l}\text { Vehicle } \\
\text { impact }\end{array}$ \\
\hline
\end{tabular}

\begin{tabular}{|l|l|l|l|}
\hline Training & 2 & 3 & 4 \\
\hline 2 & 69.877548 & 16.571428 & 13.551021 \\
\hline 3 & 4.933149 & 66.528351 & 28.538498 \\
\hline 4 & 1.356443 & 10.700829 & 87.942726 \\
\hline
\end{tabular}

\begin{tabular}{|l|l|l|l|}
\hline Cross Validation & 2 & 3 & 4 \\
\hline 2 & 74.065422 & 14.252337 & 11.682243 \\
\hline 3 & 5.153203 & 66.295265 & 28.551533 \\
\hline 4 & 0.804598 & 8.505747 & 90.689651 \\
\hline
\end{tabular}


(11)

\begin{tabular}{|l|l|l|l|}
\hline Input & D W i & $\begin{array}{l}\text { Speed } \\
\text { limit }\end{array}$ & $\begin{array}{l}\text { Driver } \\
\text { age }\end{array}$ \\
\hline
\end{tabular}

\begin{tabular}{|l|l|l|l|}
\hline Training & 2 & 3 & 4 \\
\hline 2 & 63.591835 & 18.938776 & 17.469387 \\
\hline 3 & 1.290918 & 69.110191 & 29.598894 \\
\hline 4 & 1.959307 & 9.608139 & 88.432556 \\
\hline
\end{tabular}

\begin{tabular}{|l|l|l|l|}
\hline Cross Validation & 2 & 3 & 4 \\
\hline 2 & 64.018692 & 21.728971 & 14.252337 \\
\hline 3 & 1.392758 & 72.841225 & 25.766016 \\
\hline 4 & 1.494253 & 9.080460 & 89.425285 \\
\hline
\end{tabular}

(12) All Variables after Eliminating D W I

\begin{tabular}{|l|l|l|l|}
\hline Input & $\begin{array}{l}\text { Speed } \\
\text { limit }\end{array}$ & $\begin{array}{l}\text { Driver } \\
\text { age }\end{array}$ & $\begin{array}{l}\text { Vehicle } \\
\text { impact }\end{array}$ \\
\hline
\end{tabular}

\begin{tabular}{|l|l|l|l|}
\hline Training & 2 & 3 & 4 \\
\hline 2 & 82.285713 & 9.795918 & 7.918367 \\
\hline 3 & 4.794837 & 78.653755 & 16.551407 \\
\hline 4 & 1.281085 & 8.703843 & 90.015068 \\
\hline
\end{tabular}

\begin{tabular}{|l|l|l|l|}
\hline Cross Validation & 2 & 3 & 4 \\
\hline 2 & 85.046730 & 7.943925 & 7.009346 \\
\hline 3 & 6.267409 & 77.158775 & 16.573816 \\
\hline 4 & 0.689655 & 9.885057 & 89.425285 \\
\hline
\end{tabular}


(13)

\begin{tabular}{|l|l|l|}
\hline Input & $\begin{array}{l}\text { Driver } \\
\text { age }\end{array}$ & $\begin{array}{l}\text { Vehicle } \\
\text { impact }\end{array}$ \\
\hline
\end{tabular}

\begin{tabular}{|l|l|l|l|}
\hline Training & 2 & 3 & 4 \\
\hline 2 & 87.918365 & 4.081633 & 8.0 \\
\hline 3 & 13.785154 & 66.159523 & 20.055325 \\
\hline 4 & 14.204973 & 9.834212 & 75.960815 \\
\hline
\end{tabular}

\begin{tabular}{|l|l|l|l|}
\hline Cross Validation & 2 & 3 & 4 \\
\hline 2 & 91.355141 & 2.336449 & 6.308411 \\
\hline 3 & 15.877438 & 65.181061 & 18.941504 \\
\hline 4 & 11.954023 & 10.0 & 78.045975 \\
\hline
\end{tabular}

(14)

\begin{tabular}{|l|l|l|}
\hline Input & $\begin{array}{l}\text { Speed } \\
\text { limit }\end{array}$ & $\begin{array}{l}\text { Vehicle } \\
\text { impact }\end{array}$ \\
\hline
\end{tabular}

\begin{tabular}{|l|l|l|l|}
\hline Training & 2 & 3 & 4 \\
\hline 2 & 58.367348 & 24.897959 & 16.734694 \\
\hline 3 & 0.599355 & 71.692024 & 27.708622 \\
\hline 4 & 0.791258 & 18.538055 & 80.670685 \\
\hline
\end{tabular}

\begin{tabular}{|l|l|l|l|}
\hline Cross Validation & 2 & 3 & 4 \\
\hline 2 & 60.280373 & 22.663551 & 17.056074 \\
\hline 3 & 0.0 & 76.601669 & 23.398329 \\
\hline 4 & 0.229885 & 21.264368 & 78.505745 \\
\hline
\end{tabular}


(15)

\begin{tabular}{|l|l|l|}
\hline Input & $\begin{array}{l}\text { Speed } \\
\text { limit }\end{array}$ & $\begin{array}{l}\text { Driver } \\
\text { age }\end{array}$ \\
\hline
\end{tabular}

\begin{tabular}{|l|l|l|l|}
\hline Training & 2 & 3 & 4 \\
\hline 2 & 52.734695 & 11.510204 & 35.755100 \\
\hline 3 & 0.0 & 54.402950 & 45.597050 \\
\hline 4 & 0.0 & 10.700829 & 89.299171 \\
\hline
\end{tabular}

\begin{tabular}{|l|l|l|l|}
\hline Cross Validation & 2 & 3 & 4 \\
\hline 2 & 53.738319 & 9.112149 & 37.149532 \\
\hline 3 & 0.0 & 49.442898 & 50.557102 \\
\hline 4 & 0.0 & 9.885057 & 90.114944 \\
\hline
\end{tabular}

\section{Five variables}

\begin{tabular}{|l|l|l|l|l|l|}
\hline Input & $\begin{array}{l}\text { Driver } \\
\text { age }\end{array}$ & $\begin{array}{l}\text { Vehicle } \\
\text { impact }\end{array}$ & $\begin{array}{l}\text { Light } \\
\text { condition }\end{array}$ & $\begin{array}{l}\text { Road } \\
\text { surface }\end{array}$ & $\begin{array}{l}\text { Guardrail } \\
\text { type }\end{array}$ \\
\hline
\end{tabular}

\begin{tabular}{|l|l|l|l|}
\hline Training & 2 & 3 & 4 \\
\hline 2 & 83.346939 & 9.387755 & 7.265306 \\
\hline 3 & 1.429230 & 92.761642 & 5.809129 \\
\hline 4 & 0.0 & 3.202713 & 96.797287 \\
\hline
\end{tabular}

\begin{tabular}{|l|l|l|l|}
\hline Cross Validation & 2 & 3 & 4 \\
\hline 2 & 85.747665 & 5.841122 & 8.411215 \\
\hline 3 & 1.392758 & 91.086349 & 7.520891 \\
\hline 4 & 0.0 & 3.678161 & 96.321838 \\
\hline
\end{tabular}




\section{Best Results With Six Variables}

\begin{tabular}{|l|l|l|l|l|l|l|}
\hline Input & Driver age & $\begin{array}{l}\text { Vehicle } \\
\text { impact }\end{array}$ & $\begin{array}{l}\text { Light } \\
\text { condition }\end{array}$ & $\begin{array}{l}\text { Road } \\
\text { surface }\end{array}$ & App- End & $\begin{array}{l}\text { Guardrail } \\
\text { type }\end{array}$ \\
\hline
\end{tabular}

\begin{tabular}{|l|l|l|l|}
\hline Training & 2 & 3 & 4 \\
\hline 2 & 96.261681 & 2.102804 & 1.635514 \\
\hline 3 & 0.835655 & 96.796654 & 2.36788 \\
\hline 4 & 0.229885 & 1.954023 & 97.816093 \\
\hline
\end{tabular}

\begin{tabular}{|l|l|l|l|}
\hline Cross Validation & 2 & 3 & 4 \\
\hline 2 & 96.261681 & 2.102804 & 1.635514 \\
\hline 3 & 0.835655 & 96.796654 & 2.367688 \\
\hline 4 & 0.229885 & 1.954023 & 97.816093 \\
\hline
\end{tabular}

